IZA DP No. 5463

The Japanese Lost Decade and Beyond:

A Chain Reaction Theory Approach

Pablo Agnese

January 2011 


\title{
The Japanese Lost Decade and Beyond: A Chain Reaction Theory Approach
}

\author{
Pablo Agnese \\ IESE Business School \\ and IZA
}

\section{Discussion Paper No. 5463 \\ January 2011}

IZA

P.O. Box 7240

53072 Bonn

Germany

\author{
Phone: +49-228-3894-0 \\ Fax: +49-228-3894-180 \\ E-mail: iza@iza.org
}

Any opinions expressed here are those of the author(s) and not those of IZA. Research published in this series may include views on policy, but the institute itself takes no institutional policy positions.

The Institute for the Study of Labor (IZA) in Bonn is a local and virtual international research center and a place of communication between science, politics and business. IZA is an independent nonprofit organization supported by Deutsche Post Foundation. The center is associated with the University of Bonn and offers a stimulating research environment through its international network, workshops and conferences, data service, project support, research visits and doctoral program. IZA engages in (i) original and internationally competitive research in all fields of labor economics, (ii) development of policy concepts, and (iii) dissemination of research results and concepts to the interested public.

IZA Discussion Papers often represent preliminary work and are circulated to encourage discussion. Citation of such a paper should account for its provisional character. A revised version may be available directly from the author. 


\section{ABSTRACT \\ The Japanese Lost Decade and Beyond: A Chain Reaction Theory Approach ${ }^{*}$}

The Japanese lost decade has become an intriguing puzzle for both economists and policymakers alike, as the unemployment rate climbed to unprecedented levels and the growth rate of productivity decreased considerably. More recent times seem to present with a more optimistic outlook, but this is not yet the last word in the matter. In this paper we estimate two alternative multi-equation structural models descriptive of the Japanese labor market, that are then used to conduct dynamic simulations both for the lost decade period (1990-2002) and beyond (2002-2007). Our results point, primarily, to the damaging effects of the everincreasing public debt as a major source of labor market inefficiencies. In addition, we find the fall in labor union power to have a significant easing effect on the unemployment rate, but also to be a major driver in the apparently eroding pattern of the labor income share in recent years.

JEL Classification: $\quad$ C32, E17, E24, J08

Keywords: labor market dynamics, structural multi-equation models, chain reaction theory, simulations

Corresponding author:

Pablo Agnese

IESE Business School

Pearson Ave. 21

08034 Barcelona

Spain

E-mail: pagnese@iese.edu

\footnotetext{
* I am thankful to Professors Hector Sala and Joan Enric Ricart for their helpful comments and continuous and resolute support during the elaboration of this paper.
} 


\section{Introduction}

What are the forces behind the sudden and prominent unemployment rise in Japan during the 1990s? Are there some distinguishing features, inherent to the Japanese labor market, which might account for its odd dynamics? Is the Japanese experience helpful to prevent a recession of this sort in other East Asian economies? More, are we to see the economic upturn following the "lost decade" as a real recovery? These are important questions that need to be answered, and this paper intends to be a step in that direction.

The lost decade merited a revival in the international interest for Japan. Its labor market, though, seems to have received little attention from mainstream studies, perhaps due to the peculiarities that the Western economies are so unfamiliar with. Our analysis tries to fulfill this void and, among other things, shed new light on the driving forces of the unemployment upsurge during the 1990s.

To study the Japanese labor market we take the viewpoint of the Chain Reaction theory (CRT) of unemployment, which is an alternative to the Structuralist and Institutionalist approaches $^{1}$ and, as explained in Section 2, provides a wider analytical perspective of the labor market. For example, beyond shocks and institutions as main causes of unemployment, it also considers the role of growth drivers (variables such as capital accumulation, productivity, or working-age population) in determining the labor market performance. Moreover, it does not rely on the existence of a natural (or non-accelerating inflation) rate of unemployment as the key analytical variable, which has already been found scarcely relevant in Japan and kept apart from the policy debate (see Hirose and Kamada, 2002, and Nishizaki, 1997).

We believe that the specificities of the Japanese labor market require such a wider perspective, as well as the inclusion of macroeconomic variables that the existing literature has already found relevant. For example, the decline in productivity (Fukao and Kwon, 2006, and Hayashi and Prescott, 2002), the explosion in the government debt (Barseghyan, 2006a), the rising long-term debt of firms in terms of their assets (Ogawa, 2003), the tax policy management (Kuttner and Posen, 2001), or the demographic behavior and the aging population problem (Koga, 2006). These and other more specific labor market variables are considered in the estimation of two alternative dynamic models.

Our analysis leaves aside potential monetary causes of unemployment which have been substantiated in several studies to explain the Japanese slump. ${ }^{2}$ The shared idea is that Japan has since long fallen into a liquidity trap from which the only way out seems to be an unorthodox monetary policy targeting high levels of inflation. In contrast to these studies,

\footnotetext{
${ }^{1}$ See Agnese and Sala (2009), Bande and Karanassou (2009), Karanassou and Sala (2009, 2010), and Karanassou et al. (2008a, 2008b, 2010) for some recent contributions on the CRT. See also Phelps (1994) and Phelps and Zoega (2001) for the Structuralist theory; and Layard et al. (2005) and Nickell et al. (2005) for the Institutionalist approach.

${ }^{2}$ Braun and Waki (2006), Hamada (2004), Krugman (1998), and Svensson (2001).
} 
our analysis is based on a real labor market model where nominal variables play no role.

The contribution of the paper can be summarized as follows. First, we carry out the estimation of time-series multi-equation structural models covering the last decades, and then conduct a comprehensive macroeconomic analysis of the Japanese labor market from 1990 onwards. During these years unemployment rose from 2.1\% in 1990 to a historical maximum of $5.5 \%$ in 2002, just to recede a little in the subsequent years. Second, we consider labor market variables, together with other macroeconomic variables examined in the literature, to assess their relative contributions in the evolution of unemployment in those years. Some of these variables noticeably shifted from their previous paths and produced a new outcome on employment performance that, so far, has not been put to test. And third, after endogenizing some features of our simpler model, we repeat the analysis for another variable of interest, the labor income share. We are interested in identifying the drivers behind the fall in this variable for the lost decade and beyond.

Under a very simple setting that we will discuss below, our main result points at the extremely influential role played by the decline in the growth rate of productivity and the overwhelming increase in the government debt. These two, but especially the latter, appear as the driving forces of the rise in unemployment in Japan during the 1990s. About the low rate of productivity growth, it is still dubious what mechanisms made it perform so poorly in comparison to previous decades. Nevertheless, various hypotheses are discussed. On the other hand, the government debt owes its unrelenting pace to the unholy alliance between government, banks, and firms in the private sector that has characterized the economy throughout the postwar era.

A look at the post-1990s years will deliver a different picture though. Carrying on with the previous analysis in a very simple setting, we observe that the economic upturn that followed those problematic years is far from being a total recovery. To the damaging effects of the still increasing government debt and the low rate of capital accumulation, we should add the also detrimental effect of growing real wages and the increase of direct taxes on firms. All these effects contribute to a higher unemployment rate than it could have been possibly achieved otherwise.

Taking a step forward in terms of elucidating the puzzling performance of Japan in the last two decades would require for us to add some other features to the original analysis. We then propose a second setting accounting for other additional features that can enrich our study significantly. Here we find again the harming effect of the government debt during the lost decade, to which we should add the fall in the growth of capital accumulation for the following years. From this second analysis it is possible to identify an important offsetting force, the decline in union power. This major force, we discover, has another important connotation for the labor market. It remains a very substantial driver of the labor income share, both during the 1990s and in the years that follow. 
The rest of the paper is structured as follows. Section 2 presents three major views of the labor market from a macroeconomic perspective: the natural rate hypothesis, hysteresis, and the CRT. We will go over the reasons that make the CRT our framework of choice over other more mainstream views. Section 3 offers a thorough empirical analysis taking two CRT models that are estimated for the period 1970-2008. Both a simple model and an augmented version of this model are brought into the analysis. We also evaluate how the major determinants of the labor market have contributed to shape the unemployment rate trajectory in the fading 1990s and beyond. Complementing the analysis on unemployment we repeat the study for the labor income share. Section 4 concludes.

\section{Macroeconomics of labor markets: three major views}

From a strictly macroeconomic perspective the labor markets have been analyzed in various ways. We here focus on just three of these views, and review the different interpretations that have been put forward to explain the movements in the unemployment rate. Chronologically, we would first find the so called frictionless equilibrium view, which encompasses all models relying on the natural or non-accelerating inflation rate of unemployment hypothesis (NRU/NAIRU). ${ }^{3}$ Here the labor market is envisioned at equilibrium or pretty much near to it most of the times.

The second view receives the name of hysteresis, where short-run effects lead to permanent changes in the long-run unemployment rate. This is more than just an extreme case of prolonged adjustment, since the temporal dimension practically disappears and there is no distinction between the short-run and long-run.

Lastly, we have the prolonged adjustment view, or chain reaction theory approach (CRT), with its emphasis on the slow adjustments within the labor market. In recognizing that labor can become similar to capital due to the costs of adjustment, the CRT focuses more intensively in the frictions and interactions that appear with time underlying the employment decisions by employers and employees. Under this view, current decisions are strongly contingent on past outcomes. ${ }^{4}$

The question whether to rely on one or another view implicitly makes reference to the

\footnotetext{
${ }^{3}$ Even though they are not exactly the same, we will stick to the NRU acronym. This will serve well for our purposes since our focus is strictly on the real side of the economy, with no role played by the nominal variables (e.g. monetary aggregates) so often taken into consideration by NAIRU theorists. This distinction between both theoretical concepts could be further disentangled by looking up at the vast literature on the subject. The reader is referred to Friedman (1968) and Phelps $(1967,1968)$ for the NRU, and Gordon (1997), Layard and Nickell (1986), Layard, Nickell and Jackman (2005), and Staiger, Stock and Watson (1997) for the NAIRU.

${ }^{4}$ The most representative works in the frictionless view are Blanchard and Wolfers (2000), Layard, Nickell and Jackman (2005), Nickell, Nunziata and Ochel (2005), Phelps (1994), and Phelps and Zoega (2001). Within the hysteresis view it is to remark Blanchard and Summers (1986). Finally, the CRT was originally developed by Karanassou and Snower $(1997,1998)$ and Henry et al. (2000).
} 
degree to which one could consider the labor market as deserving equal treatment as any other market. This particular feature is known as "compartmentalization", which also bears a temporal dimension. In frictionless NRU-based models the short and long-run are compartmentalized, whereas in the CRT models the short and long-run are interrelated due to frictional growth. It is to observe that frictional growth, as opposed to the frictionless view of the NRU and its derivatives, implies growing or non-stationary variables that would entail additional aspects for the analysis. Moreover, the effect of these growth drivers and their interplay with external shocks can determine for temporary shocks to have persistent effects. Quite different is the story with hysteresis, where temporary shocks can have permanent effects and the short-run translates directly into the long-run.

Hence, in some practical cases it makes more sense to treat the labor market slightly differently, since the events that occur there might be somewhat dependent on what happens elsewhere. To throw light on this, the chain reaction theory targets the series of lagged adjustment processes that take place when moving back to the once-disrupted equilibrium. These adjustment processes have to do, respectively, with the employment and working decisions by employers and employees.

Of especial importance for this theory are the interactions between these processes and the role played by some growing variables, such as the capital stock or population. In the presence of economic growth, the adjustment processes within the labor market might never be complete. Therefore, the actual levels of employment and unemployment are always at odds with the moving frictionless targets, mainly because such adjustments never get to work themselves out. In later sections we will rely on the CRT for the empirical analysis, but before that, a review of the three views is in order.

\subsection{The frictionless view and the NRU}

The frictionless view departs from the idea that a natural or equilibrium rate of unemployment is not only achievable but always at sight. That is, whenever the labor market is hit by a shock, it takes little or no time for the equilibrium to be reestablished. The actual rate of unemployment would always be chasing its natural counterpart at close range. Under this setting the NRU could be thus seen as an attractor of the rate of unemployment.

The American and British experiences most noticeably, and the Anglo-Saxon commonwealth in general, are often associated with this equilibrium view. Not surprisingly, these labor markets, but especially the American, stand apart when it comes to government intervention. Resilience still is a distinguishing feature when compared with other regions (e.g. Europe or Japan). But let us go deeper into the workings of the frictionless view.

Involuntary unemployment is a shared characteristic of all non-clearing models in mainstream (e.g. NRU) and non-mainstream theories (e.g. CRT) alike. However, for the former it is also true that the economy usually finds itself in a situation where employment and 
wage decisions by firms are consistent with those by workers. Accordingly, disequilibrium occurs only temporarily, with little or no consideration whatsoever to the phenomenon of unemployment persistence. But in reality, unemployment persistence turns more important the wider (or more persistent) the separation between the actual rate of unemployment and the NRU. This is mainly due to the existence of frictions, during the employment adjustment process, that bring about the inertia in unemployment.

The frictionless view, with the NRU at its very core (Friedman, 1968, and Phelps, 1967, 1968), relies on well-known neoclassical microeconomic foundations (Phelps, 1968, 1969). On these lines, the compartmentalization hypothesis implies that while capital is a fixed factor in the short run, labor is variable and adjusts (almost) instantly. In such a way, unemployment can be decomposed in its short-run (or cyclical) and long-run (or structural) components. Therefore, we have that short-run unemployment fluctuations take place around the NRU or long-run equilibrium. In general, all policy recommendations derived from this theoretical standpoint deal with policies that aim at reducing the NRU.

All models standing on the frictionless view and the NRU theory share a very fundamental characteristic: single-equation modelling. Since the NRU can be defined as the rate to which unemployment is headed in the long-run (Ball and Mankiw, 2002), a dynamic single-equation setting would suffice to explain this relation:

$$
u_{t}=\alpha u_{t-1}+\beta^{\prime} X_{t}
$$

where $u$ is the unemployment rate, $\beta^{\prime}$ a (transposed) vector of coefficients, and $X$ a vector of non-growing exogenous variables (errors are ignored). Reparametrizing (1) we get:

$$
u_{t}=\underbrace{\frac{\beta^{\prime}}{1-\alpha} X_{t}}_{\text {steady-state }}-\underbrace{\frac{\alpha}{1-\alpha} \Delta u_{t}}_{\text {cycle }}
$$

where $\Delta$ is the difference operator, and the first and second terms on the right-hand side of the equation are, respectively, the "steady-state" and the "cyclical" unemployment. Both types of unemployment can also be seen as long and short-run components, evolving independently from one another. Further, since the variables in $X$ are not growing, the unemployment rate stabilizes in the long-run $\left(u_{t}=u_{t-1} \Longleftrightarrow \Delta u_{t}=0\right)$ and equation (2) becomes:

$$
u^{L R}=u^{n}=\frac{\beta^{\prime}}{1-\alpha} X^{L R}
$$

and the long-run rate of unemployment $\left(u^{L R}\right)$ or NRU $\left(u^{n}\right)$ equals its steady-state. In the presence of growing variables in $X$, however, the second term in (2) gives rise to frictional 
growth (Karanassou and Sala, 2010). Although frictional growth does not impose any serious drawback on single-equation models, it does have important consequences for structural multi-equation models, as seen in the CRT framework. This is because frictional growth is the result of interactions between lagged adjustment processes and economic growth.

Layard et al. (2005) propose a formal price and wage-setting (PS-WS) framework to derive the natural rate, involving both a price and a wage-setting equation. Formally, a baseline representation of this approach is given by:

$$
\begin{aligned}
& p_{t}=w_{t}^{e}+\left(\delta_{0}-\delta_{1} u_{t}\right) \\
& w_{t}=p_{t}^{e}+\left(\gamma_{0}-\gamma_{1} u_{t}\right)
\end{aligned}
$$

The downward slopping price setting curve is essentially an inverted labor demand equation, where prices $p_{t}$ are set as a mark-up over the expected nominal wages $w_{t}^{e}$. This mark-up includes $\delta_{0}$, price pressure factors (the effect of firms' monopoly power, for example), and $\delta_{1} u_{t}$, a proxy of demand-side pressures where $\delta_{1}$ is the price flexibility on unemployment. The upward slopping wage-setting curve is the result of the bargaining process between firms and unions, and simply states that nominal wages $w_{t}$ are set as a mark-up over the expected level of prices $p_{t}^{e}$. The mark-up now includes $\gamma_{0}$, which stands for wage pressure factors (due to labor market institutions mainly), and $\gamma_{1} u_{t}$, a term depending on the state of the market where $\gamma_{1}$ is wage flexibility on unemployment.

In equilibrium, where expectations are fulfilled, the following conditions hold: $p_{t}=p_{t}^{e}$ and $w_{t}=w_{t}^{e .5}$ It follows that substituting in (4) and (5) and then adding up both equations gives the NRU:

$$
u^{n}=\frac{\delta_{0}+\gamma_{0}}{\delta_{1}+\gamma_{1}}
$$

Notice from (6) that higher intensities of price $\left(\delta_{0}\right)$ and wage $\left(\gamma_{0}\right)$ pressure factors tend to raise the NRU, while a higher flexibility of prices $\left(\delta_{1}\right)$ and wages $\left(\gamma_{1}\right)$ has the opposite effect. Notice too that the NRU is independent of growth drivers, such as the capital stock or the working-age population. We will see how these features gain relevance when examining the CRT below.

\subsection{Hysteresis}

The process by which permanent effects are the natural outcome of temporary shocks receives the name of hysteresis. In other words, the unemployment rate tends to get stuck

\footnotetext{
${ }^{5} \mathrm{~A}$ less restrictive condition would hold when nominal surprises are the same, that is when $p_{t}-p_{t}^{e}=$ $w_{t}-w_{t}^{e}$.
} 
at wherever it has been, so the unemployment rate of the last period becomes the best predictor of the current unemployment rate $\left(E_{t-1} u_{t}=u_{t-1}\right)$. More formally, and following up with our simple representation of the unemployment rate in (1), hysteresis arises when there is a unit root process in the data (e.g. $\alpha=1)$ :

$$
u_{t}=u_{t-1}+\beta^{\prime} X_{t} \Rightarrow \Delta u_{t}=\beta^{\prime} X_{t}
$$

implying an extreme dependence on the past. Accordingly, whenever a shock hits the economy (e.g. a change of any exogenous variable in $X$ ), unemployment is taken away from its original path and there is no reversing mechanism that can bring it back to where it was before.

The idea of hysteresis in unemployment emerges formally in the 1980s (Blanchard and Summers, 1986), when the pronounced difference between the unemployment rate in the EU and the US made it necessary to look for alternative explanations. Persistent higher rates of unemployment in Europe made the NRU theories look rather unfitting with their main focus on equilibrium. The need to account for the protracted effects of temporary shocks put the hysteresis hypothesis in the center of attention, at least for a time.

There are mainly three mechanisms through which hysteresis can be understood. These involve, in the words of Blanchard and Summers (1986), the physical capital, the human capital, and the insider-outsider theories. As for physical capital, they state that reductions in the capital stock associated with the reduced employment that accompanies adverse shocks can reduce the subsequent demand for labor and so cause protracted unemployment. A second mechanism, human capital, argues that long-term unemployed workers cannot update their working skills, which, combined with the disaffection (also, "discouraging effect") entailed by unsuccessful job searching, determines a reduction of the effective supply of labor. The final and, according to the authors, most promising explanation to highly persistent unemployment, is to be found in the insider-outsider behavior created by the existence of labor unions. In general, labor unions look after the wage claims of currently employed members (the insiders) while having little or no concern for the situation of those unaffiliated or in the pool of unemployed (the outsiders). Therefore, when a temporary shock diminishes the demand for labor and some insiders lose their status, the following wage claims are set according to this new level of employment. As a result, there is no recovery after the shock is done and gone, and employment and unemployment are determined solely by the history of shocks. ${ }^{6}$ Therefore, the wage bargaining process is here a prevalent feature of the labour market, as it is in the NRU models (see here Hoon and Phelps, 2002, and Phelps, 1994). One key difference, however, is that the weight of the explanation is shifted from the shocks (NRU) to their propagation mechanisms (hysteresis).

\footnotetext{
${ }^{6}$ See Lindbeck and Snower (1988) for a complete account of the insider-outsider dynamics of labor market activity.
} 
There are yet several objections to the usual interpretations produced by the hysteresis theory, as enumerated in Karanassou et al. (2007). First, there is no reason for the autocorrelation coefficient in an equation like (7) to equal unity. If any, it can be said that $\alpha=1$ holds only by accident. Second, when this does hold however, and the error term is a white noise, the unemployment rate follows a random walk. This means that it either hits 100 or zero percent with certainty in a finite time span. And third, permanent shocks on the unemployment rate cannot be intuitively rationalized, since these shocks lead to a explosive labor market behavior.

Another drawback in the use of hysteresis models is that they only provide a statistical representation of the evolution of the unemployment rate. Unlike the NRU and the CRT views, hysteresis models lack the instruments to fully identify the driving forces of unemployment and, therefore, understand the structure of the labor market. Furthermore, hysteresis is in line with the NRU and in sharp contrast with the CRT, in that the unemployment rate is seen as the sum of a cyclical (short-run) and a natural (long-run) component (Karanassou et al., 2010). This definition presupposes different implications for both these views, for whereas the hysteresis view claims that the cyclical variations of unemployment propagate to its natural rate, the NRU assumes that the cyclical and natural rate components of unemployment are independently determined (e.g. "compartmentalization").

This more sophisticated reformulation of hysteresis is taken up by Jaeger and Parkinson (1994), who propose an unobserved components model. ${ }^{7}$ It is assumed there that the unemployment rate is the sum of a non-stationary "natural rate component" $\left(u_{t}^{n}\right)^{8}$ and a stationary "cyclical" component $\left(u_{t}^{c}\right)$ :

$$
u_{t}=u_{t}^{n}+u_{t}^{c}
$$

where the two unobservable components of unemployment have the following paths:

$$
\begin{gathered}
u_{t}^{c}=\phi_{1} u_{t-1}^{c}+\phi_{2} u_{t-2}^{c}+\varepsilon_{t}^{c} \\
u_{t}^{n}=u_{t-1}^{n}+\varepsilon_{t}^{n}+\alpha u_{t-1}^{c}
\end{gathered}
$$

and the innovations in both equations $\left(\varepsilon_{t}^{c}\right.$ and $\left.\varepsilon_{t}^{n}\right)$ are mutually uncorrelated shocks. The authors argue that a stationary $\operatorname{AR}(2)$ process in (9) usually fits the data well, although other more general specifications can be used. In (10), the natural rate is modeled as to allow hysteresis effects through the cyclical component with a lag of one period. The size of $\alpha$ is their measure of hysteresis, and indicates by how much the natural rate increases when the economy experiences a cyclical unemployment rate of 1.0 percent.

\footnotetext{
${ }^{7}$ Another interesting contribution is Røed (1996).

${ }^{8}$ This is logical, since hysteresis has the strong implication that unemployment is non-stationary.
} 


\subsection{Problems with the mainstream views}

Both mainstream views discussed before encompass the works of a few of the most prominent economists in the last three decades. But in spite of the important leaps in knowledge that all these contributions signified for the profession of economics and, in particular, for the field of labor economics, there were still some substantial gaps to be filled. Also, the theory in general felt rather at odds with the empirical evidence on some developed countries (e.g. the upsurge in unemployment during the 1980s in Europe). The CRT then appeared to lay a bridge between the sound theoretical analysis and the actual data, at a time when it was most needed.

Let us here review some of the drawbacks entailed by both the frictionless and hysteresis views. The only goal of this section is to make it clear from the outset why we decided to put them aside and, consequentially, chose another theoretical and methodological standpoint.

- Compartmentalization: in characterizing unemployment as the sum of two independently determined components (steady-state and cycle), these theories fail to account for frictional growth. ${ }^{9}$ Frictional growth is the result of lagged adjustment processes within the labor market and of economic growth. The feature of frictional growth enters the CRT framework through the consideration of growing variables (e.g. growth drivers) in determining the path of unemployment.

- Dynamics: a direct consequence of this compartmentalization, the proper dynamics of labor markets cannot be easily explained. Under these mainstream views not only are we faced with a well-defined separation of the structural and cyclical components of unemployment, but also with their temporal counterparts. Or what is the same, the long and short-run are clearly disconnected from one another. ${ }^{10}$ The CRT, on the contrary, breaks with this structure and allows for unemployment persistence. Temporary shocks on the labor market can have lasting effects as to make the actual rate of unemployment drift away from its so called natural or equilibrium level. This equilibrium can only be achieved once all the lagged adjustment processes have been completed.

- Methodology: under certain circumstances, single-equation reduced-form models of the NRU type may oversimplify the description of labor markets. Besides, despite its theoretical soundness the data do not seem to fit the evidence quite well, with the exception of the US case of course. As for hysteresis, its over-descriptive approach lacks the theoretical foundations to understand the labor markets appropriately, and sometimes can

\footnotetext{
${ }^{9}$ In the original hysteresis theory there is actually no room for compartmentalization, since every cyclical fluctuation is said to become part of the structural component.

${ }^{10}$ In the original hysteresis theory they become impossible to discern.
} 
generate counterintuitive conjectures. On the other hand, the multi-equation structural models of the CRT provide a more detailed analysis of labor markets. The CRT thus emphasizes the interplay between the dynamics of the model (e.g. lagged adjustment processes) and the trajectories of the exogenous variables and, at the same time, accounts for the spillover effects among the different parts of the labor market. On more technical grounds, we will see below that the econometric strategy endorsed by CRT models (ARDL) has been proved superior to other competing alternatives.

\subsection{The chain reaction theory}

\subsubsection{Theoretical underpinnings}

The benchmark for our analysis is the Chain Reaction theory of unemployment: an interactive dynamics approach that relies on dynamic multi-equation models to study the labor market. A stylized model representative of this approach would be:

$$
\begin{aligned}
n_{t} & =\alpha_{1} n_{t-1}+\beta_{1} p r_{t}-\gamma_{1} w_{t}, \\
l_{t} & =\alpha_{2} l_{t-1}+\beta_{2} z_{t}+\gamma_{2} w_{t},
\end{aligned}
$$

where $n$ denotes employment, $l$ the labor force, $p r$ labor productivity, $w$ real wages, and $z$ is working-age population. The autoregressive parameters are $0<\alpha_{1}, \alpha_{2}<1$, while the $\beta$ 's and the $\gamma$ 's are positive constants. All variables are in logs; constant and error terms are ignored for ease of exposition; and real wages, productivity, and working-age population are assumed to be growing variables with growth rates that stabilize in the long-run. Because $l$ and $n$ are defined in logs, the unemployment rate, $u$, is approximated by

$$
u_{t} \simeq l_{t}-n_{t}
$$

Microfoundations for this sort of model are provided in Karanassou et al. (2007). Most important for our analysis is that this simple model allows a clear distinction with competing views of the labor market that, like the Structuralist and Institutionalist theories, rely on reduced-form unemployment models (see Blanchard and Wolfers, 2000; Nickell et al., 2005; or Phelps and Zoega, 2001). In particular, because all variables in the labor demand and labor force equations (11)-(12) are $I(1)$, they need to cointegrate to match the unemployment rate stationary behavior. The cointegrating vectors implied by equations (11)-(12) are $\left(\begin{array}{ccc}1 & \frac{\beta_{1}}{1-\alpha_{1}} & \frac{-\gamma_{1}}{1-\alpha_{1}}\end{array}\right)$ and $\left(\begin{array}{ccc}1 & \frac{\beta_{2}}{1-\alpha_{2}} & \frac{\gamma_{2}}{1-\alpha_{2}}\end{array}\right)$. Of course, when we turn to the estimation of such equations the econometric methodology is chosen according to this characterization of the labor market. 


\subsubsection{The reduced-form unemployment rate equation}

Let us rewrite equations (11)-(12) as

$$
\begin{aligned}
\left(1-\alpha_{1} B\right) n_{t} & =+\beta_{1} p r_{t}-\gamma_{1} w_{t} \\
\left(1-\alpha_{2} B\right) l_{t} & =\beta_{2} z_{t}+\gamma_{2} w_{t}
\end{aligned}
$$

where $B$ is the backshift operator. Multiplying both sides of equations (11) and (12) by, respectively, $\left(1-\alpha_{2} B\right)$ and $\left(1-\alpha_{1} B\right)$, and using definition (13), we are left with:

$$
\left(1-\alpha_{1} B\right)\left(1-\alpha_{2} B\right) u_{t}=\beta_{2}\left(1-\alpha_{1} B\right) z_{t}-\beta_{1}\left(1-\alpha_{2} B\right) p r_{t}+\left[\gamma_{2}\left(1-\alpha_{1} B\right)+\gamma_{1}\left(1-\alpha_{2} B\right)\right] w_{t}
$$

from which the reduced-form unemployment rate equation can be easily obtained:

$$
\begin{aligned}
u_{t}= & \left(\alpha_{1}+\alpha_{2}\right) u_{t-1}-\alpha_{1} \alpha_{2} u_{t-2}+\beta_{2} z_{t}-\alpha_{1} \beta_{2} z_{t-1}-\beta_{1} p r_{t}+\beta_{1} \alpha_{2} p r_{t-1} \\
& +\left(\gamma_{1}+\gamma_{2}\right) w_{t}-\left(\alpha_{1} \gamma_{2}+\alpha_{2} \gamma_{1}\right) w_{t-1}
\end{aligned}
$$

Observe that growing variables enter the reduced-form equation regardless of their nonstationarity. While the unemployment rate is usually $I(0)$, explanatory variables can be either $I(0)$ or $I(1)$. This is in contrast to the Structuralist and Institutionalist theories, and their focus on non-growing variables such as institutions.

Institutional variables play a role in the CRT framework, though it turns out smaller than in mainstream theories. Previous studies from the CRT, instead, highlight the relative importance of growth drivers. Particularly, capital accumulation, productivity, and demographics can add to an improved explanation of the unemployment rate and its dynamics through time (see Karanassou et al., 2008a, and the references therein provided).

Furthermore, it is important to note that the CRT provides precise tools for the evaluation of the shocks and their impacts through an impulse-response function analysis. And not only of temporary shocks, as it is commonly done, but also of persistent and permanent shocks (see, for example, Karanassou et al., 2008b). An impulse-response function analysis, however, escapes the goals of the present study. 


\subsubsection{The long-run unemployment rate}

Let us now rewrite equations (11)-(12) in their long-run solution forms: ${ }^{11}$

$$
\begin{aligned}
n_{t}^{L R} & =\frac{\beta_{1}}{1-\alpha_{1}} p r_{t}^{L R}-\frac{\gamma_{1}}{1-\alpha_{1}} w_{t}^{L R}-\frac{\alpha_{1}}{\left(1-\alpha_{1}\right)} \Delta n^{L R} \\
l_{t}^{L R} & =\frac{\beta_{2}}{1-\alpha_{2}} z_{t}^{L R}+\frac{\gamma_{2}}{1-\alpha_{2}} w_{t}^{L R}-\frac{\alpha_{2}}{\left(1-\alpha_{2}\right)} \Delta l^{L R} .
\end{aligned}
$$

Note that the variables maintain the subscript $t$, despite being a long-run solution (indicated by the superscript $L R$ ). The reason is the non-zero long-run growth rates of the exogenous variables, which we have plausibly assumed to be growing variables. In other words, both the labor demand and the labor force grow at a constant rate in the long-run.

In the long-run, the unemployment rate definition (13) becomes $u_{t}^{L R}=l_{t}^{L R}-n_{t}^{L R}$ and yields:

$$
\begin{aligned}
u_{t}^{L R}= & {\left[\frac{\beta_{2}}{1-\alpha_{2}} z_{t}^{L R}-\frac{\beta_{1}}{1-\alpha_{1}} p r_{t}^{L R}+\frac{\left(1-\alpha_{1}\right) \gamma_{2}+\left(1-\alpha_{2}\right) \gamma_{1}}{\left(1-\alpha_{1}\right)\left(1-\alpha_{2}\right)} w_{t}^{L R}\right] } \\
& +\left[\frac{\alpha_{1}}{\left(1-\alpha_{1}\right)} \Delta n^{L R}-\frac{\alpha_{2}}{\left(1-\alpha_{2}\right)} \Delta l^{L R}\right]
\end{aligned}
$$

It follows that the stability of the unemployment rate in the long-run, $\Delta u^{L R}=0$, is achieved only when the labor demand and the labor force grow at the same rate, which we call $g$. Using again equations (18)-(19), the condition that $\Delta l^{L R}=\Delta n^{L R}=g$ can be expressed as

$$
\frac{\beta_{1}}{1-\alpha_{1}} \Delta p r^{L R}=\frac{\beta_{2}}{1-\alpha_{2}} \Delta z^{L R}+\frac{\left(1-\alpha_{1}\right) \gamma_{2}-\left(1-\alpha_{2}\right) \gamma_{1}}{\left(1-\alpha_{1}\right)\left(1-\alpha_{2}\right)} \Delta w_{t}^{L R}=g
$$

Further, under this condition equation (20) becomes:

$$
u_{t}^{L R}=\underbrace{\left[\frac{\beta_{2}}{1-\alpha_{2}} z_{t}^{L R}+\frac{\left(1-\alpha_{1}\right) \gamma_{2}+\left(1-\alpha_{2}\right) \gamma_{1}}{\left(1-\alpha_{1}\right)\left(1-\alpha_{2}\right)} w_{t}^{L R}-\frac{\beta_{1}}{1-\alpha_{1}} p r_{t}^{L R}\right]}_{\text {natural rate of unemployment }}+\underbrace{[21)}_{\text {frictional growth }}
$$

The first term in brackets is the natural rate of unemployment (NRU); that is, the equilibrium unemployment rate that would be achieved in the absence of growth $(g=0)$. A strong implication drawn from the mainstream labor market theories is that in the long-run the unemployment rate equals the NRU. This is the main outcome of the standard analysis conducted via single-equation reduced-form unemployment models, where only stationary

\footnotetext{
${ }^{11}$ To see it more clearly, depart for the simplest dynamic equation $y_{t}=\alpha y_{t-1}+\gamma x_{t}+\varepsilon_{t}$. To derive the long-run solution it is convenient to rewrite it as $y_{t}=\frac{\gamma}{1-\alpha} x_{t}-\frac{\alpha}{1-\alpha} \Delta y_{t}+\frac{1}{1-\alpha} \varepsilon_{t}$. The long-run equilibrium is generally obtained by the unconditional expectation of the dynamic equation $E\left(y_{t}\right)=\frac{\gamma}{1-\alpha} E\left(x_{t}\right)-$ $\frac{\alpha}{1-\alpha} E\left(\Delta y_{t}\right)$ or, equivalently, $y_{t}^{L R}=\frac{\gamma}{1-\alpha} x_{t}^{L R}-\frac{\alpha}{1-\alpha} \Delta y^{L R}$. See Karanassou et al. (2008b), Section 2, for a full developement.
} 
variables are considered. The NRU is thus an attractor or, in other words, the rate to which the actual rate of unemployment converges in the long-run.

On the contrary, when growing variables are allowed to play a role in the labor market (capital accumulation, productivity, or working-age population, for example), the phenomenon of frictional growth emerges. This is captured by the second term in brackets, which shows that frictional growth arises from the interaction between the lagged adjustment processes in labor demand and labor supply decisions (captured by $\alpha_{1}$ and $\alpha_{2}$ ) and growth $(g)$. Therefore, frictional growth requires two realistic conditions: the presence of adjustment costs in firms and households' activities, and economic growth.

Frictional growth has other important implications. For example, the very common compartmentalization between labor economics (with no growing variables considered) and economic growth (with no role for the labor market) no longer holds. Moreover, the compartmentalization within labor economics in terms of the structural and the business cycle components of unemployment (the NRU being the structural component) is also ruled out. These and other features of the CRT approach are explained in depth in Karanassou et al. $(2007,2010)$ and in some related references provided there.

Frictional growth is thus a crucial concept because it diminishes the role of the NRU granted by mainstream theories. The more sluggish is the labor market (i.e., the more costly the adjustments are) and the faster economic growth, the further the NRU lags behind the long-run unemployment rate. This is the reason why the NRU cannot be seen any more as an attractor of actual unemployment, and thus ceases to be of paramount importance. It is in this context that the CRT approach advocates the estimation of the dynamic contributions of the exogenous variables to the evolution of unemployment. This is the task we undertake after the presentation of the estimated Japanese labor market models.

\section{Empirical analysis}

Here we set ourselves to the difficult task of understanding the puzzling performance of Japan in later years. With the labor market at the center of attention and the chain reaction theory as our analytical tool, we aim at explaining the poor outcome reflected in unexpectedly high unemployment rates during the 1990s and the shy recovery that followed. Further, not only do we pay special attention to unemployment, but we also focus with keen interest on the unit labor costs. We will see that the pronounced fall in this variable can be understood as the result of a natural adjustment. More importantly, the unit labor costs can proxy for the labor income share, something that will come in handy later on. We

will take up the analysis of the unit labor costs/labor income share in the last part of the empirical section, once we endogenize certain features of the model.

Basically, our empirical analysis consists of two structural models that stem from the 
theoretical and analytical apparatuses embedded in the CRT, as explained in the previous sections. We start with a simple model accounting for labor demand and supply functions, and then move on to a more complete characterization of the labor market. For instance, endogenizing real wages through a wage-setting equation would account for the bargaining process between labor and management. In addition, introducing a production function into the system of equations can further enrich the analysis. ${ }^{12}$

Once the models are estimated, it is possible to simulate the paths of our endogenous variables of interest (e.g. unemployment) through the years of the lost decade and afterwards. Not surprisingly, in recent years and after a long-lived slump, Japan has experienced a moderate upturn worth of analysis. This could well be interpreted as the upward trend of an economic cycle. It is for us to decide whether this signifies the way out of the slump or just another mirage in the economic desert of stagnation. Perhaps once the simulations are discussed we will be in a better position to express a judgment.

Therefore, the dynamic simulations simply wonder about the hypothetical paths of the endogenous variables of the model, had some of the explanatory variables remained fixed at an arbitrarily chosen year. With independence of the endogenous variable under study, we will set these years coinciding with the minimum and maximum of the unemployment rate during the last two decades. Thus, we have that unemployment went down to $2.1 \%$ in 1990, reached a historical maximum at $5.5 \%$ in 2002, and then fell back to $3.9 \%$ in 2007 . These three years distinguish our two periods of analysis for the simulations: 1990-2002 and 2002-2007.

\subsection{Data and methodology}

We will use time-series macro data from different sources, depending on the model specification. Our general database contains data from the OECD Economic Outlook, the IMF International Financial Statistics (IFS), the Ministry of Finance of Japan, and the Statistics and Information Department of the Minister's Secretariat, Ministry of Health, Labour and Welfare.

With respect to the econometric strategy, the need to deal with $I(0)$ and $I(1)$ variables leads us to follow the Autoregressive Distributed Lagged (ARDL) or Bounds testing approach, developed in Pesaran and Shin (1999) and Pesaran et. al. (2001). Two are the main features of this approach. First, it yields consistent estimates both in the short and long-run while standing as an alternative procedure to the standard cointegration techniques. And second, as shown in Pesaran and Shin (1999), the ARDL can be reliably used in small samples to estimate and test hypotheses on the long-run coefficients in both cases where the underlying regressors are $I(1)$ or $I(0)$.

\footnotetext{
${ }^{12}$ The two-equation model is the one derived in section 2.4 above. Theoretically, it can be extended as to incorporate a wage-setting equation and a production function.
} 
This is important because the ARDL approach avoids the pretesting problem implicitly involved in the cointegration analysis of long-run relationships. The standard cointegration techniques are Johansen's maximum likelihood method (Johansen, 1991) and the PhillipsHansen's procedure (Phillips and Hansen, 1990). Pesaran and Shin (1999) show that the ARDL is "directly comparable to the semi-parametric, fully-modified OLS approach of Phillips and Hansen (1990) to estimation of cointegrating relations". When they undertake this comparison they find that the Phillips and Hansen's estimator is outperformed by the ARDL-based estimator, especially when having a relatively small sample period of analysis as in our case. In particular, Pesaran and Shin show that, using the delta method or the Bewley's approach, valid standard errors can be computed for the estimated long-run coefficients.

It is also important to note that the estimated ARDL equations can be reparametrized and expressed in terms of an error correction model (ECM) which, on its own, indicates cointegration of the variables in case of being negatively signed and significant. ${ }^{13}$ Furthermore, we will show below that the long-run relationships implied by the ECM can be compared with those obtained using Johansen's cointegration analysis. This will demonstrate that the long-run relationships between the growing variables estimated in our models are not spurious.

Therefore, we will follow the ARDL approach to determine the concrete specifications of the models under consideration. Specifically, we will consider two structural models of the labor market, consisting of: (i) labor demand and supply functions, and (ii) labor demand, labor supply, wage-setting, and production functions. ${ }^{14}$ We ensure that all equations pass the standard battery of misspecification and structural stability tests. When available, these are: a Lagrange multiplier test for serial correlation $(S C)$, Ramsey's linearity test $(L I N)$, plus heteroskedasticity $(H E T)$ and conditional heteroskedasticity $(A R C H)$ tests, all distributed as $\chi^{2}(1)$. We also check if the residuals are normally distributed using a test of skewness and kurtosis of the residuals, in this case distributed as $\chi^{2}(2)$. Lastly, we ensure, by means of the Cusum and Cusum $^{2}$ tests, that the estimated equations are structurally stable. ${ }^{15}$ The best specifications are selected on the basis of the standard selection criteria (Akaike and Schwarz Bayesian) and re-estimated as a system by 3SLS, so the estimates are safe from endogeneity and cross-equation correlation problems.

In table 1 we define the variables (and their sources) entering the chosen specifications of the equations in our two models.

\footnotetext{
${ }^{13}$ More details on the empirical application of this econometric methodology can be found in Karanassou et al. (2008a) and Bahmani-Oskooee et al. (2008).

${ }^{14} \mathrm{~A}$ three-equation system adding a wage-setting equation to the simpler two-equation model was also considered, although the results were not consistent with both the two and four-equation systems. Seemingly, endogenizing the real wages without a production function (the natural counterpart of the wage-setting equation), would cause this lack of consistency in the results.

${ }^{15}$ All estimations and $t$ - tests were carried out with Eviews, while both the misspecification and stability tests and the ARDL/Johansen's methodology were run using Microfit.
} 


\begin{tabular}{|c|c|c|c|}
\hline \multicolumn{4}{|c|}{ Table 1: Definitions of variables and sources } \\
\hline & & & Source: \\
\hline$n$ & : & total employment (log) & $(1)$ \\
\hline$l$ & : & total labor force (log) & (1) \\
\hline$u$ & : & unemployment rate $(\simeq l-n)$ & $(1)$ \\
\hline$w$ & $:$ & total real compensation per employee (log) & (1) \\
\hline$b$ & : & social security benefits ( $\%$ of GDP) & (1) \\
\hline$\tau^{f}$ & : & direct taxes on business ( $\%$ of GDP) & (1) \\
\hline$g d$ & : & government debt (\% of GDP) & $(1)$ \\
\hline$d^{97}$ & $:$ & dummy (value 0 up to 1997,1 afterwards) & (1) \\
\hline \multicolumn{4}{|c|}{$u_{t} * d^{97}$} \\
\hline$k$ & : & real capital stock $(\log )$ & $(1)$ \\
\hline$k d$ & : & capital deepening $(=k-n)$ & (1) \\
\hline$y$ & $:$ & real GDP $(\log )$ & (1) \\
\hline$p r$ & $:$ & real labor productivity $(=y-n)$ & (1) \\
\hline ulc & : & unit labor costs $(=\exp [w-(y-n)])^{*}$ & $(1)$ \\
\hline$z$ & & working-age population (log) & $(1)$ \\
\hline fi & : & firms' long-term indebtedness $\left(=\frac{\text { long-term borrowings and bonds }}{\text { assets }}\right)$ & $(2)$ \\
\hline ro & $:$ & unions, rate of organization $\left(=\frac{\text { membership }}{\text { employees }}\right)$ & $(3)$ \\
\hline oil & $:$ & real oil prices, yens per barrel (log) & $(4)$ \\
\hline$t$ & $:$ & time trend & \\
\hline$\Delta$ & $=$ & difference operator & \\
\hline \multicolumn{4}{|c|}{$\begin{array}{l}\text { Sources: (1) OECD, Economic Outlook; (2) Ministry of Finance of Japan; (3) Ministry of } \\
\text { Health, Labour and Welfare, Japan; (4) IMF-IFS. } \\
\text { *. Also, a proxy of the labor income share } L I S(\simeq \exp [(w+n)-u]) .\end{array}$} \\
\hline
\end{tabular}

Appendix A (tables A1 and A2) collects the values of all these variables for our two periods of analysis. These values are then used as a reference for the dynamic simulations undertaken both under the 2-equation and 4-equation settings. We have worked with other variables that turned out not significant, namely: prices, financial wealth, real balances, other demand-side variables (such as private consumption, government expenditures, and foreign demand), and other variables related to the tax system (such as social security contributions, direct taxes on households, indirect taxes, a measure of fiscal pressure, and the fiscal wedge).

\section{$3.2 \quad$ A two-equation model}

\subsubsection{Estimated equations}

As already mentioned, we will move from a simple model specification to a more complex representation of the labor market. This first model thus includes a labor demand and supply functions. The underlying goal is to provide a more disaggregate account of the labor market, in comparison to what is usually seen in the more traditional approaches 
(e.g. NRU). In opposition to the single-equation models so often found in the mainstream literature, this alternative two-equation representation puts the stress in the dynamics of adjustment as well as in the spillover effects occurring among different parts of the labor market. Table 2 below presents the joint estimation of both these equations, and table 3 offers several tests corresponding to each of the equations.

\begin{tabular}{|c|cr|}
\hline Table 2: A labor demand and supply model. Japan, 1970-2008 \\
Estimation method: 3SLS
\end{tabular}

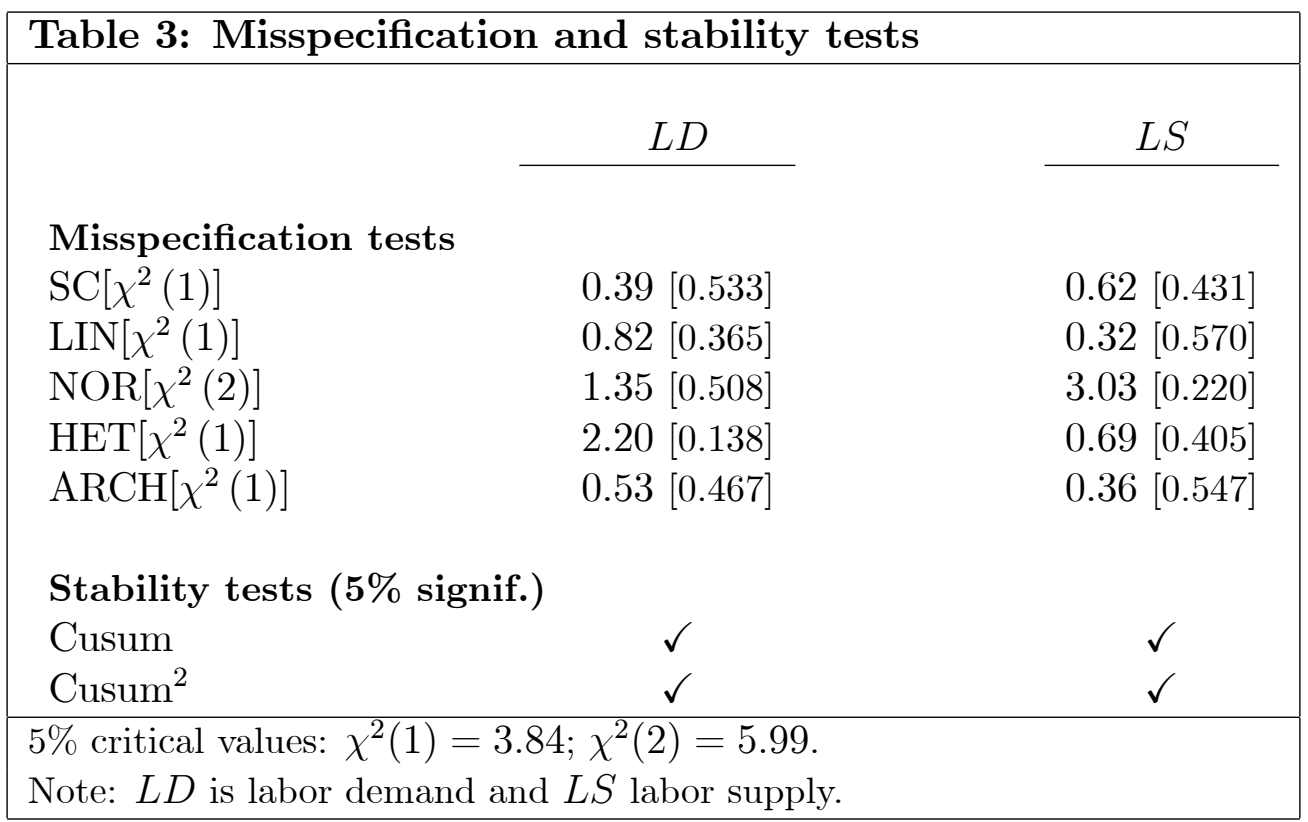


Labor demand The labor demand equation is characterized by a large persistence coefficient (0.87), indicating strong inertia in firms' aggregate level of employment. Wages exert the expected negative influence with a short-run elasticity of -0.06 and a long-run one of $-0.46\left(=\frac{-0.06}{1-0.87}\right)$. This implies that a $1 \%$ rise in this variable would reduce labor demand by $0.46 \%$.

The coefficient of labor productivity is restricted as to comply with the argument that all productivity increases are expected to translate eventually into wage increases. Thus, in this equation we have that the long-run elasticity of employment to wages plus the longrun elasticity of employment to productivity equals zero. Or what is the same, the long-run elasticity of wages with respect to productivity equals one. This restriction is not rejected by the data. ${ }^{16}$ Related to this variable, the capital deepening $(k d)$ displays short and long-run elasticities of 0.04 and 0.31 . We must notice that both the labor productivity and the capital deepening remain the growth drivers behind the employment decisions by entrepreneurs. ${ }^{17}$

As for direct taxation on firms' benefits the variable exerts a negative influence on employment. Given the definition of this variable, the estimated coefficient needs to be interpreted as a semielasticity indicating that a 1 percentage point (p.p.) rise in this variable would decrease employment by 0.25 p.p. in the short-run and 1.92 p.p. in the long-run. Kuttner and Posen (2001) estimate the effects of fiscal policies for Japan using a structural VAR and find that a tax cut was an effective measure for stimulating the economy in the 1990s. Further, and as we will see here, they conclude that the tax burden increase in 1997, which is a direct result of previous fiscal stimulus packages, aggravated the stagnation during the lost decade.

The public and private sectors are deeply intertwined in Japan. To account for this we should consider variables that reflect the intervention of government into the employment decisions of Japanese entrepreneurs. On this, Phelps (1994) considers government expenditures and public debt as relevant determinants of the labor market performance. However, the direct effect of Keynesian fiscal policy (government expenditures) is not significant here, so it is taken out of the equation. As for the government debt $(g d)$ it shows up with a negative and significant coefficient that represents the Japanese "burden of the debt" and the implied opportunity cost for the private sector. ${ }^{18}$ This opportunity cost refers to the job destruction and jobs that fail to open due to central planning mismanagement (e.g. the "zombie firms" hypothesis; Ahearne and Shinada, 2005, and Caballero et al., 2008). Short

\footnotetext{
${ }^{16}$ All restrictions in this and the next model are tested using a Wald test distributed as a $\chi^{2}(1)$.

${ }^{17} \mathrm{~A}$ capital stock variable (in lieu of capital deepening) also works fine in the labor demand. However, to keep consistency with the next model we here stick to the capital deepening variable. The problem emerges when introducing a production function into the model. In this situation, the coefficient associated with the capital stock in the labor demand equation should conform to the constant returns to scale hypothesis (CRS), but this is not the case. We will see that CRS do hold for the production function.

${ }^{18}$ Of course, government expenditures and direct taxes on firms are related to the government debt. Nevertheless, the explosion in the latter and its magnitude during a substantial part of the sample period have little to do with the evolution of the first two variables.
} 
and long-run semi-elasticities are, respectively, -0.02 and -0.15 .

More precisely, the sign of the coefficient of government debt accounts for the implied layoffs that more inefficient and "subsidized" firms have to incur to keep working. At the same time, new and productive firms are prevented to gain market share (or even enter the market) due to the supportive actions endorsed by the government towards banks which, in turn, preserve inefficient firms through bad loan practices. In short, this coefficient captures both job destruction and new job opportunities that fail to open due to inefficiencies that arise from a noncompetitive outcome. A traceable link that goes from government to banks in the form of large bailouts, and from banks to troubled companies through bad loans, has been at the center stage of Japanese postwar development. In recent times the impact of the debt on the economy has aroused interest (see Barseghyan, 2006a and 2006b, for instance), as also has the effect of inefficient firms on employment (Ahearne and Shinada, 2005, Caballero et al., 2008). The existence of such firms, it is argued, prevents the competitive outcome from becoming realizable.

The labor demand equation also entertains other additional variables. Along with the government debt, firms' indebtedness $(f i)$ is yet another variable relevant to firms' labor demand decisions in Japan. Massive debt outstanding in the corporate sector and bad loans in the banking sector are two sides of the same coin. The incidence of $f i$ in the labor market has been studied in Ogawa (2003) to evaluate the consequences of financial distress on employment. In our macro model this variable is also significant with a short-run semielasticity of -0.08 (-0.61 in the long-run). Ogawa (2003) explains up to four channels whereby this variable should affect negatively the labor demand and provides evidence for a sample of Japanese firms in the 1990s. First, the higher cost of external finance to over-burdened debtors. Second, the differing interests between managers and shareholders when faced with bankruptcy, that make the former to cut back on labor and investment in order to raise efficiency (a disciplinary role of the debt). Third, the decrease in investment that might occur with debt overhang (this often happens when, having borrowed in foreign currency, the country is faced with a depreciation). And fourth, the effects of bad loans for banks, which can raise the cost of external finance (for banks) and thus restrain their lending capacity.

Finally, the change in the available labor supply for firms $(\Delta l)$ provides a source of interactions between the two estimated equations (the presence of the unemployment rate in the labor force equation is the other source). In Karanassou et al. (2008b), the role of $\Delta l$ in the labor demand equation is rationalized as a matching effect. As Coles and Smith (1996) show, firms search primarily for new job applicants so that job matches depend more on new entrants to the labor force than on the level of the labor force. Thus the greater the number of new applicants, the greater the consequent number of matches. The coefficient of 1.15 implies that a $1 \%$ rise in $\Delta l$ is fully translated into employment gains. Nevertheless, 
because it is a difference this variable does not entail a long-run elasticity of employment with respect to the labor force.

Labor supply The labor force equation is standard. As in the labor demand equation, the adjustment coefficient is large (0.92) and indicates strong persistence in aggregate household's labor supply decisions. Real wages exert the expected positive influence with short and long-run coefficients of 0.03 and 0.37 respectively. The higher the wage, the more the incentives to participate in the labor market due to the relative prices of leisure and work. Note that in both cases the indirect effect on unemployment is the expected positive one.

Unemployment discourages the labor force, but less so after 1997 as indicated by $u^{d 97}$, which is included to solve the structural stability problems of the estimated coefficients (from 1997 onwards the coefficient of $u$ is $-0.63=-0.85+0.22)$. The higher the unemployment rate, the less people searching actively for a job and the lower the sensitiveness of the labor force to the growing unemployment problem. This change in 1997 reflects the sudden stabilization in the participation rate, indicative of the growing amount of discouraged workers.

We also introduce institutional variables that might deter individuals from entering the labor market. These variables are the rate of organization of unions and the social benefits, yet enter the labor supply equation only in differences. Remember that the social security benefits, in proxying the minimum wage, should be here understood as a deterrent to work (as should all other provisions of the welfare state).

Finally, the working-age population is the labor supply only driving-force. It captures the important demographic influences on the labor market with a unit long-run elasticity not rejected by the data.

\subsubsection{Model diagnosis}

To further check the validity of the estimated model we use the Johansen procedure to confirm that our long-run relationships comprise indeed cointegrating vectors. First, the maximal eigenvalue and trace statistics indicate that the variables involved in the equations are cointegrated. Second, we estimate a VAR featuring the main characteristics of the estimated equations (same order, same sample period and variables, and inclusion of unrestricted intercepts and no trends) and obtain the cointegrating vectors $(C V s)$. Third, we test whether the long-run relationships implied by our model conform with the ones obtained using Johansen's method. It is a likelihood ratio (LR) test, distributed as a $\chi^{2}(q)$, that restricts Johansen's CVs to take the corresponding ARDL values (being $q$ the number of restrictions). These restrictions are not rejected at conventional critical values, a result that adds to the negative and significant sign of the ECM term in both equations.

The $I(1)$ variables in the model are $n, l, w, p r$ and $z$; therefore, we test two restrictions in each equation. See that these tests are conducted using the restricted estimates of both 
the labor demand and supply equations taken from their individual regressions, so they are not exactly the same as the long-run coefficients that would be drawn from the joint estimation in table 2. For the sake of brevity we only present the final results of this exercise in table $4 .^{19}$

Table 4: Validity of the long-run relationships

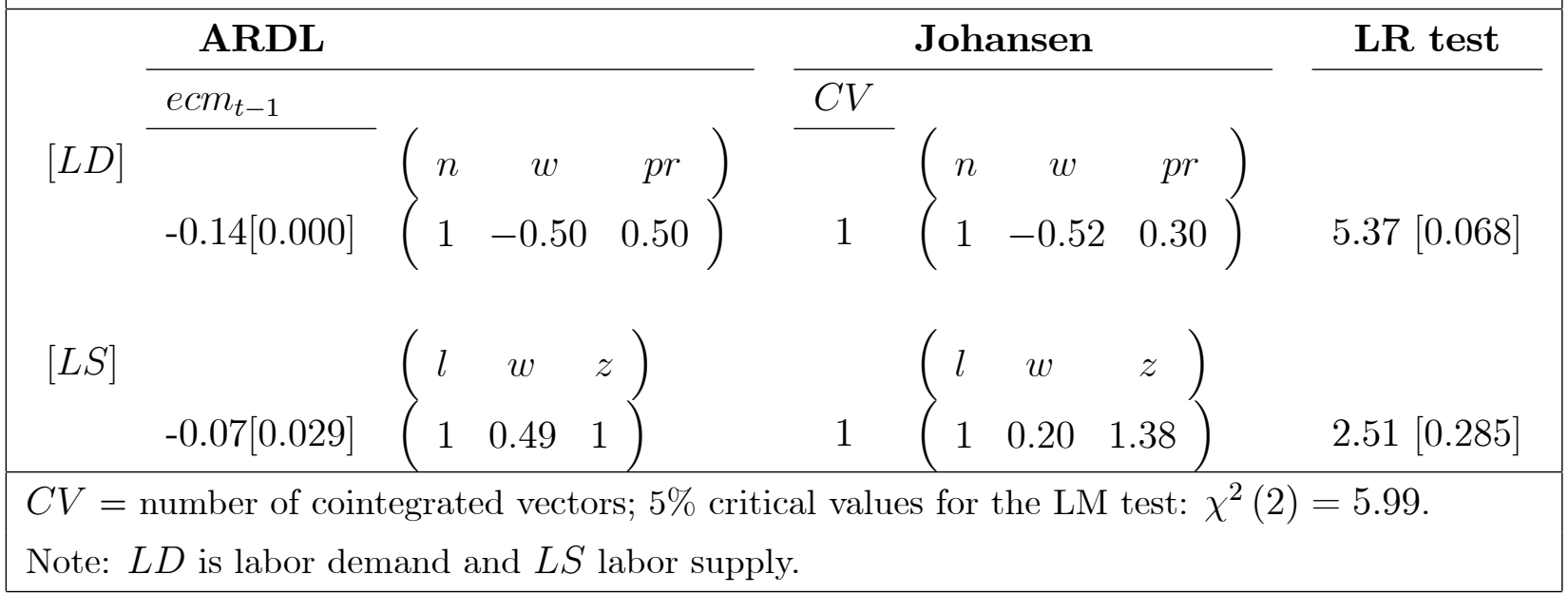

As shown in figure 1, our model tracks closely the actual evolution of unemployment, despite being computed from a multi-equation model with various sources of interactions across equations. This figure is also interesting because it depicts the magnitude of the unemployment problem that came with the fading 1990s and, at the same time, arises the issue of a possible recovery in later times. Our next objective is to use this model to shed some light on the causes that made the unemployment path unusually higher in those years.

Figure 1. Actual unemployment and fitted values

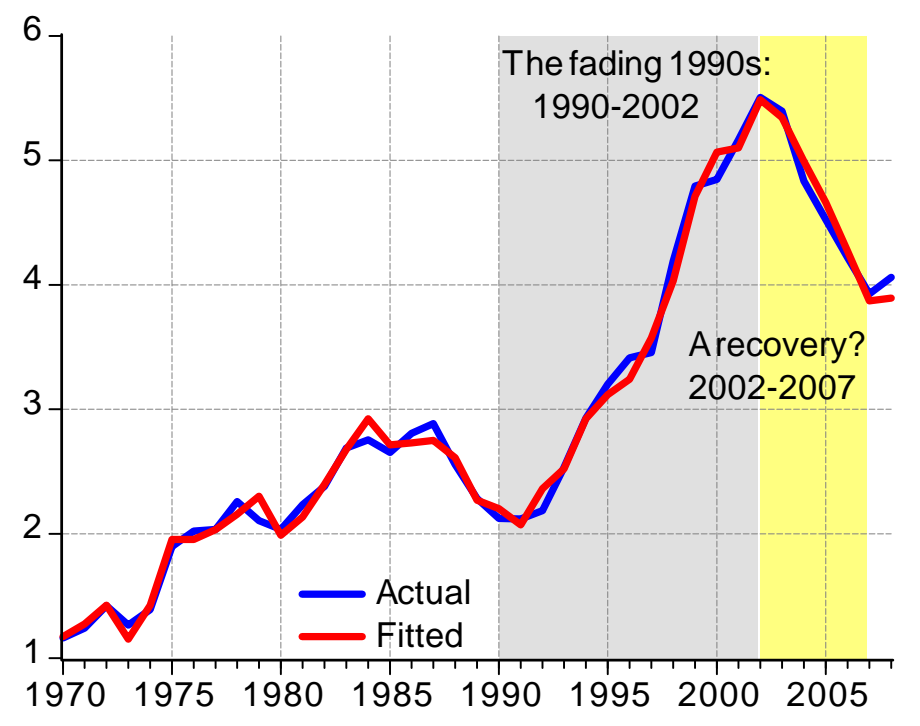

\footnotetext{
${ }^{19}$ Underlying this table there is sizable information, which is available upon request. In particular, that of the unit root tests and the whole cointegration analysis using Johansen's method.
} 


\subsubsection{The lost decade: $1990-2002$}

To what extent this trajectory would have changed had a particular variable followed a different path? We conduct dynamic simulations that aim at disentangling the relative contribution of the model's explanatory variables to this rising path. For example, if direct taxes on firms had stayed at its 1990 value, $5.6 \%$ of GDP, instead of falling to $2.9 \%$ in 2002 , it is interesting to ask how the rate of unemployment would have evolved. This is a simple, transparent, and informative way to analyze the driving forces behind the upward trajectory of Japanese unemployment in those years. By no means, however, should this be taken as an assessment of what would have actually happened had this or that variable behaved differently than it actually did; in which case we would run afoul of the Lucas Critique (Lucas, 1976).

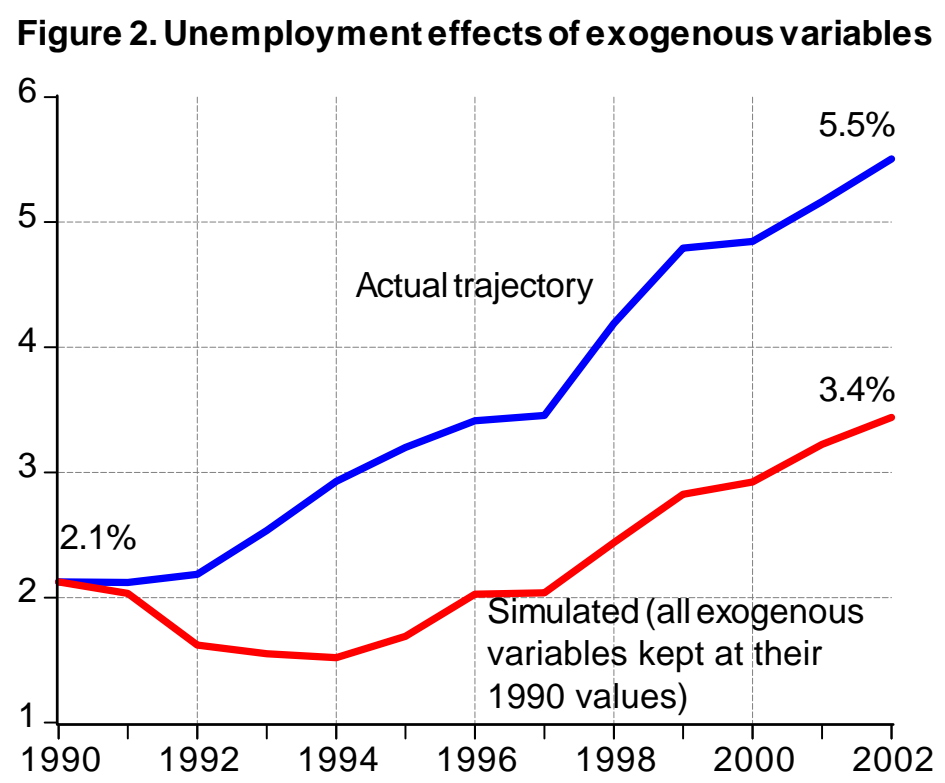

Figure 2 presents the evolution of unemployment when all explanatory variables are simultaneously fixed at their 1990 values. Observe that in such scenario unemployment would have moved up to $3.4 \%$ in 2002 . Instead, it reached a historical maximum of $5.5 \%$. The actual and simulated evolution of each exogenous variable, and the corresponding actual and simulated paths of the unemployment rate, are plotted and grouped in the next pages. The information contained in those figures is summarized in table 5 .

According to our simulations the rise in unemployment was not a 'labor market problem'. Mainstream accounts of the labor market performance emphasize the role of wage-push factors, in particular of labor market institutions, that generate real wage rigidities and hamper adjustments in the demand and supply of labor. In Japan, on the contrary, the decreasing growth rate of real wages was the most important offsetting force (by 3.5 percentage points, figures $3 \mathrm{a}$ and $3 \mathrm{~b}$ ) of the unusual unemployment rise in the 1990s. 


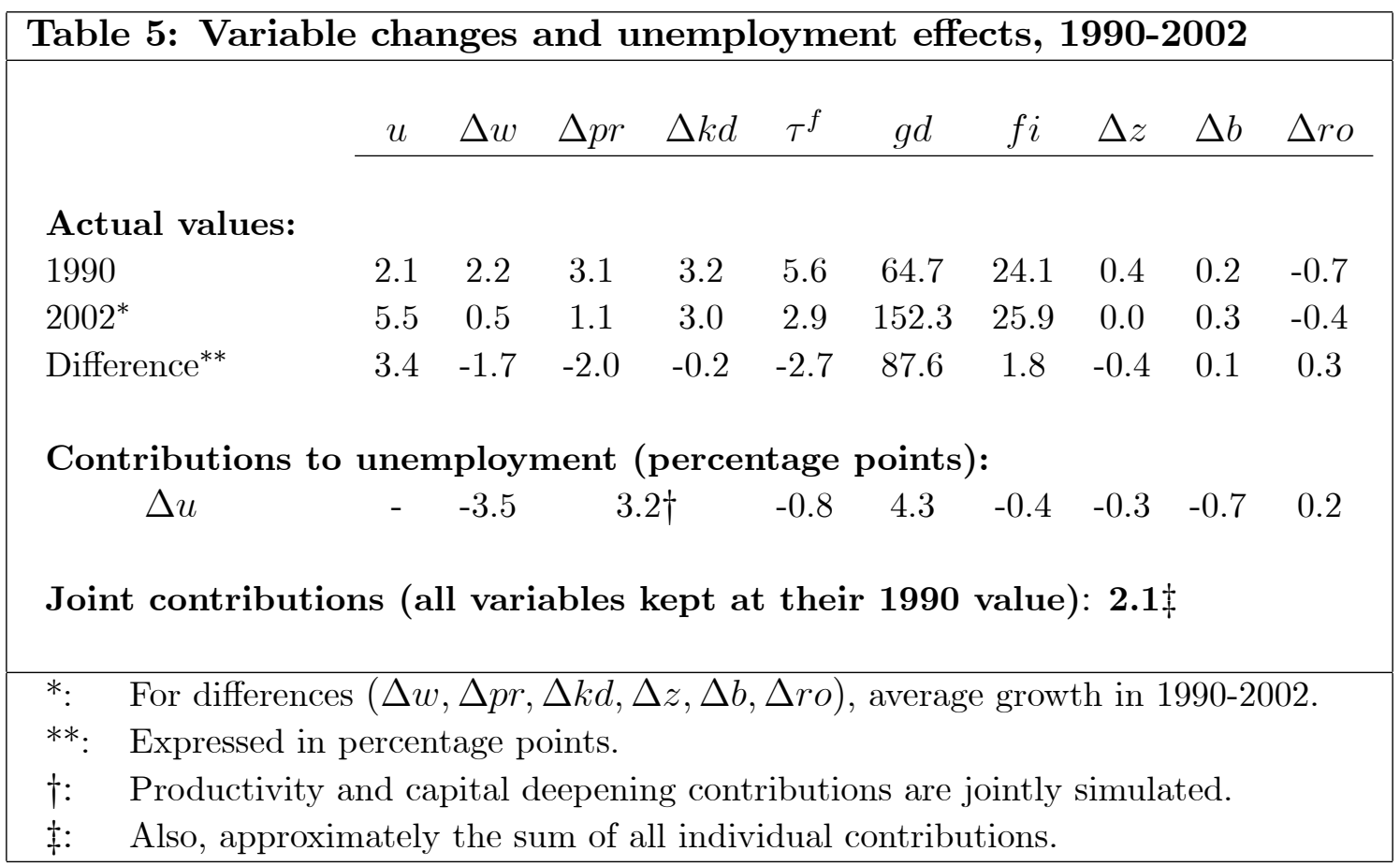

Reasonably, this coincided with a strong and continuous decline in the rate of organization of labor unions and the noticeable reduction in the workweek length (average hours worked per week). According to the 2006 Basic Survey on Labour Unions provided by the Ministry of Health, Labour and Welfare, the organization rate of unions came down from $25 \%$ in 1990 to $20 \%$ in 2002 . The labor market is notably heading towards a strong deunionization in recent times. On the other hand, the new workweek length set by the revision of the Labor Standards Law in 1988 brought the amount of hours down from 44 to 40 during the period 1988-1993. More, average annual hours worked dropped from 2000 to 1800 for the period 1990-2002 (OECD Economic Outlook, 2009).

Figure 3. Real wages and contribution to unemployment

a. Real wage growth

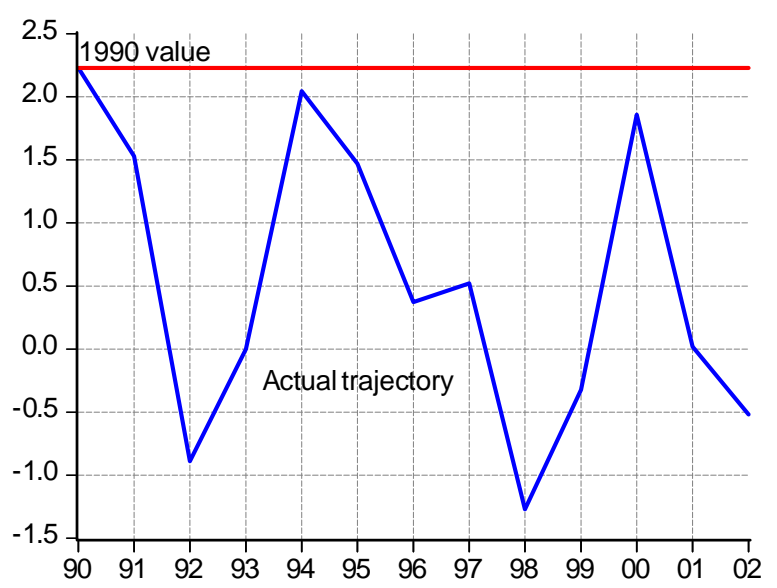

b. Contribution of real wages

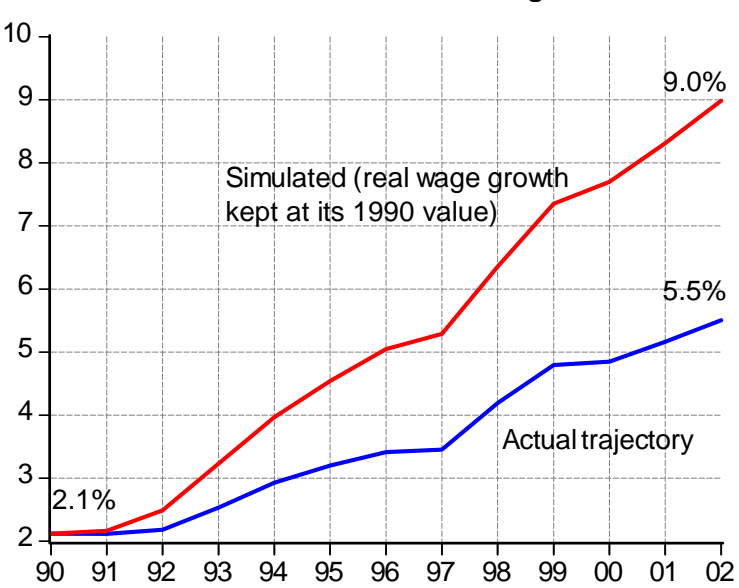


Under this 2-equation setting the major causes behind the sudden increase in unemployment are to be found in the rapidly exploding government debt and the sharp decline in productivity and capital deepening growth. They contribute, respectively, with 4.3 and 3.2 percentage points. These two variables are considered together since the decisions by entrepreneurs as regards capital are expected to influence productivity levels. However, it is the slowdown in labor productivity which seems to capture most of the contribution, as we checked this by running separate simulations. Further, capital deepening has not changed much in the 1990s (see table 5).

Figure 4. Government debt, direct taxes, and contributions to unemployment

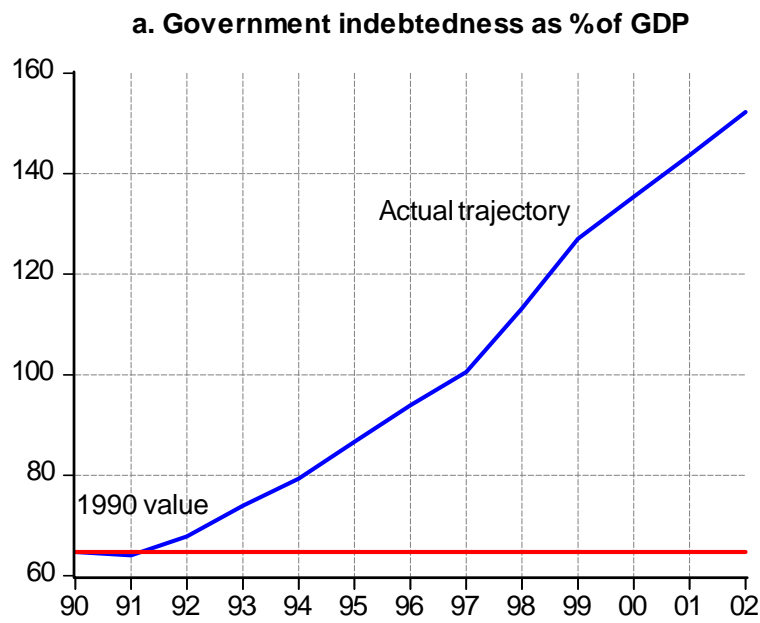

b. Contribution of government indebtedness

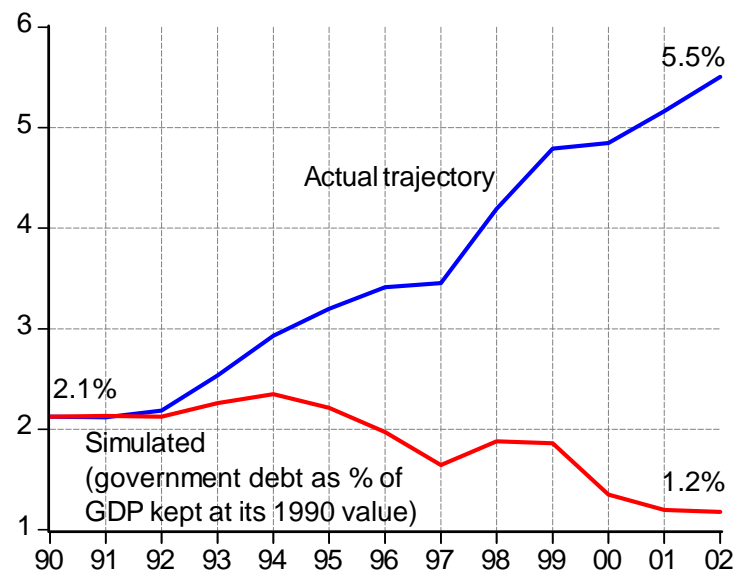

c. Direct taxes on firms as \% of GDP

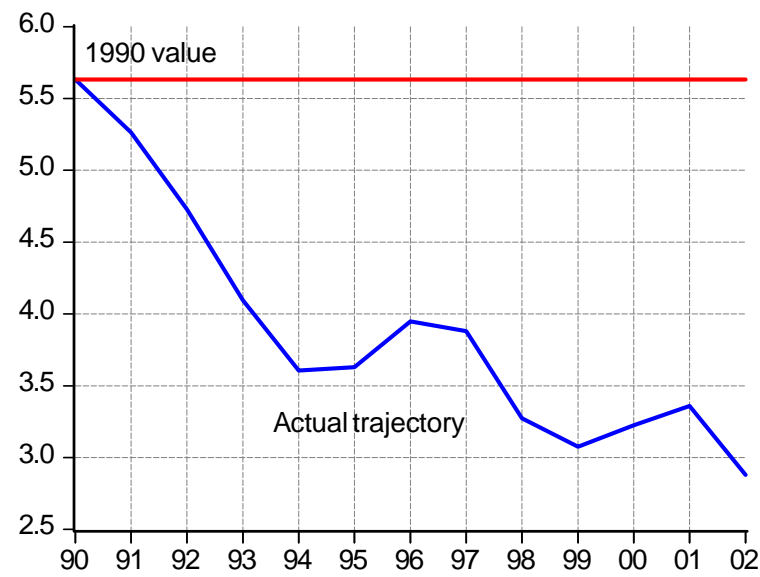

d. Contribution of direct taxes on firms

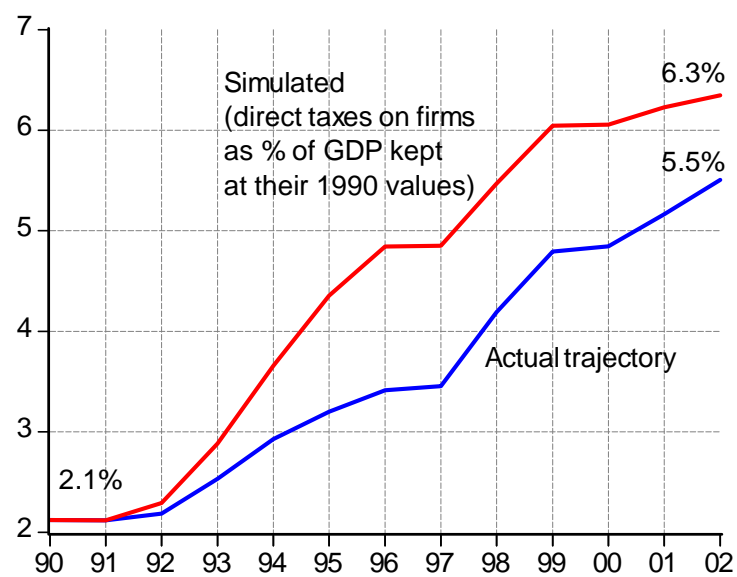

Generally speaking, the reaction from the government to the fading 1990s is embedded both in the increased spending ${ }^{20}$ as well as in the soaring national debt. ${ }^{21}$ On the other

\footnotetext{
${ }^{20}$ Remember that the government spending variable was dropped due to its non-significance. This variable went from $20 \%$ in 1990 to $24 \%$ of GDP in 2002.

${ }^{21}$ Barseghyan (2006b) claims that the Japanese slump in the 1990s was mainly due to the existence of nonperforming loans combined with a delay in the government bailout. In other words, for this author the slump could have been subdued had the government stepped in more rapidly.
} 
hand, an easy tax policy during that period probably avoided a more pronounced hike in unemployment (see Kuttner and Posen, 2001). In our model this is captured via direct taxes on firms, which contribute with a 0.8 p.p. reduction. This expansionary effect, however, was much lower than the distortions brought about by the huge national debt and the rapid pace it followed (see figures $4 \mathrm{a}$ to $4 \mathrm{~d}$ ).

The Japanese government is well known for its meddling with the private sector since postwar. It has for long fed a strong alliance with big financial conglomerates that easily embodied the "culture of harmony" laid out by a deep-rooted Confucian culture. But whether this is the result of Confucianism or crony capitalism, the Japanese government indebtedness has gone well beyond the goals of an expansionary fiscal policy, just to deliver a noncompetitive outcome that harms employment in the end.

The cumulative debt appears as a burden and not as the result of some specific expansionary fiscal policy. The fact that the government spending has barely budged (in the range of $20 \%$ to $24 \%$ of GDP since 1970) while the gross government debt reached a maximum of $175 \%$ in 2005 , growing at a pace of $7 \%$ for the previous ten years, provides a first rough indication of this burden. ${ }^{22}$ It is hard to think that the debt burden would leave the labor market unaffected. Particularly, in what refers to creation of new and more efficient firms (and employment) that would have turned up if the extinction of most inefficient ones had not been prevented through government bailout. This fact comes at a substantial opportunity cost in terms of job creation, and adds to the already harming effect of inefficient firms laying off workers to remain competitive.

Many doubt about the effectiveness of fiscal policy in Japan during the 1990s (Hamada, 2004; Ihori et al., 2003; Krugman, 1998). Besides, banks, conglomerates, and government have formed up a tightly intertwined network characterized by an uneasy lending-borrowing dynamics. In fact, Japanese banks own large shares of their corporate borrowers, and thus there is little financial advantage in corporate debt foreclosure (Fukao, 2003). It seems as though the government had somehow diverted useful resources that would have been helpful in supporting new efficient firms entering the industry.

It should also be noted that, since the beginning of industrialization, the national banking regime in Japan has solely grown to achieve efficiency for financing export production. Japanese exporting firms never had to compete for capital or credit the way their American peers, for instance, used to. Credit is rife and easy for such firms, and usually at a rate that guarantees their competitiveness in the export market. Arguably, this is also why Japan is not that well equipped to finance new entrepreneur ventures. Further, since the economy has suffered dearly in terms of productivity growth, it seems as if the bailouts had turned out an unfair reward to a less efficient private sector. In fact, one is left to wonder if the

\footnotetext{
${ }^{22}$ Indeed, excessive bailouts targeting a financial sector already damaged by the bubble crisis were commonplace during the mid-1990s. For instance, during 1997 a $\$ 232.5$ billion bank bailout was introduced to prop up the financial sector.
} 
aggressive bailing out conducted by the government in the 1990s might have harmed the economy's productivity to a greater extent. ${ }^{23}$

Figure 5. Productivity, capital deepening, and contributions to unemployment

a. Productivity growth

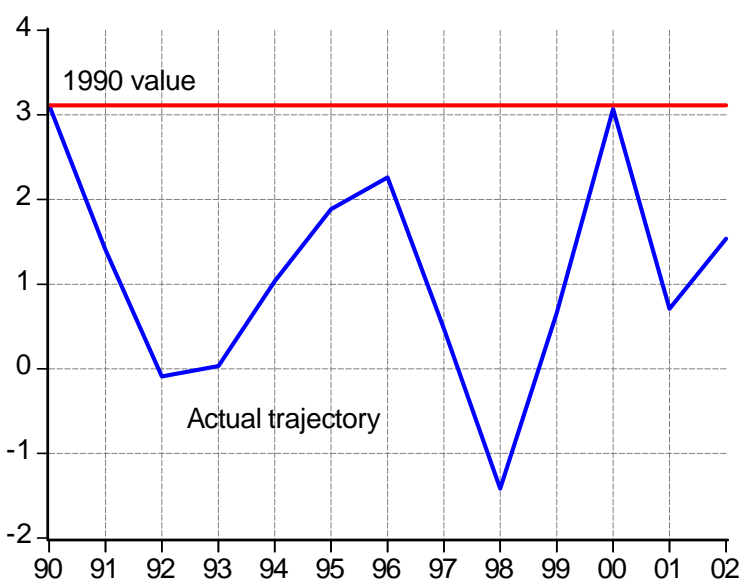

b. Capital deepening growth

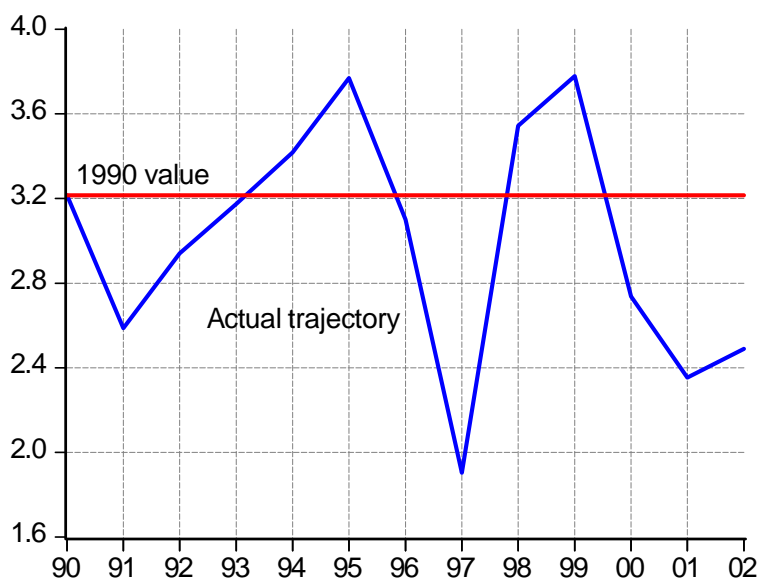

c. Contribution of productivity and capital deepening

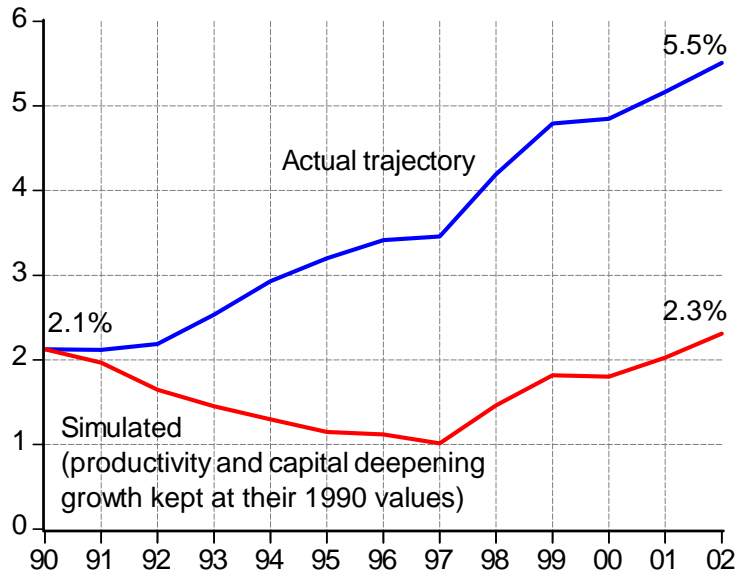

On the productivity side (figures $5 \mathrm{a}$ to $5 \mathrm{c}$ ), our results are in accordance with several recent studies relying on productivity slowdown as the major cause for the recent stagnation in Japan. Hayashi and Prescott (2002), for example, believe that the 1990s can be explained as a low productivity growth problem alone. Since the financial system did not break down, they argue that a neoclassical growth model might well account for the Japanese lost decade of growth. They furthermore argue that treating productivity as exogenous, as we do in this 2-equation model, would account well for the Japanese lost decade of growth. ${ }^{24}$

Fukao and Kwon (2006), in turn, stress the lack of ability for the private sector to reallocate resources from less efficient to more efficient firms. This "low metabolism", they argue,

\footnotetext{
${ }^{23}$ The study of such connection is beyond the scope of this paper.

${ }^{24}$ Theirs is a TFP measure though, whereas ours is a labor productivity measure.
} 
seems to be an important cause for the productivity slowdown in the lost decade. Finally, Miyagawa et al. (2006), in studying the pro-cyclicality of measured productivity, conclude that policies to revive the Japanese economy should focus on promoting productivity growth.

There are different hypotheses that explain the sharp decline of productivity growth in Japan. First, the end of Japan's catching up process has led capital accumulation, labor reallocation, and investment in human capital to cease being the prime sources of growth (see Kim and Lau, 1994, 1996). This has allowed productivity to become the real growth driver until recent times, when Japan arguably reached a first-class membership in the industrialized world. The problem with this argument is that a decade of slump almost surely cannot be explained by growth theory alone. Japan has not only stopped catching up, but has also lost considerable ground relative to industrial leaders. Further, growth theory restraints itself from explaining frictions in financial intermediation, something we try to grasp with the inclusion of firms' indebtedness in the labor demand equation. Second, the overinvestment process that took place in the 1980s due to overrated asset and land prices could have translated into a productivity slowdown after the bubble burst on the last day of 1989. Third, the crowding out of capital exerted by persistent increases in government debt has brought down the rate of return on capital, leading to a decline in investment and productivity growth rates (Barseghyan, 2006a). And finally, the "zombie firms" hypothesis has been laid out to help understand the relation between Japanese banks and their borrowers. It suggests that inefficient insolvent borrowers (the "zombies") have benefited from poor banking practices and, therefore, have prevented more productive companies from gaining market share. This, consequently, has shut down an important source of productivity gains for the economy (Ahearne and Shinada, 2005), since the competitive outcome where "zombies" lay off workers and lose market share is frustrated (Caballero et al., 2008; and Kobayashi, 2007). The last hypothesis is particularly related to the above discussion on the explosion of the government debt and the aggressive policy of bailouts.

With respect to firm's financial indebtedness, our simulation shows a small negative effect (figures $6 \mathrm{a}$ and $6 \mathrm{~b}$ ). The variable shows a mild increase in our subsample of analysis but with a downward trend in the final part. This is in contrast to the steep rise it experienced in the second half of the 1980s and early 1990s. Roughly, it went from $20 \%$ in 1985 to $28 \%$ in 1994, and then down to $26 \%$ in 2002 . This result certainly does not preclude a relevant role of financial distress, especially at the root of the crisis. We will see how this changes during 2002-2007, when the financial indebtedness of firms went markedly down, thus contributing to ameliorate the unemployment rate significantly. 
Figure 6. Miscellaneous variables and contributions to unemployment

a. Long-term firms' indebtedness as \%of total assets

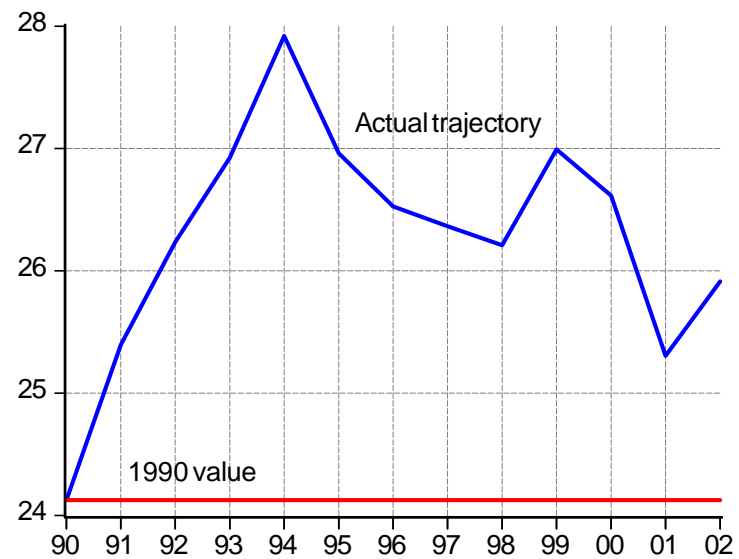

c. Social security benefits as \% of GDP, growth

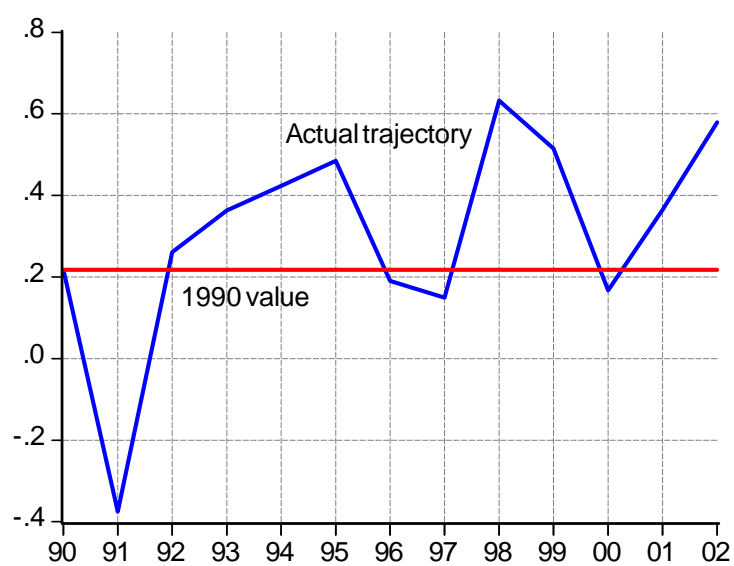

e. Union membership as \%of employees, growth

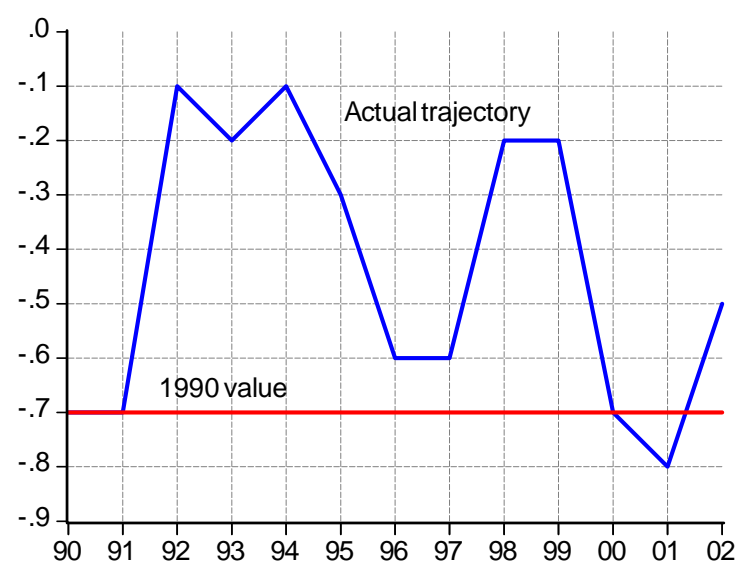

b. Contribution of long-term firms' indebtedness

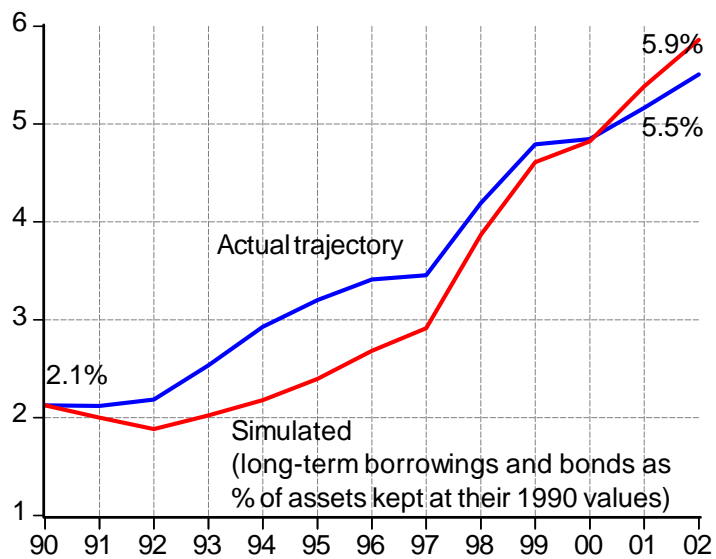

d. Contribution of social security benefits

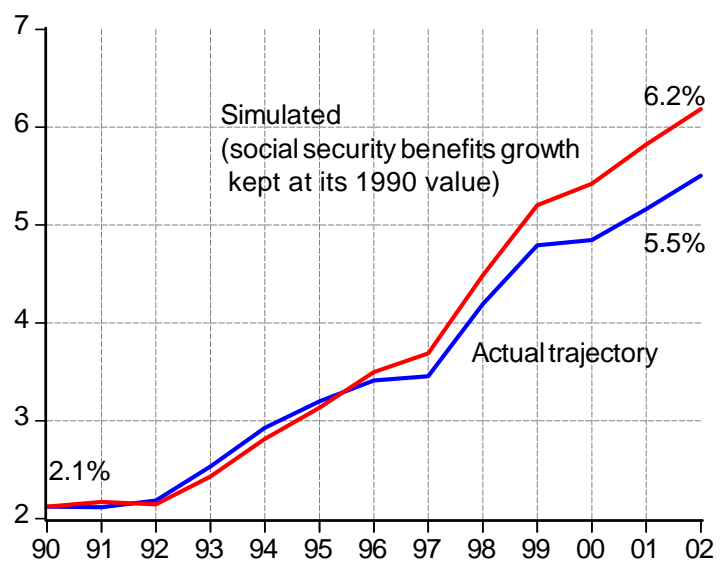

f. Contribution of union membership

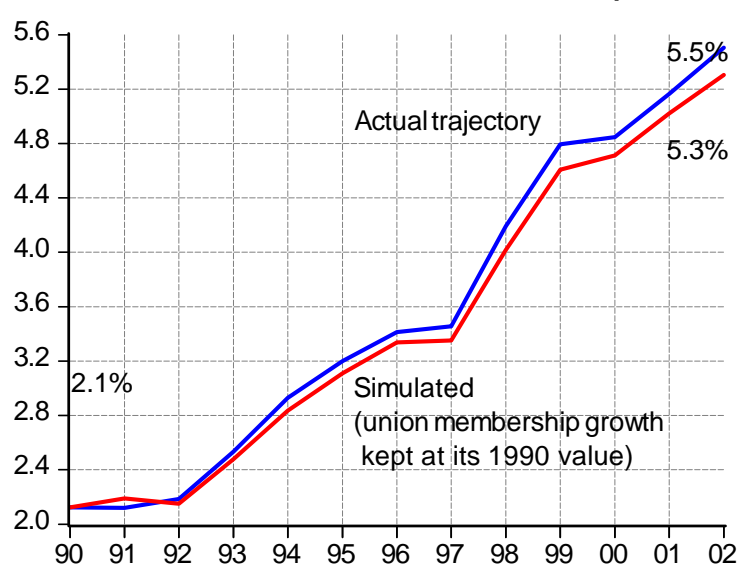

Rapid aging population is another important issue well deserving the government's attention in later years, despite its relieving effect on unemployment. Indeed, the growth rate of working-age population went down in the 1990s, at the same time that the aggregate 
participation rate stabilized around $78 \%$ in the second half of the 1990 s and early 2000s. According to our model this contributed to reduce unemployment by 0.3 percentage points despite the damaging consequences for future generations (see figures $7 \mathrm{a}$ and $7 \mathrm{~b}$ ). The speed at which the growth rate of working-age population has been gradually decreasing to reach negative values in the last years posits a true challenge to the maintenance of the welfare system.

Alarming figures by the Statistic Bureau of the Ministry of Internal Affairs show the radical change in the population pyramid that is to be expected in a not so far future. While 1950 presented the standard broad-based pyramid (35\% at the 0-14 years range), the projection for year 2050 delivers an almost exactly inverted chart (near $40 \%$ for 65 years and over). This is an important issue the country will have to address as it could otherwise lead to labor shortages in the future, once the unemployment problem is solved. Opening the labor market begins to be seen as an alternative, considering the registered alien population accounts for only less than $2 \%$ of the total population, one of the world's lowest.

Figure 7. Working-age population and contribution to unemployment
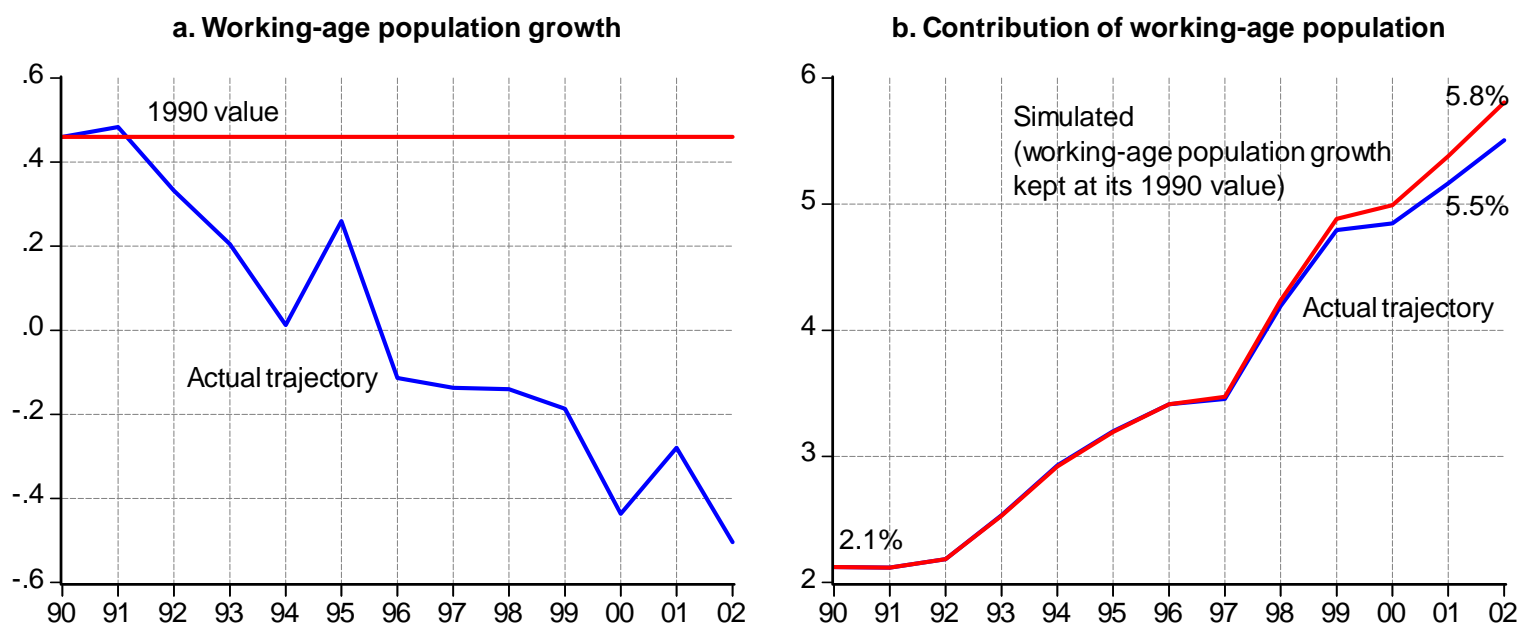

\subsubsection{A light in the dark? 2002-2007}

Now it is time to see what our model explains for 2002-2007, when unemployment went down from $5.5 \%$ to $3.9 \%$. Figure 8 shows what happens with the model when all explanatory variables are simultaneously fixed at their 2002 values. Unemployment would have been much lower than it actually was: $1.5 \%$ instead of $3.9 \%$. This major difference should be taken seriously, since it points to a full recovery that never was and, at the same time, echoes the recent fears about Japan entering a second lost decade. 
Figure 8. Unemployment effects of exogenous variables

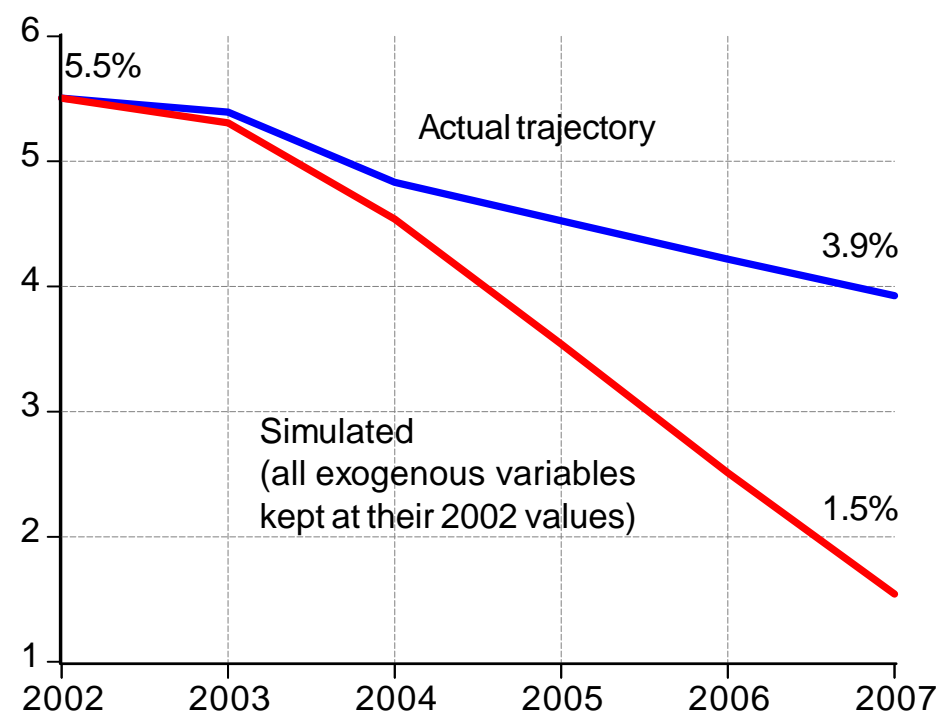

The figures below gather all the individual simulations for this second subsample, whereas table 6 summarizes all the information contained in the figures. Notice that the discussion underneath does not detour to other related issues, as it did before when discussing the lost decade. We will now focus directly on the numbers and the assessment that can be drawn from them in relation to unemployment.

\begin{tabular}{|c|c|c|c|c|c|c|c|c|c|c|}
\hline & $u$ & $\Delta w$ & $\Delta p r$ & $\Delta k d$ & $\tau^{f}$ & $g d$ & $f i$ & $\Delta z$ & $\Delta b$ & $\Delta r_{O}$ \\
\hline \multicolumn{11}{|c|}{ Actual values: } \\
\hline 2002 & 5.5 & -0.5 & 1.5 & 2.5 & 2.9 & 152.3 & 25.9 & -0.5 & 0.6 & -0.5 \\
\hline $2007^{*}$ & 3.9 & 0.4 & 1.8 & 0.8 & 4.2 & 167.1 & 21.3 & -0.6 & 0.2 & -0.4 \\
\hline Difference** $^{* *}$ & -1.6 & 0.9 & 0.3 & -1.7 & 1.3 & 14.8 & -4.6 & -0.1 & -0.4 & 0.1 \\
\hline \multicolumn{11}{|c|}{ Contributions to unemployment (percentage points): } \\
\hline$\Delta u$ & - & 1.0 & & $7 \dagger$ & 0.4 & 1.2 & -1.1 & 0.0 & 0.0 & 0.2 \\
\hline \multicolumn{11}{|c|}{ Joint contributions (all variables kept at their 2002 value): $2.4 \ddagger$} \\
\hline \multicolumn{11}{|c|}{$\begin{array}{ll}*: & \text { For differences }(\Delta w, \Delta p r, \Delta k d, \Delta z, \Delta b, \Delta r o), \text { average growth in 2002-2007. } \\
* *: & \text { Expressed in percentage points. } \\
\dagger: & \text { Productivity and capital deepening contributions are jointly simulated. } \\
\dagger: & \text { Also, approximately the sum of all individual contributions. }\end{array}$} \\
\hline
\end{tabular}


Figure 9. Real wages and contribution to unemployment

a. Real wage growth

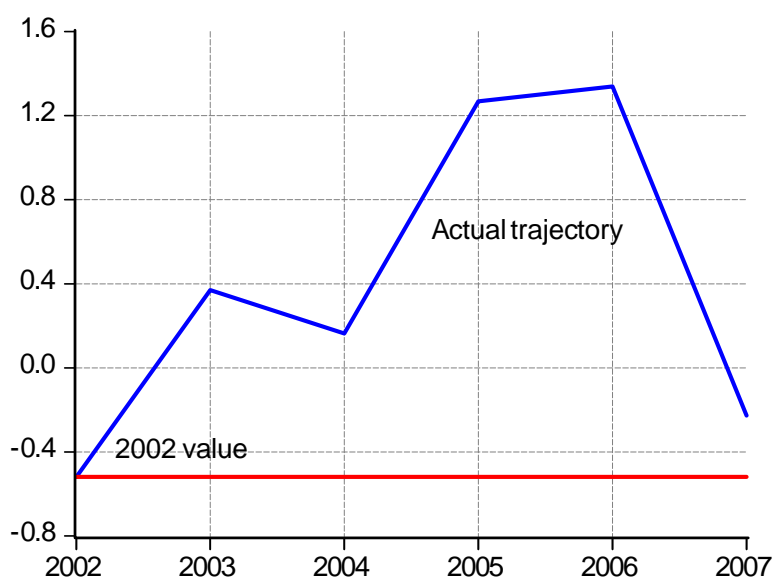

b. Contribution of real wages

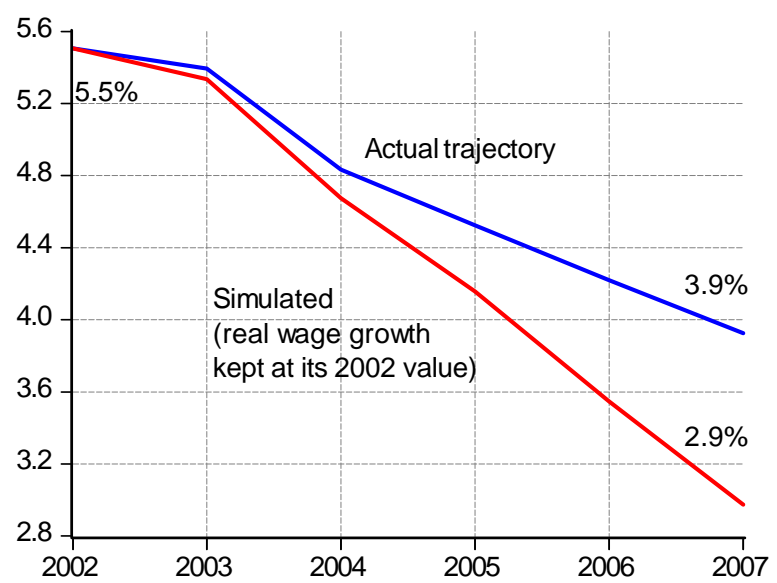

Figure 10. Government debt, direct taxes, and contributions to unemployment

a. Government indebtedness as \% of GDP

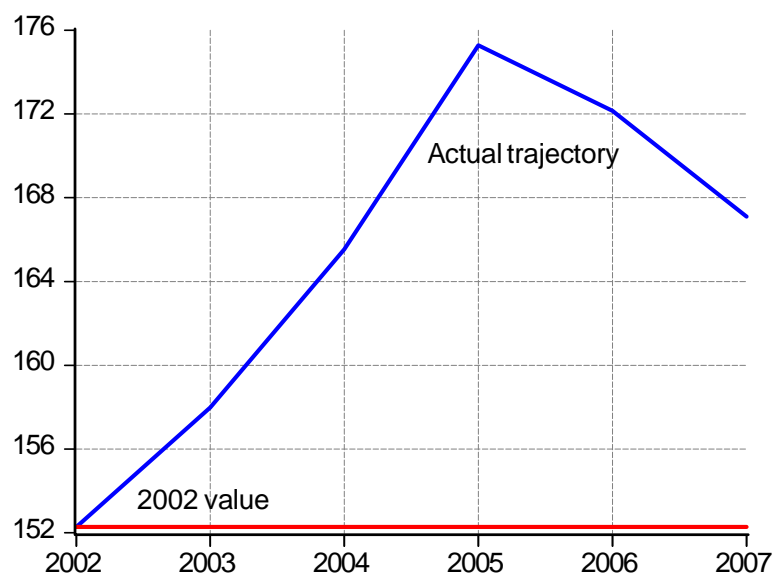

c. Direct taxes on firms as \% of GDP

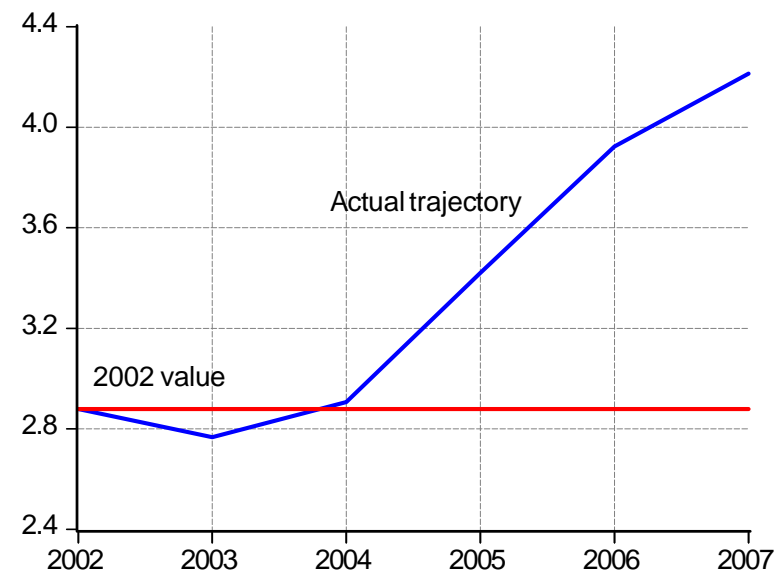

b. Contribution of government indebtedness

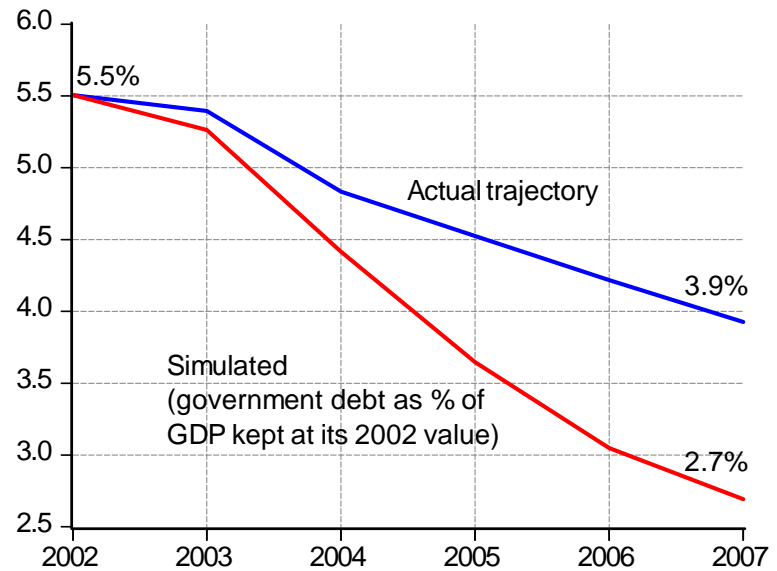

d. Contribution of direct taxes on firms

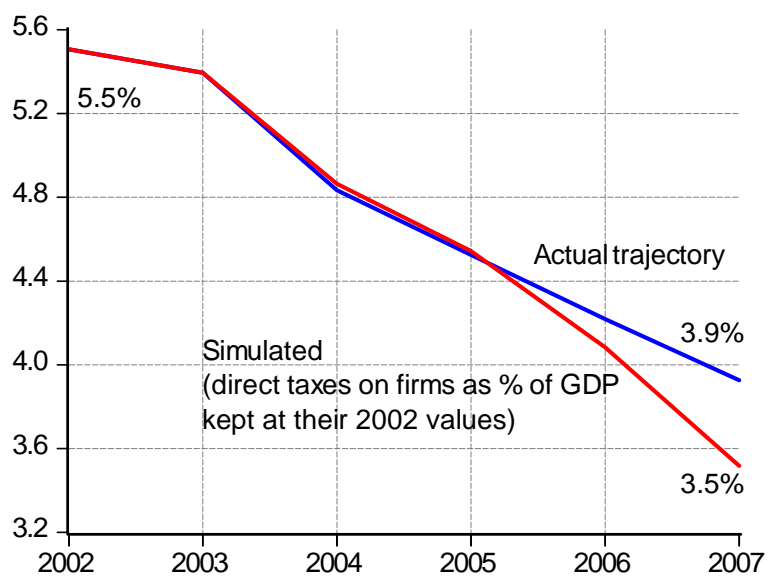


Increasing wages seemingly prevented a full recovery during 2002-2007. In fact, according to our simulation unemployment could have been lower, nearly to pre-1990s levels. In its changing of direction real wages contribute with 1 p.p. to this "virtual" increase of unemployment (figures 9a and 9b). They are now one of the major contributors along with the government debt. One thing to note is that the very nature of the dynamic simulations implies that, for example, the final contribution in a figure like $9 \mathrm{~b}$ (the difference between the actual and simulated rates in 2007) captures all the accumulated effects of the variable in 9a, from 2002 to 2007.

Once again the government debt appears as the great hampering force behind the creation of new jobs. Its contribution is the largest, 1.2 p.p., implying that the Japanese central authorities have not made a change for austerity. This argument is reinforced by the tightening of the tax policy during the same period, which contributes with 0.4 p.p. to the "virtual" growth in unemployment (see figures 10a to 10d, and in particular for the effects of fiscal policy refer also to Kuttner and Posen, 2001).

Figure 11. Productivity, capital deepening, and contributions to unemployment
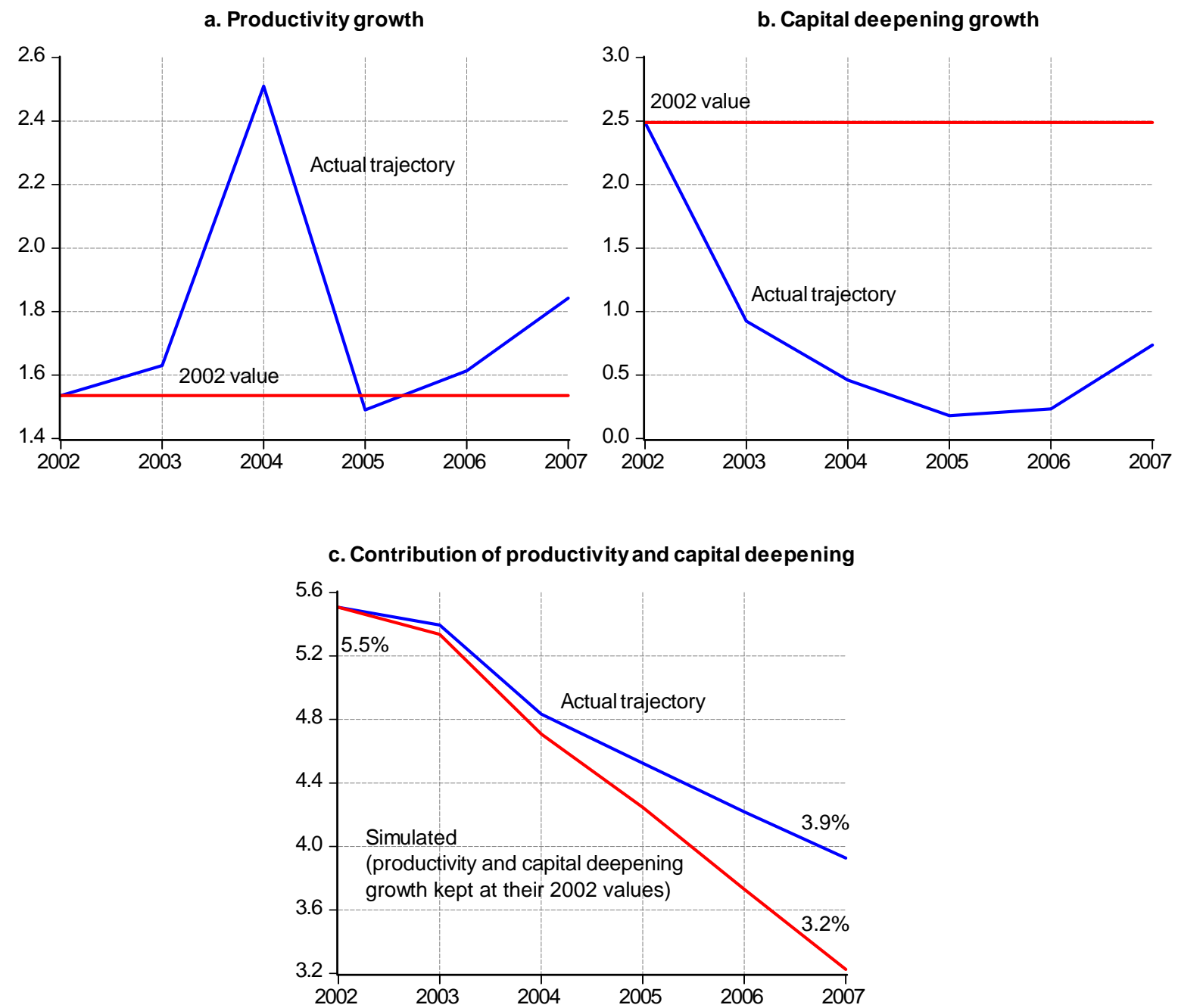
With the end of the 1990s productivity levels seem to have regained some strength. However, the capital deepening has remarkably fallen behind. It is this effect which pushes for a joint contribution of 0.7 p.p. (see figures 11a to 11c).

Figure 12. Miscellaneous variables and contributions to unemployment

a. Long-term firms' indebtedness as \%of total assets

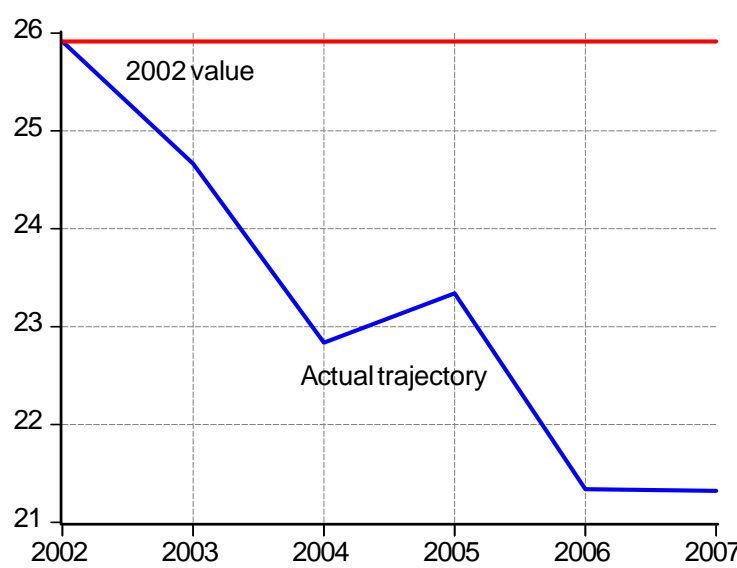

c. Social security be nefits as \% of GDP, growth

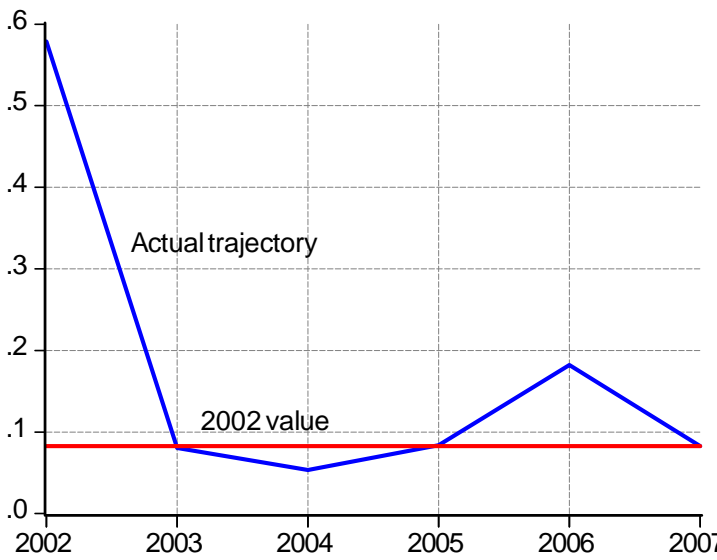

e. Union membership as \%of employees, growth

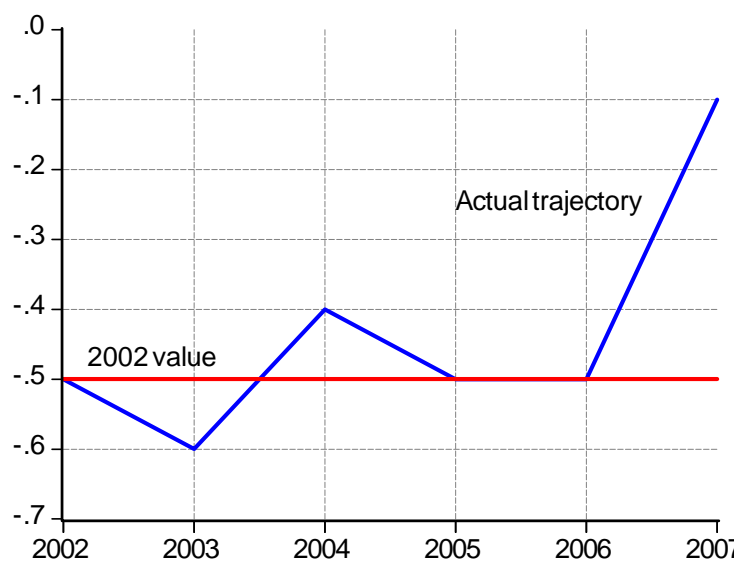

b. Contribution of long-term firms' indebtedness

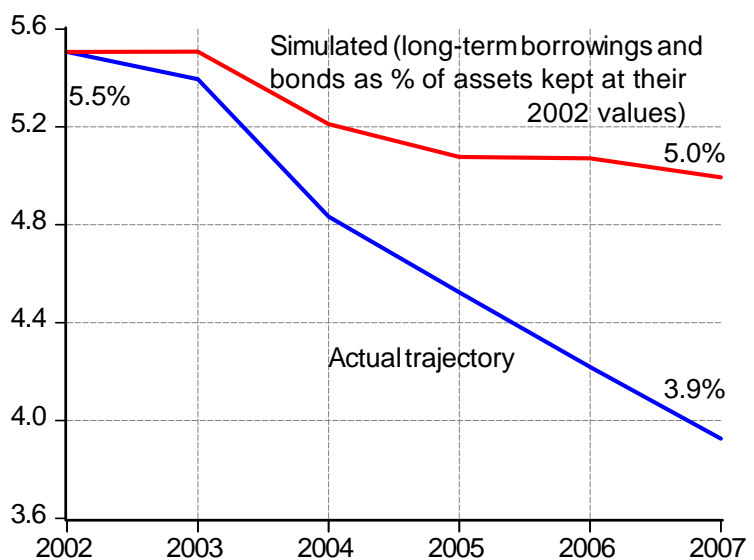

d. Contribution of social security benefits

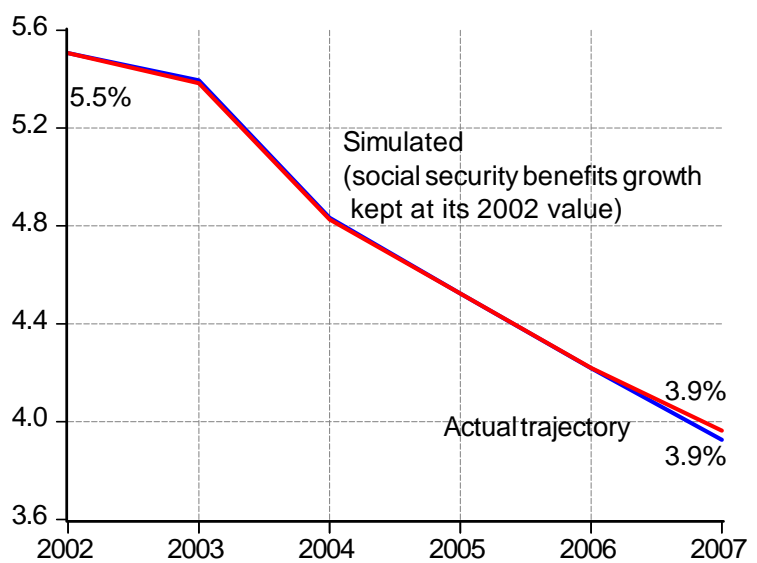

f. Contribution of union membership

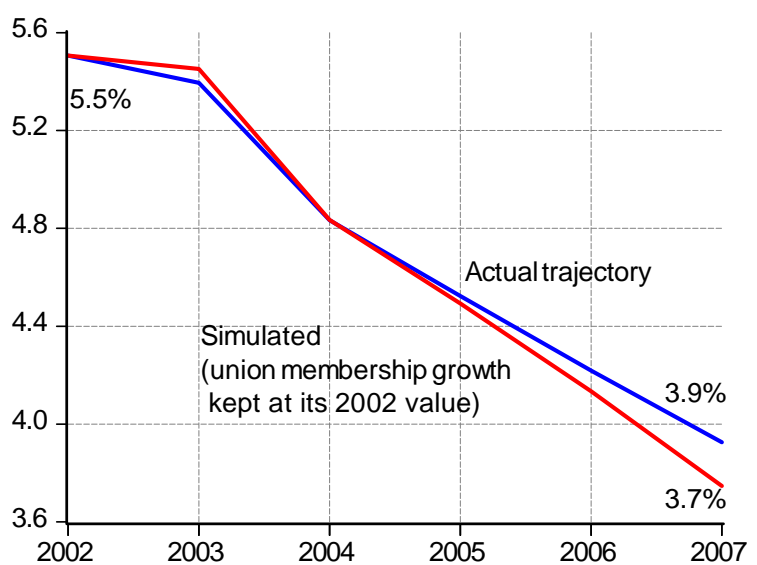


The firms' indebtedness variable has now a noticeable downward trend which determines a powerful offsetting effect of 1.1 p.p. This is the only factor which, according to our model, really contributed to the recovery of the economy during 2002-2007 (figures 12a and 12b).

Figure 13. Working-age population and contribution to unemployment

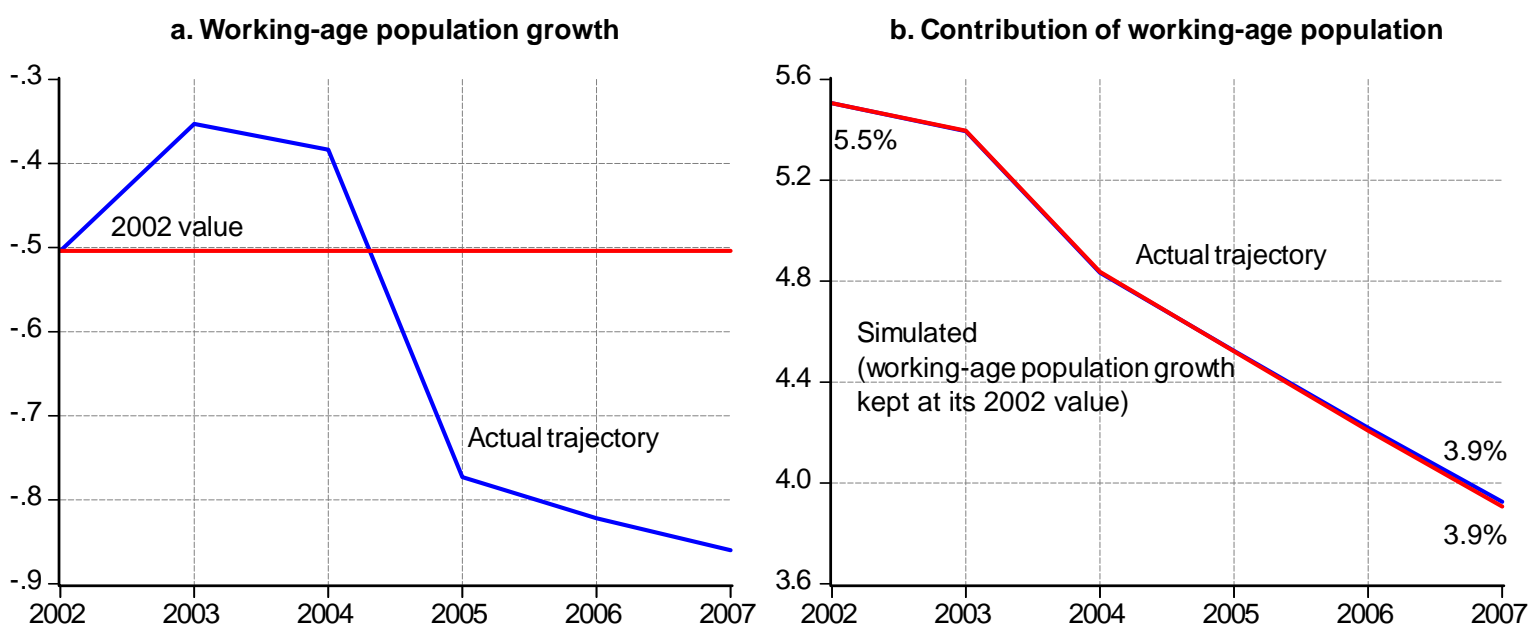

Finally, the Japanese population continues with its aging process as the economy enters the 21st century, but this does not seem to have any effect on unemployment (see figures $13 \mathrm{a}$ and $13 \mathrm{~b})$.

\subsubsection{Concluding remarks}

Under this simple setting we find that the steep rise in unemployment during the "lost decade" was essentially a government debt and productivity-led phenomenon. The significant increase in the former plays a major role by supporting inefficient firms which nevertheless incurred in job layoffs, while preventing new job opportunities to emerge. In particular, the increasing debt and the relatively low productivity growth rate (jointly with the unchanged growth rate of capital deepening) account, respectively, for 4.3 and 3.2 percentage points (p.p.) rise in the unemployment rate for 1990-2002. These effects are, to some extent, offset by dynamic contributions going in the opposite direction: (i) falling real wages, which stand out as the strongest force (with a contribution of -3.5 p.p.); (ii) direct tax cuts (-0.8 p.p.); and (iii) demographics (-0.3 p.p.). The variable representing the financial distress in the private sector as well as those presented in differences are either small or difficult to reconcile. The results presented for this subsample are consistent with those obtained by Agnese and Sala (2009) in a similar study. ${ }^{25}$

\footnotetext{
${ }^{25}$ Agnese and Sala (2008) study the Japanese lost decade with a single-equation reduced-form model, while borrowing some elements from Phepls' Structuralist theory.
} 
During the more promising period of 2002-2007 where the unemployment rate went down, our model identifies several sources that prevented a full recovery to be achieved (e.g. pre-1990s rates of unemployment): (i) the still growing government debt (a 1.2 p.p. contribution); (ii) increasing real wages (1.0 p.p.); (iii) productivity and capital deepening (0.7 p.p., this time with a larger part of the contribution being due to the significant drop in the latter variable); and (iv) higher direct taxes on firms (0.4 p.p.). On the other hand, the reduced financial indebtedness by firms helped somehow in heading the economy back into the right tracks (with a contribution of -1.1 p.p.).

All in all, we have that our 2-equation model explains up to $62 \%$ of the upsurge in unemployment during 1990-2002 (that is, 2.1 p.p. out of an increase of 3.4 p.p) and $250 \%$ of the fall during 2002-2007 (-4 p.p. of -1.6 p.p.). For the post-1990s period the percentage is not straightforward. Whereas the unemployment rate went down 1.6 p.p. in 2002-2007, our model suggests that it would have been much lower had all variables been kept constant at their 2002 values. The difference between the actual rate in 2007 (3.9\%, in figure 8) and the simulated one (1.5\%) makes the 2.4 p.p. which, added to the 1.6 p.p. of "real" fall, yields the part "explained" by our model.

\subsection{A four-equation model}

\subsubsection{Estimated equations}

Our second model offers a full-fledged system of four equations, including labor demand and supply functions, a wage-setting function, and a production function for the economy. Endogenizing wages and production would allow us to explain the evolution of other variables of interest during the lost decade and beyond. Most importantly, taking this step forward will help us explain what drove the labor income share down during recent years (see Iiuduka, 2006, and Takeuchi, 2005). Do remember that our measure of the labor income share is just a rough proxy. Other studies have pointed to the relative stability of this share for the past decades (see Wakita, 2006, who also identifies several measurement issues).

Table 7 shows the estimated coefficients for this "augmented" model, which includes virtually the same information for the labor demand and supply (the coefficients turn out with the same sign and rather similar values). ${ }^{26}$ Therefore, we will only discuss the additional equations: the wage-setting and the production function. Table 8 shows the misspecification and stability tests for this system of equations.

Wage-setting A new feature in our study of the labor market is given by the introduction of a wage-setting equation. In real-life situations, wage determination is substantially affected by the institutional frictions so typical within the labor markets of all developed

\footnotetext{
${ }^{26}$ Notice too that the results of the tests for the labor demand and supply equations are the same as before, since they are run individually on the unrestricted version of each equation.
} 
countries. Two major institutions are here considered: union power and the minimum wage law. We expect both these variables to have a positive effect on real wages, as well as an increasing effect on unemployment.

Table 7: Labor demand and supply, wage-setting, and PF. Japan, 1970-2008 Estimation method: 3SLS

Dependent variable: $n_{t}$

\begin{tabular}{lr}
\hline & coef. [probs.] \\
\cline { 2 - 2 }$c$ & $1.65[0.000]$ \\
$n_{t-1}$ & $0.87[0.000]$ \\
$w_{t}$ & $-0.06[0.000]$ \\
$p r_{t}$ & $0.06[*]$ \\
$\tau_{t-1}^{f}$ & $-0.25[0.000]$ \\
$k d_{t}$ & $0.04[0.000]$ \\
$g d_{t}$ & $-0.02[0.000]$ \\
$f i_{t}$ & $-0.09[0.000]$ \\
$\Delta l_{t}$ & $1.16[0.000]$
\end{tabular}

$\begin{array}{ll}\text { s.e. } & 0.001 \\ \bar{R}^{2} & 0.999\end{array}$

Dependent variable: $w_{t}$

\begin{tabular}{lc} 
& coef. [probs.] \\
\cline { 2 - 2 }$c$ & $-0.33[0.000]$ \\
$w_{t-1}$ & $0.68[0.000]$ \\
$p r_{t}$ & $0.32[*]$ \\
$r o_{t}$ & $0.77[0.000]$ \\
$b_{t}$ & $0.23[0.204]$
\end{tabular}

Dependent variable: $l_{t}$

\begin{tabular}{lr}
\hline & coef. [probs.] \\
\cline { 2 - 2 }$c$ & $-0.48[0.000]$ \\
$l_{t-1}$ & $0.93[0.000]$ \\
$w_{t}$ & $0.03[0.000]$ \\
$u_{t}$ & $-0.75[0.000]$ \\
$u_{t}^{d 97}$ & $0.15[0.018]$ \\
$\Delta r o_{t}$ & $-0.50[0.000]$ \\
$\Delta r o_{t-1}$ & $0.27[0.010]$ \\
$\Delta b_{t}$ & $-0.67[0.001]$ \\
$z_{t}$ & $0.07[\dagger]$ \\
& \\
$s . e$. & 0.003 \\
$\bar{R}^{2}$ & 0.999
\end{tabular}

Dependent variable: $y_{t}$

\begin{tabular}{lr}
\hline & coef. [probs.] \\
\cline { 2 - 2 }$c$ & $5.39[0.000]$ \\
$y_{t-1}$ & $0.50[0.000]$ \\
$n_{t}$ & $0.35[0.000]$ \\
$\Delta n_{t}$ & $2.24[0.000]$ \\
$k_{t}$ & $0.15[\ddagger]$ \\
oil $_{t}$ & $-0.007[0.003]$ \\
$t$ & $0.005[0.000]$
\end{tabular}

s.e.

0.008

s.e.

0.011

$\bar{R}^{2}$

0.998

$\bar{R}^{2}$ 0.999

s.e.: standard error of regression.

$\left.{ }^{*}\right)$ restricted coefficient so that the long-run elasticity of $w$ with respect to $p r$ is unity.

$(\dagger)$ restricted coefficient so that the long-run elasticity of $l$ with respect to $z$ is unity.

$(\ddagger)$ restricted coefficient so that the constant returns to scale hypothesis holds. 
To measure the power of unions we use the rate of organization provided by the Ministry of Health, Labour and Welfare of Japan. This is defined by the ratio between membership and total employees. ${ }^{27}$ To proxy for the effect of the minimum wage on wages we use the social security benefits paid by the central government (OECD Economic Outlook, 2009). ${ }^{28}$

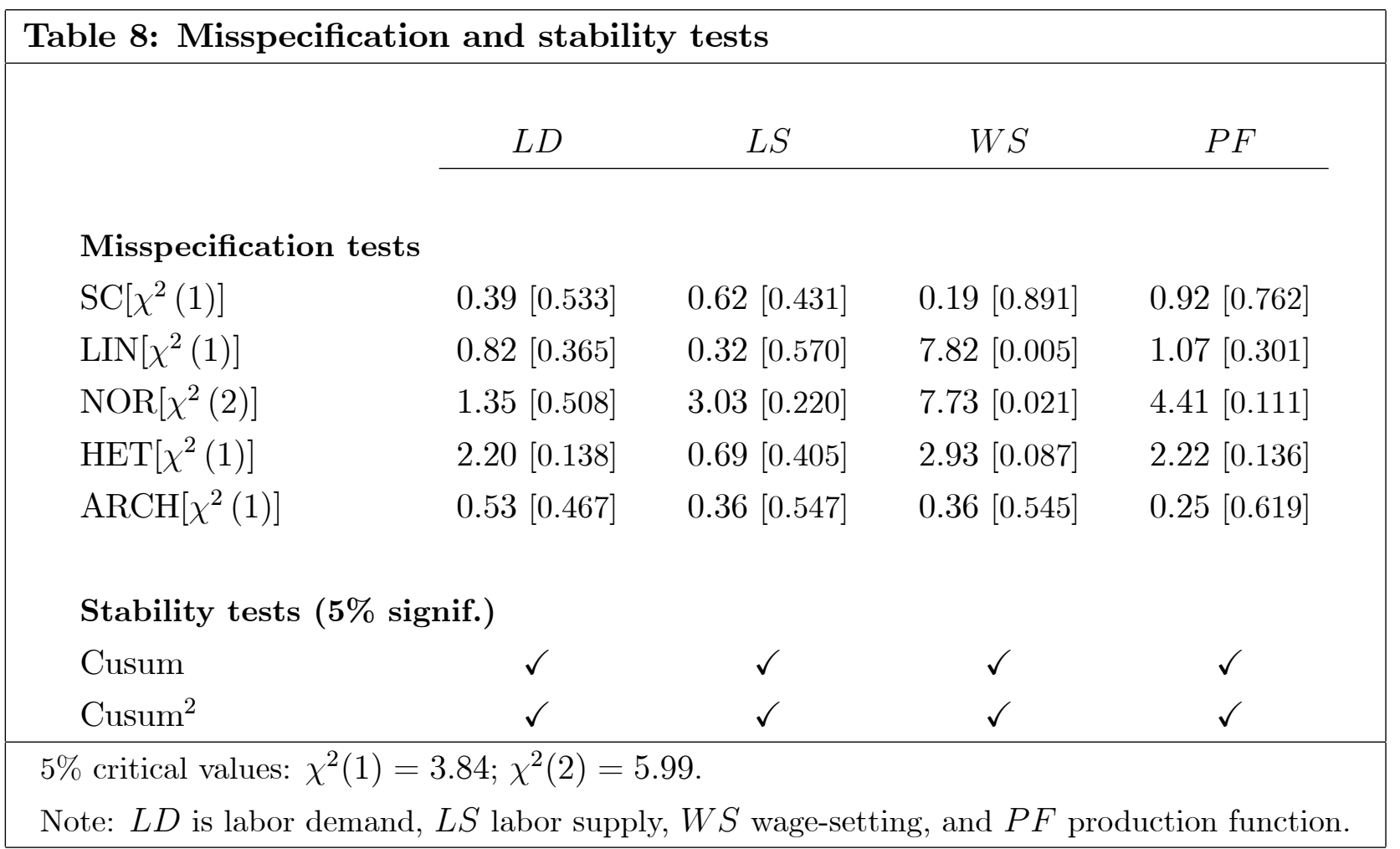

As for the estimation results we see that the coefficient of the lagged endogenous variable (0.68) is not as large as in the other two equations of the system, implying that current wage decisions are not as much dependent on past decisions. We further see that some of the tests on this equation are passed marginally (table 8). Again, and after testing for it, we restrict the equation as to have the long-run elasticity of wages with respect to productivity being equal to one. As for the institutional variables ( $r o$ and $b$ ) both show the expected positive sign, yet the coefficient of social benefits is only marginally significant $(\mathrm{p}=0.2$, table 7$)$. This might explain the rather counterintuitive results obtained for this variable in some of the simulations. Short-run semi-elasticities are, respectively, 0.77 and 0.23 , while long-run ones are 2.41 and 0.72 .

\footnotetext{
${ }^{27}$ Fuess (2001) elaborates a measure of union power using the Japanese case. The measure is represented as the share of the actual raise in wages over the raise demanded by unions. Even though it is an interesting proxy, it covers the span 1960-1999, making it unfitting for our study. The mean of this variable has been around $65 \%$ for the whole period. According to the author, this should be enough to dismiss the misleading preconception that "labor unions in Japan are relatively docile, meekly submitting to managerial objectives".

${ }^{28} \mathrm{In}$ Japan the minimum wage depends on the industry and the region. According to the Ministry of Health, Labour and Welfare, as of 2006, the lowest minimum wage for a region (Miyazaki) was $¥ 4,712$ ( $\sim$ US\$47.34) per day, while the highest minimum wage for a region (Tokyo, Kanagawa, Osaka) was $¥ 5465$ $(\sim \mathrm{US} \$ 54.91)$ per day.
} 
It is to note the potential importance of union power (as proxied by the rate of organization) for the Japanese labor market. Seemingly, Japanese labor unions are not as easygoing as one is usually led to believe (Fuess, 2001). The simulation exercise below confirms this suspicion.

Production function Our production function includes the lagged output, the usual inputs, labor and capital, real oil prices (accounting for foreign inputs), and a time trend (as a technical change measure). We test for the constant returns to scale (CRS) hypothesis in the unrestricted version of the production function in table 7. Passing this test allows us to impose the restriction that the long-run elasticity of output to both labor and capital equals one. ${ }^{29}$ Short-run elasticities are 0.35 and 0.15 for labor and capital respectively, whereas these figures become $0.7\left(=\frac{0.35}{1-0.50}\right)$ and $0.3\left(=\frac{0.15}{1-0.50}\right)$ in the long-run. These values are certainly among the average for a fully developed economy, and in line with those calibrated for Japan in the benchmark work by Hayashi and Prescott (2002).

\subsubsection{Model diagnosis}

We should now ensure the validity of the long-run relationships for the additional equations of our second model (the wage-setting and the production function). As before, the maximal eigenvalue and trace statistics indicate cointegration of the variables involved. Again we rely on VAR estimation for both equations (same order, same sample and variables, unrestricted intercepts, and a trend for the production function) to get their cointegrating vectors $(C V s)$. The results are satisfactory since the restrictions imposed cannot be rejected and the ECM coefficients turn out negative and significant in both cases.

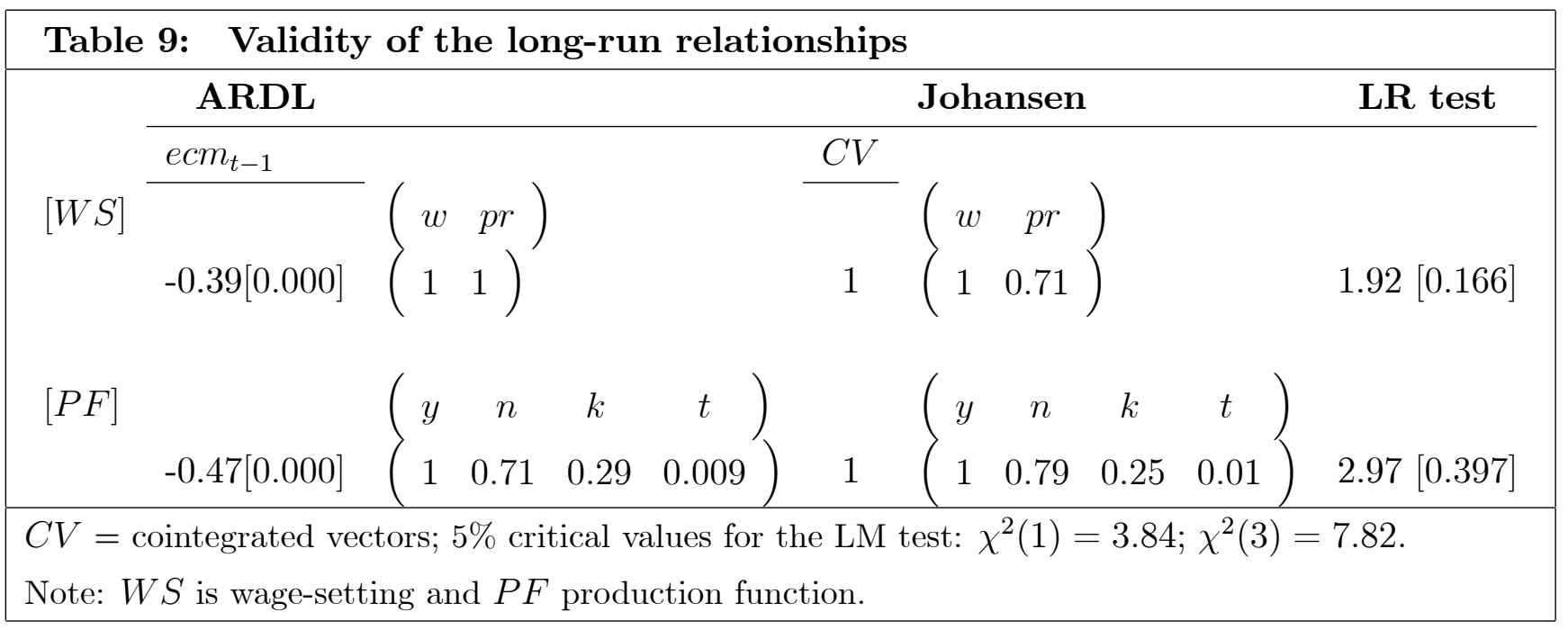

\footnotetext{
${ }^{29}$ Several economists have worked with CRS for Japan, for instance: Fukao and Kwon (2006), Hayashi and Prescott (2002), Jorgenson and Motohashi (2005), and Kawamoto (2005), among others.
} 
The $I(1)$ variables considered for these equations are $w, y, p r, n, k$, and $t$, and we now impose one restriction on the wage-setting and three on the production function. The tests are run on the restricted estimates of both equations, as drawn from the individual regressions. Table 9 outlines the main results of this analysis.

Figure 14a shows how the 4-equation model tracks the actual evolution of the unemployment rate at a close range. In the next few sections we will repeat the simulation analysis for the unemployment rate but now adding the study of the unit labor costs (a proxy for the labor income share, $L I S) .{ }^{30}$ Some attention will be dedicated to the latter since its non-stop fall coincided with the weakening of the Japanese labor unions in a similar time pattern that started way back in the 1970s. The correlation between these two variables is 0.89 for the whole sample period (1970-2008).

Allegedly, the declining path of both variables is related to the decreasing growth rate of real wages (also to be perceived from the mid-1970s onwards).The correlation coefficients between the growth in the real wages and both the $L I S$ and the ratio of organization of unions are, respectively, 0.40 and 0.71 (1970-2008). Figure 14b exhibits how our model also fits the $L I S$ quite well.

Figure 14. Actual and fitted values

a. Unemployment

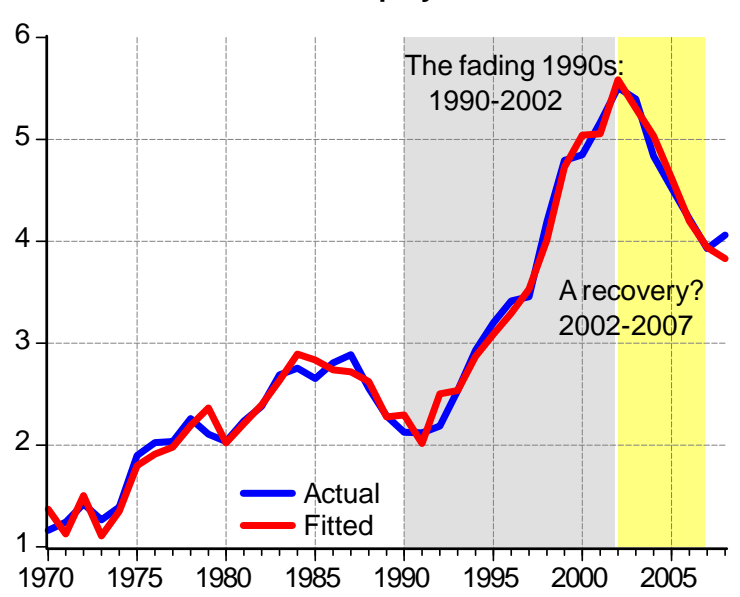

b. LIS

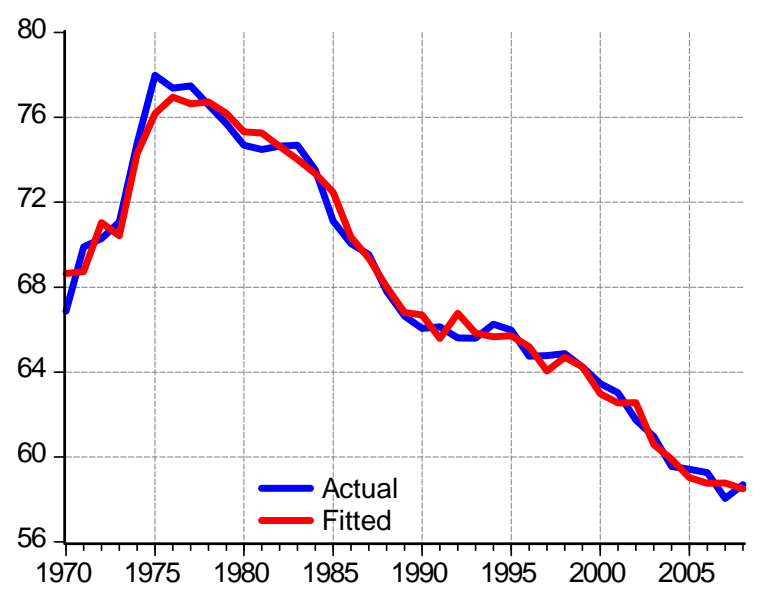

\subsubsection{New insights on the lost decade: 1990-2002}

Figure 15a shows the path of the unemployment rate when all exogenous variables in our 4-equation model are held at their 1990 values. Here unemployment would have been 3.7\% in 2002. ${ }^{31}$ As for the labor income share, figure $15 \mathrm{~b}$ also displays the actual path against the simulated one. See how the LIS would have stayed practically unchanged had all the

\footnotetext{
${ }^{30}$ Remember that ulc $(=\exp [w-(y-n)])$, and $L I S(\simeq \exp [(w+n)-y])$.

${ }^{31}$ For the 2-equation model it was $3.4 \%$ (figure 2 ).
} 
exogenous variables remained at their 1990 values. Instead, it fell from $66.1 \%$ to $61.7 \%$ during 1990-2002.

Figure 15. Effects of exogenous variables

a. Unemployment

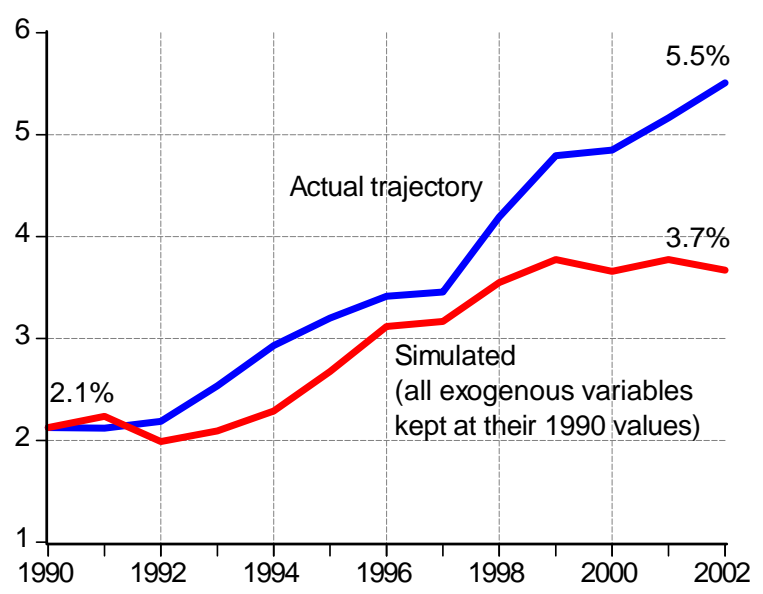

b. LIS

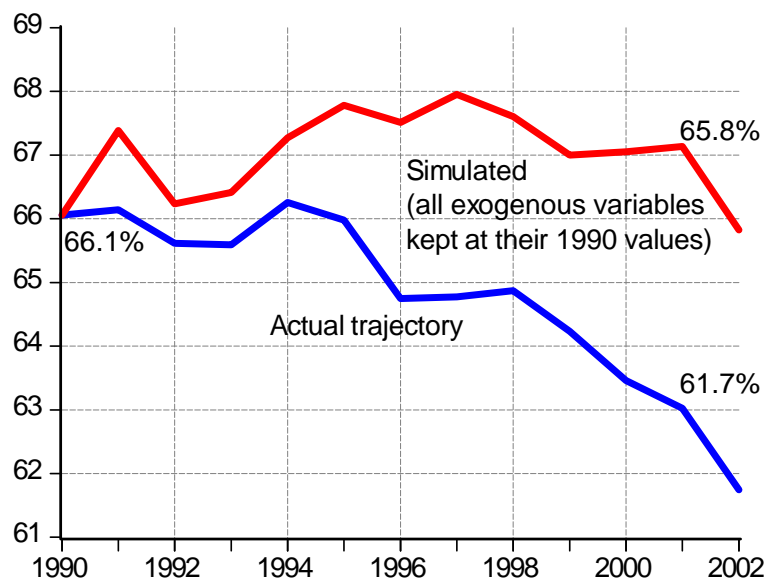

Table 10: Variable changes, unemployment and LIS effects, 1990-2002

Actual values:

Contributions (p.p.):

$1990 \quad 2002^{*}$

Difference** $^{* *}$

$\triangle L I S$

$u$

2.1

5.5

3.4

LIS

66.1

61.7

$-4.4$

$\Delta k$

5.2

3.3

$-1.9$

$\Delta u$

$-0.2$

$\Delta k d$

3.2

3.0

$-2.7$

0.2

1.0

$\tau^{f}$

5.6

2.9

87.6

$-0.4$

$g d$

64.7

152.3

1.8

4.3

1.0

fi

24.1

25.9

$-138$

$-0.8$

$-0.3$

oil

3,347

3,209

12

0.2

$-0.5$

$t$

7.33

11.1

3.77

0.2

0.2

b

25.2

20.2

$-5.0$

$-0.4$

$-1.0$

ro

0.4

0.0

$-0.4$

$-1.3$

$-6.1$

$-0.3$

$-0.1$

\section{Joint contributions $\ddagger$}

1.8

*: $\quad$ For differences $(\Delta k, \Delta k d, \Delta z)$, average growth in 1990-2002.

$* *$ : Expressed in percentage points (except oil : real yens, and $t:$ years).

$\dagger$ : Capital stock and capital deepening contributions are jointly simulated.

‡: Also, approximately the sum of all individual contributions. 
Table 10 above shows the individual contributions of all the exogenous variables to these two endogenous variables. From a quick overlook at the table it is possible to see that we are now dealing with a slightly different set of exogenous (and endogenous) variables. Some of them, like real wages and productivity, have been endogenized under the current setting. Others, like the capital stock, oil prices, and the time trend have been introduced. And finally, some others now enter the model in levels and not in differences (social benefits and unions).

For the ease of presentation we will limit ourselves to highlight only the relevant contributions in table 10. We must mention at this point that the contributions of the exogenous variables to other endogenous variables of interest are also inferred for both periods and both models. These endogenous variables are, apart from $u$ and $L I S$ : the growth in real wages $(\Delta w)$, the growth in labor productivity $(\Delta p r)$, the growth in output $(\Delta y)$, and the growth in employment $(\Delta n)$. Appendix B summarizes all the results from our dynamic simulations; both for the 2-equation (table B1) and 4-equation models (table B2).

Let us first take a look at the effects on unemployment. One more time the model puts all the weight of the upsurge in the government debt variable (4.3 p.p., just as before). Nevertheless, those variables associated with the accumulation of capital are of no effect now (only 0.2 p.p.). Remember that the productivity is now endogenous, and that it was the diminishing rate of this variable what brought about the large contribution in the previous model during 1990-2002. In opposition to these effects we have the loosening of fiscal policy with regards to direct taxes on firms (-0.4 p.p.), the fall of population (-0.3 p.p.) and, above all, the weakening of union power (contributing with a -1.3 p.p. reduction in unemployment). The latter is a new variable with strong implications. Certainly, one variable that one would have presumed relatively unimportant at first. But the truth is that the ratio of organization stood as high as 35\% in 1970, and fell around 50\% in the last forty years while showing no apparent change in the trend (see table A2).

Deunionization can lead to strengthen productivity while allowing for more competition. And competition is a reflection of healthy and dynamic markets, something perceived as good in all societies. But deunionization has yet another consequence worth of our attention. According to these simulations, it can lead to a smaller share of the GDP being allotted to workers. This should be of no concern, for as societies grow technologically, capital becomes more abundant and its share gets larger. The problem arises when the economy grinds to a halt, like Japan during the 1990s, or even moves back as in the aftermath of the East Asian crisis of 1997. Japan's GDP growth was negative (and for two consecutive years) for the first time in more than twenty years: -2.1\% in 1998 and -0.14 in 1999 (OECD Economic Outlook, 2009). Figure 16a isolates the trajectory of the rate of organization (this time in levels) and figure $16 \mathrm{~b}$ shows the large effect of this variable on the $L I S$ (-6.1 p.p. in all). 
Figure 16. Union membership and contribution to LIS
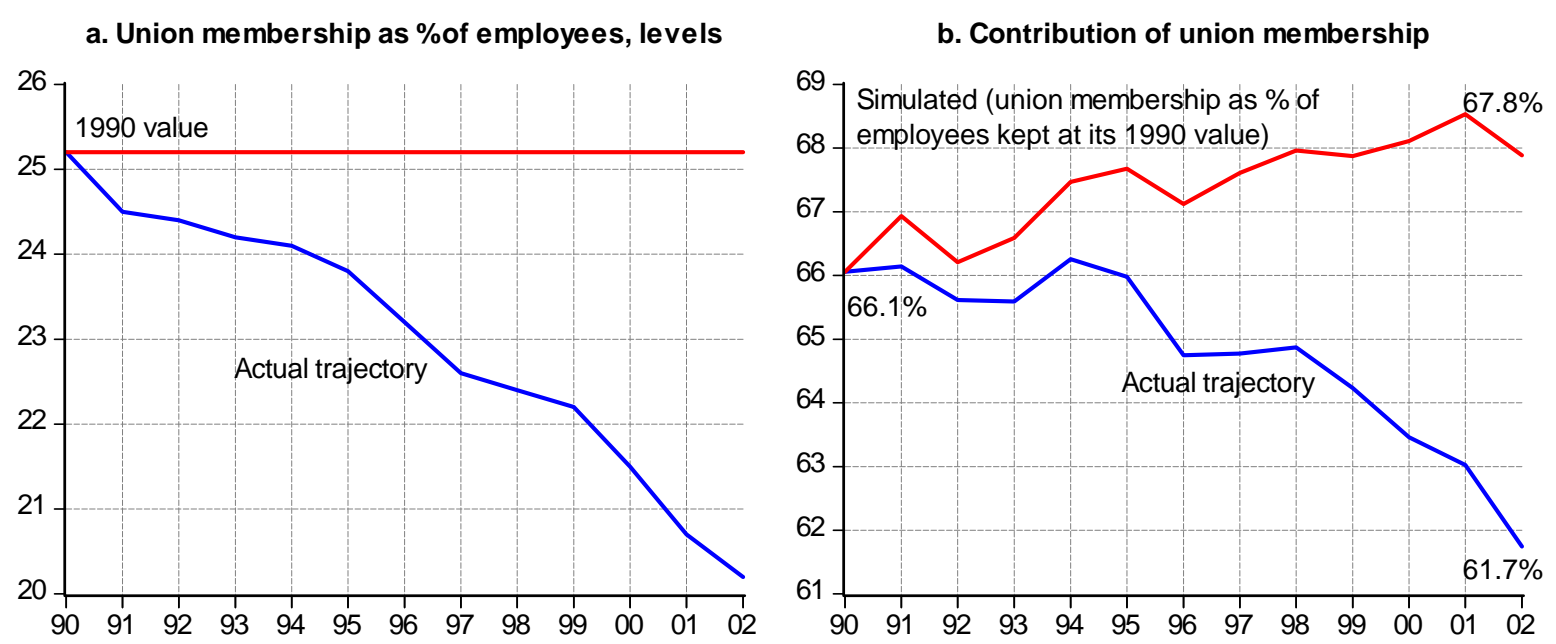

Accompanying the effect of the labor unions on the $L I S$, another important effect is determined by the time trend, which is a measure representative of the technical change (-1.0 p.p.). Other contributions going in the same direction are the financial indebtedness, the government debt, and the growth of population, yet they are small or ambiguous. On the other hand, the major forces pushing the LIS upwards are the increase of social benefits (1.3 p.p.) and the slower growth in the accumulation of capital, measured by both the stock of capital and the capital deepening (with a 1.0 p.p. of joint contribution). The reduction of the tax burden for firms has also a large effect (1.0 p.p.) yet this is not easy to reconcile with the effect which goes in the same direction for the next simulation period, when direct taxes experienced a dramatic increase. Finally, the oil prices have a small effect that is common to all simulations. Arguably, this is due to Japan's relative closeness.

As compared to our previous model, the 4-equation model reasonably allows for a wider understanding of the evolution of some important variables during an important period in Japan. Complementing the information in table 10, appendix $\mathrm{C}$ shows graphically the actual and simulated paths of all the exogenous variables plus their effects on the unemployment rate and the $L I S$.

\subsubsection{On the crossroads: 2002-2007}

Our final simulation exposes again the "half-way" recovery experienced by the economy during 2002-2007. Figure 17a shows the simulated joint contribution of all exogenous variables to unemployment, with a value of $2.8 \%$ in $2002 .{ }^{32}$ As for the $L I S$, in figure $17 \mathrm{~b}$ we still get to see its plummeting fall to never seen before lows. This time the model explains less of this change as compared to the 1990-2002 period. As before, here we will only focus

\footnotetext{
${ }^{32}$ For the 2-equation model it was notably lower, $1.5 \%$ (figure 8 ).
} 
on those variables in table 11 below which seem more relevant. For additional information, appendix D offers the figures of all these simulations, both for the unemployment rate and the $L I S$.

Figure 17. Effects of exogenous variables

a. Unemployment

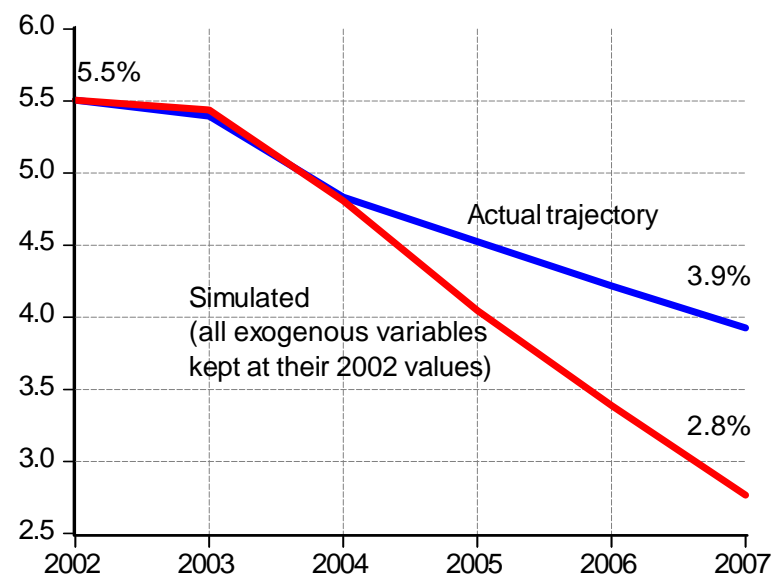

b. LIS

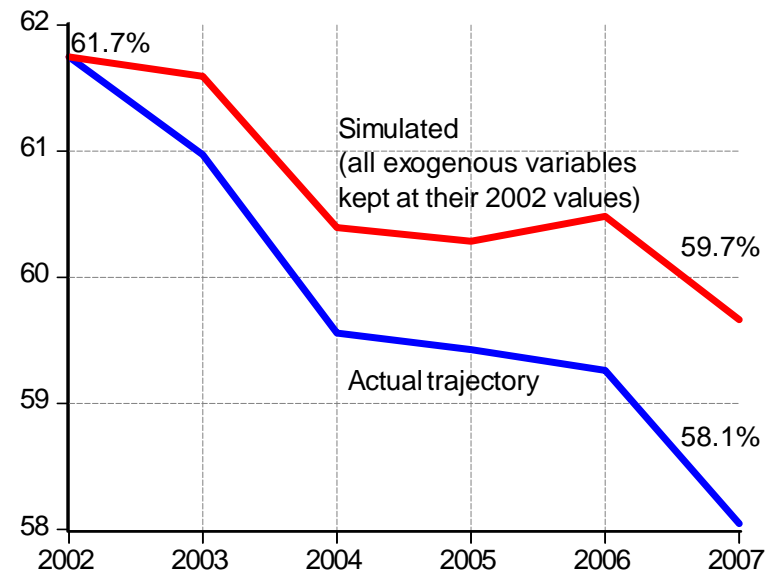

Table 11: Variable changes, unemployment and LIS effects, 2002-2007

Actual values:

Contributions (p.p.):

$2002 \quad 2007^{*}$ Difference**

$\Delta u$

$\triangle L I S$

$u$

LIS

5.5

3.9

$-1.6$

$\Delta k$

61.7

58.1

$-3.6$

$\Delta k d$

1.2

0.8

$-0.4$

$\tau^{f}$

2.5

0.8

$-1.7$

2.9

4.2

$-1.3$

152.3

167.1

14.8

$-4.6$

fi

25.9

21.3

5,887

5

0.5

11.6

$-2.1$

1.2

0.6

oil

3,209

9,096

$-0.1$

$\dagger$

0.5

0.4

1.4

0.3

$-1.3$

$-0.4$

0.1

0.4

$b$

11.1

18.1

$-0.3$

$-1.0$

ro

20.2

$-0.6$

0.0

0.1

$-0.4$

$-2.0$

$\Delta z$

$-0.5$

Joint contributions $\ddagger$

1.1

$-1.6$

*: $\quad$ For differences $(\Delta k, \Delta k d, \Delta z)$, average growth in 2002-2007.

$* *$ : Expressed in percentage points (except oil : real yens, and $t:$ years).

$\dagger$ : Capital stock and capital deepening contributions are jointly simulated.

$\ddagger$ : Also, approximately the sum of all individual contributions. 
On the unemployment side the government debt keeps on being the major contributor (with 1.4 p.p.), but now this effect is reinforced by the lower rates of capital accumulation (1.2 p.p.). Another effect worth noting is that which comes with the tightening of the fiscal policy (0.5 p.p.). Notice that the change in the sign of this contribution is also perceived in the previous model, and in accordance with conclusions in the study by Kuttner and Posen (2001). Countering these effects we have the fall in firms' indebtedness (-1.3 p.p.), ${ }^{33}$ the decrease of union power (-0.4 p.p.), and the technical change (-0.3 p.p.). Oil prices, social benefits, and demographics play no role in this simulation.

Deunionization is by large the strongest force behind the changes in the LIS for both periods of analysis. In this second simulation though, its contribution is somewhat less important when compared to the actual change in the variable (a -2.0 p.p. contribution in -3.6 p.p.). To throw some more light on this particular effect, figures $18 \mathrm{a}$ and $18 \mathrm{~b}$ illustrate the scenario.

Figure 18. Union membership and contribution to LIS
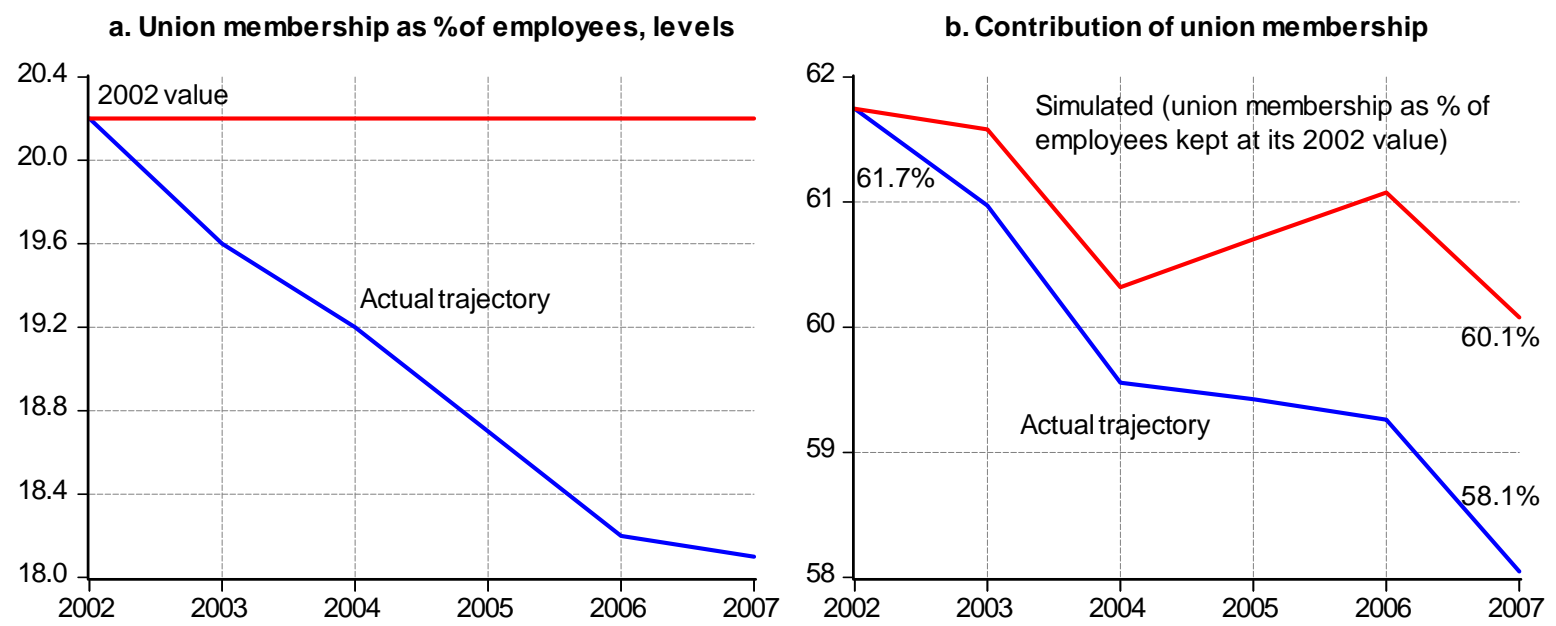

The technical change shows again a significant contribution (-1.0 p.p., as before) to the drop in the LIS. On the other hand, we should stress the offsetting force of lower growth rates of capital accumulation (0.6 p.p.). The rest of the effects are either unimportant or not straightforward. All in all, our dynamic simulations for this period picture Japan as standing on the crossroads. First, the unemployment rate, albeit lower than in the 1990s, could have been much lower. And second, a lower unemployment rate does not mean higher employment, as can be seen from the zero growth of this variable in 2002-2007, a performance that is even worse than that of the lost decade (see figure A1). The latter point seems to

\footnotetext{
${ }^{33}$ See the strange behavior of the effects on unemployment that is drawn from this variable in both models. Following the trajectory from figures C1c and D1c one can see how it went up in the years previous to the 1997 crisis and then markedly down once the regional turmoil was all over.
} 
explain why the LIS has been declining even during 2002-2007, when the GDP growth rate experienced a shy recovery (figure A1).

\subsubsection{Concluding remarks}

A 4-equation model greatly improves the possibilities of our original analysis, and at the same time gives strength to our previous conclusions. Among these, we see that the everincreasing government debt poses as a real threat to employment creation, contributing with 4.3. percentage points (p.p.) in the rise of unemployment during the lost decade. Precisely because of our wider scope, we are now able to identify a new and major offsetting effect behind the rise of unemployment: weakening labor unions (-1.3 p.p.). For this period our model explains $53 \%$ of the rise in unemployment (in numbers, 1.8 p.p. out of an increase of 3.4 p.p.).

During the post-1990s subsample we observe two major drivers that prevented a full recovery in terms of unemployment rates: again the rising government debt (1.4 p.p.) and the declining growth of capital accumulation (1.2 p.p.). A major counteracting force is the fall of firms' indebtedness (with -1.3 p.p.). Under this more complex setting, the model again overshoots the actual change in the unemployment rate that is explained by the simulation: $175 \%$ (or -2.8 p.p. in -1.6 p.p.).

Another issue deserving our attention is the declining trend in the labor income share (LIS) and how this can be explained by our model. What we find for the 1990-2002 period is that most of the fall is explained by less powerful labor unions (-6.1 p.p.) and by the technical change (-1.0 p.p.). On the other side of the story, growing social benefits act as the most important counterbalancing force (1.3 p.p.). Here the model gets the most accurate result, for it explains a $93 \%$ of the total fall in the $L I S$ ( -4.1 p.p. of joint contributions in -4.4 p.p. ).

Finally, we should mention again the fall in union power proxied by its rate of organization (-2.0 p.p. contribution) and the technical change (-1.0 p.p.) as important players behind the fall of the LIS during 2002-2007. Here the model is not as "good" as in the previous period; only $44 \%$ of the fall gets explained by our simulations ( -1.6 p.p. in -3.6 p.p.).

\section{Conclusions}

We have analyzed the Japanese labor market from a macroeconomic perspective taking the Chain Reaction Theory as theoretical benchmark. This choice admits a wider analytical perspective than the mainstream theories allow for. It permits to go beyond the role of institutions and consider a set of labor market macroeconomic determinants that have been found (sometimes in isolation) relevant to explain the 1990s slump. The novelty of our 
analysis is to consider these macroeconomic determinants jointly and together with standard labor market variables, and let them contend to explain the unemployment upsurge in the fading 1990s and the years that followed.

According to our two-equation model the steep rise in unemployment during the "lost decade" was essentially due to government mismanagement and a low productivity growth rate. The steep rise in government debt, in particular, plays a major role by supporting inefficient firms which nevertheless incurred in job layoffs, and by preventing new job opportunities to emerge. Our analysis seems to leave room for the "zombie firms" hypothesis, where less productive firms prevent new efficient competitors from entering the market. This mechanism entails a serious opportunity cost in terms of jobs that fail to open, whereas it allows inefficient firms to keep working and spare unneeded workers. Within this setting "zombie firms" are indirectly debt-financed through massive government bailout, which aims at keeping bad loan practices between banks and insolvent borrowers. The result is a noncompetitive performance of the labor market that affects efficiency and, hence, employment. We observe the same damaging effects for the period 2002-2007, when the economy experienced a mild upturn.

Our four-equation model offers a wider representation of the Japanese labor market that turns out consistent with our previous results. This allowed us to go farther in the study of this particular labor market. Here, the excessive indebtedness of the central government gets again most of the attention, as it stands as an important squanderer of resources and the source of inefficiencies, both during the lost decade and beyond. Additionally, we are now able to identify another player which was hidden before: labors unions. Our analysis suggests that their declining power can be seen as an effective medicine to high levels of unemployment in both subsample periods, and as the major driver behind the seemingly falling pattern of the labor income share (as proxied by the unit labor costs).

As a final observation we argue that the Japanese authorities will certainly have to address the debt problem before it becomes a real deterrent to growth. In easing this burden in the short run and giving up its role as lender of last resort for compromised banks, the government might increase efficiency and create new job opportunities that would help the economy get back into the right path once again. Such decisions should come jointly with strong measures boosting productivity. Arguably, not only has Japan fallen into a liquidity trap, but seems to have stumbled into a low productivity trap as well. 


\section{References}

Agnese, P. and H. Sala, 2008, Unemployment in Japan: A look at the lost decade,Asia Pacific Journal of Economics and Business, 12 (1), 16-35.

Agnese, P. and H. Sala, 2009, The fading 1990s in Japan: Driving forces behind the unemployment upsurge, International Review of Economics and Finance, 18 (3), 428-439.

Ahearne, A. and N. Shinada, 2005, Zombie firms and economic stagnation in Japan, International Economics and Economic Policy, 2 (4), 363-381.

Bahmani-Oskooee, M., S.W. Hegerty and A.M. Kutan, 2008, Do nominal devaluations lead to real devaluations? Evidence from 89 countries, International Review of Economics and Finance, 17 (4), 644-670.

Ball, L. and N.G. Mankiw, 2002, The NAIRU in theory and practice, Journal of Economic Perspectives, 16 (4), 115-136.

Bande, R., and M. Karanassou, 2009, Labour Market Flexibility and Regional Unemployment Rates: Spain 1980-1995, Papers in Regional Science, 88, 181-207.

Barseghyan, L., 2006a, Crowding out and the rate of return on capital in Japan, Japan and the World Economy, 18, 278-297.

Barseghyan, L., 2006b, Non-performing loans, prospective bailouts, and Japan's slowdown, Working Paper, Cornell University.

Blanchard, O. and L. Summers, 1986, Hysteresis and the European Unemployment Problem, NBER Macroeconomics Annual, 1, Cambridge, Mass: MIT Press, 15-77.

Blanchard, O. and J. Wolfers, 2002, The role of shocks and institutions in the rise of European unemployment: The aggregate evidence, The Economic Journal, 110 (462), C1-33.

Braun, R. A. and Y. Waki, 2006, Monetary policy during Japan's lost decade, The Japanese Economic Review, 57 (2), 324-344.

Caballero, R., T.Hoshi and A. Kashyap, 2008, Zombie Lending and Depressed Restructuring in Japan, American Economic Review, 98 (5), 1943-77.

Coles, M., and E. Smith, 1996, Cross section estimation of the matching function: Evidence from England and Wales, Economica, 63 (252), 589-597.

Friedman, M., 1968, The Role of Monetary Policy, American Economic Review, 58, 1-17.

Fuess, S., 2001, Union Bargaining Power: A View from Japan, IZA Discussion Paper 393.

Fukao, K., 2003, Japan's lost decade and its financial system, The World Economy, 21, 365384.

Fukao, K. and H. Kwon, 2006, Why did Japan's TFP growth slow down in the lost decade? An empirical analysis based on firm-level data of manufacturing firms, The Japanese Economic Review, 57 (2), 195-228.

Gordon, R., 1997, The Time-Varying NAIRU and its Implications for Economic Policy, Journal of Economic Perspectives, 11 (1), 11-32.

Hamada, K., 2004, Policy making in deflationary Japan, The Japanese Economic Review, 55 (3), 221-239.

Hayashi, F. and E. Prescott, 2002, The 1990s in Japan: A lost decade, Review of Economic Dynamics, 5, 206-235.

Henry, S.G.B., Karanassou, M., and D.J. Snower, 2000, Adjustment Dynamics and the Natural Rate: An Account of the UK Unemployment, Oxford Economic Papers, 52, 178-203.

Higuchi, Y. and M. Hashimoto, 2005, Issues Facing the Japanese Labor Market, in: T. Ito, H. Patrick and D.E. Weinstein, eds., Reviving Japan's economy (The MIT Press), chapter 10. 
Hirose, Y. and K. Kamada, 2002, Time-Varying NAIRU and potential growth in Japan, Working Paper 02-08, Research and Statistics Department, Bank of Japan.

Hoon, T. and E.S. Phelps, 1992, Macroeconomic Shocks in a Dynamized Model of the Natural Rate of Unemployment, The American Economic Review, 82 (4), 889-900.

Ihori, T., T. Nakazato and M. Kawade, 2003, Japan's fiscal policies in the 1990s, The World Economy, 26 (3), 325-338.

Iiduka, N., 2006, Has Japan's labor share bottomed? JCER Staff Report 53.

International Monetary Fund, International Financial Statistics, 2009.

Jaeger, A. and M. Parkinson, 1994, Some evidence on hysteresis in unemployment rates, European Economic Review, 38, 329-342.

Johansen, S., 1991, Estimation and Hypothesis Testing of Cointegrating Vectors in Gaussian Vector Autoregressive Models, Econometrica, 59, 1551-80.

Jorgenson, D. and K. Motohashi, 2005, Information Technology and the Japanese Economy, Journal of the Japanese and International Economies, 19 (4), 460-481.

Karanassou, M., and H. Sala, 2009, The Rise and Fall of Spanish Unemployment: A Chain Reaction Theory Perspective, International Papers in Political Economy, ch. 6, 209-254. PalgraveMacmillan, ISBN: 978-0-230-23600-4.

Karanassou, M. and H. Sala, 2010, Labour Market Dynamics in Australia: What Drives Unemployment?, Economic Record, forthcoming, doi: 10.1111/j.1475-4932.2009.00597.x

Karanassou, M. and D.J. Snower, 1997, Is the Natural Rate a Reference Point?, European Economic Review, 41, 559-569.

Karanassou, M. and D.J. Snower, 1998, How Labour Market Flexibility Affects Unemployment: Long-Term Implications of the Chain Reaction Theory, Economic Journal, 108, 832-849.

Karanassou, M., H. Sala and P.F. Salvador, 2008a, Capital accumulation and unemployment: New insights on the Nordic experience, Cambridge Journal of Economics, 32, 977-1001.

Karanassou, M., H. Sala and D.J. Snower, 2007, The macroeconomics of the labor market: Three fundamental views, Portuguese Economic Journal, 6 (3), 151-180.

Karanassou, M., H. Sala and D.J. Snower, 2008b, Long-run inflation-unemployment dynamics: The Spanish Phillips curve and economic policy, Journal of Policy Modeling, 30 (2), 279-300.

Karanassou, M., Sala, H., and D.J. Snower, 2010, Phillips Curves and Unemployment Dynamics: A Critique and a Holistic Perspective, Journal of Economic Surveys, 24, 1-51, doi: $10.1111 / \mathrm{j} .1467-6419.2009 .00598 . x$

Kawamoto, T., 2005, What Do the Purified Solow Residuals Tell Us about Japan's Lost Decade?, Monetary and Economic Studies, 23 (1), Bank of Japan, 113-148.

Kim, J. and L.Lau, 1994, The sources of economic growth of the East Asian newly industrialized countries, Journal of the Japanese and International Economies, 8, 235-271.

Kim, J. and L. Lau, 1996, The sources of Asian Pacific economic growth, The Canadian Journal of Economics, 53 (2), special issue, S448-S454.

Kobayashi, K., 2007, Payment uncertainty and the productivity slowdown, Macroeconomic Dynamics, 11 (2), 231-248.

Koga, M., 2006, The decline of Japan's saving rate and demographic effects, The Japanese Economic Review, 57 (2), 312-321.

Krugman, P., 1998, It's back: Japan's slump and the return of the liquidity trap, Brooking Papers on Economic Activity, 2, 137-187.

Kuttner, K. and A. Posen, 2001, The Great Recession: Lessons for macroeconomic policy from Japan, Brooking Papers on Economic Activity, 2, 93-160. 
Layard, R. and S. Nickell, 1986, Unemployment in Britain, Economica, 53 (210), Supplement: Unemployment, S121-S169.

Layard, R., Nickell, S. and R. Jackman, 2005, Unemployment: Macroeconomic Performance and the Labour Market, Oxford University Press, 2nd ed.

Lindbeck, A. and D. Snower, 1988, The Insider-Outsider Theory of Employment and Unemployment, MIT Press.

Lucas, R., 1976, Econometric Policy Evaluation: A Critique, in: K. Brunner and A. Meltzer (eds.), The Phillips Curve and Labor Markets, Carnegie-Rochester Conference Series on Public Policy, 1, 19-46.

Ministry of Finance of Japan, statistics 2009.

Ministry of Health, Labour and Welfare, Statistics and Information Department of the Minister's Secretariat, Japan, statistics 2006, 2009.

Ministry of Internal Affairs, Statistic Bureau, Japan, statistics 2009.

Miyagawa, T., Y. Sakuragawa and M. Takizawa, 2006, Productivity and business cycles in Japan: evidence from Japanese industry data, The Japanese Economic Review, 57 (2), 161-186.

Nickell, S., L. Nunziata and W. Ochel, 2005, Unemployment in the OECD since the 1960s: What do we know?, The Economic Journal, 115, 1-27.

Nishizaki, F., 1997, The NAIRU in Japan: Measurement and its implications, OECD Economics Department Working Papers, 173, OECD Publishing.

OECD Economic Outlook, 2009, no. 85.

Ogawa, K., 2003, Financial distress and employment: the Japanese case in the 90s, NBER Working Papers, 9646.

Pesaran, M.H. and Y. Shin, 1999, An Autoregressive Distributed-Lag Modelling Approach to Cointegration Analysis, in: Econometrics and Economic Theory in the Twentieth Century: The Ragnar Frisch Centennial Symposium, edited by Strom, S., Cambridge University Press, 371-413.

Pesaran, M.H., Shin, Y. and R.J. Smith, 2001, Bounds testing approaches to the analysis of level relationships, Journal of Applied Econometrics, 16, 289-326.

Phelps, E.S., 1967, Phillips Curves, Expectations of Inflation and Optimal Employment Over Time, Economica, 34, 254-281.

Phelps, E.S., 1968, Money-Wage Dynamics and Labour-Market Equilibrium, Journal of Political Economy, 76 (2), 678-711.

Phelps, E.S., 1969, The New Microeconomics in Inflation and Employment Theory, American Economic Review: Papers and Proceedings, 59, 147-160.

Phelps, E.S., 1994, Structural booms: The modern equilibrium theory of unemployment, interest and assets (Harvard University Press, Cambridge MA).

Phelps, E.S. and G. Zoega, 2001, Structural booms: productivity expectations and asset valuations, Economic Policy, 32, 85-126.

Phillips, P. and B. Hansen, 1990, Statistical Inference in Instrumental Variables Regression with I(1) Processes, Review of Economic Studies, 57, 99-125.

Røed, K., 1996, Unemployment Hysteresis - Macro Evidence from 16 OECD Countries, Empirical Economics, 21, 589-600.

Staiger, D., Stock, J. and M. Watson, 1997, The NAIRU, Unemployment and Monetary Policy, Journal of Economic Perspectives, 11 (1), 33-49.

Svensson, L., 2001, The zero bound in an open economy: a foolproof way of escaping from a liquidity trap, Monetary and Economic Studies, 19 S-1, 277-312.

Takeuchi, F., 2005, Causes of decline in labor's share in Japan, JCER Researcher Report 53. 
Wakita, S., 2006, The Lost Decade in the Japanese Labor Market: Labor's share and Okun's Law, Public Policy Review, 2 (1), 77-96. 


\section{A Appendix: Values of all variables}

Table A1: Endogenous variables of interest, values

\begin{tabular}{|rccccc|}
\hline & 1990 & 2002 & 2007 & Avg. g.r. 90-02 & Avg. g.r. 02-07 \\
\hline$u$ & 2.1 & 5.5 & 3.9 & 0.2 & -0.2 \\
ulc $(L I S)^{*}$ & 66.1 & 61.7 & 58.1 & -0.4 & -0.8 \\
$\Delta w^{*}$ & 2.2 & -0.5 & -0.2 & 0.5 & 0.4 \\
$\Delta p r^{*}$ & 3.1 & 1.5 & 1.8 & 1.1 & 1.8 \\
$\Delta y^{*}$ & 5.1 & 0.3 & 2.3 & 1.4 & 1.8 \\
$\Delta n^{*}$ & 1.9 & -1.3 & 0.5 & 0.3 & 0.0 \\
\hline
\end{tabular}

Note (tables A1 \& A2): see table 1 for definitions and sources.

*: exogenous in 2-eq. model.

\begin{tabular}{|cccccc|}
\hline \multicolumn{7}{|c|}{ Table A2: All exogenous variables, values } \\
\hline \multicolumn{7}{c}{1990} & 2002 & 2007 & Avg. g.r. 90-02 & Avg. g.r. 02-07 \\
\hline$b$ & 7.33 & 11.1 & 11.6 & 0.3 & 0.2 \\
$f i$ & 24.1 & 25.9 & 21.3 & 0.2 & -0.7 \\
$\tau^{f}$ & 5.6 & 2.9 & 4.2 & -0.3 & 0.1 \\
$g d$ & 64.7 & 152.3 & 167.1 & 6.5 & 3.9 \\
$\Delta k$ & 5.2 & 1.2 & 1.2 & 3.3 & 0.8 \\
$\Delta k d$ & 3.2 & 2.5 & 0.7 & 3.0 & 0.8 \\
oil* & 3,347 & 3,209 & 9,096 & 1.8 & 18.5 \\
$r o$ & 25.2 & 20.2 & 18.1 & -0.4 & -0.4 \\
$\Delta z$ & 0.5 & -0.5 & -0.9 & 0.0 & -0.6 \\
\hline *: real yens (not in logs). & & & \\
\hline
\end{tabular}




\section{B Appendix: All dynamic simulations}

\begin{tabular}{|c|c|c|}
\hline \multicolumn{3}{|c|}{ Table B1: Contributions to unemployment (2-eq.) } \\
\hline & $1990-2002$ & $2002-2007$ \\
\hline fi & -0.4 & -1.1 \\
\hline$\tau^{f}$ & -0.8 & 0.4 \\
\hline$g d$ & 4.3 & 1.2 \\
\hline$\Delta p r_{-} \Delta k d$ & 3.2 & 0.7 \\
\hline$\Delta w$ & -3.5 & 1.0 \\
\hline$\Delta z$ & -0.3 & 0.0 \\
\hline$\Delta b$ & -0.7 & 0.0 \\
\hline$\Delta r o$ & 0.2 & 0.2 \\
\hline Total* & 2.1 & 2.4 \\
\hline
\end{tabular}

\begin{tabular}{|c|c|c|c|c|c|c|c|c|c|c|c|c|}
\hline & & & 1990 & 2002 & & & & & 2002 & 2007 & & \\
\hline & $u$ & $L I S$ & $\Delta w$ & $\Delta p r$ & $\Delta y$ & $\Delta n$ & $u$ & $L I S$ & $\Delta w$ & $\Delta p r$ & $\Delta y$ & $\Delta n$ \\
\hline$b$ & -0.4 & 1.3 & 0.3 & -0.5 & -0.6 & -0.1 & 0.0 & 0.1 & 0.1 & 0.2 & 0.1 & 0.0 \\
\hline$f i$ & -0.8 & -0.5 & 0.4 & -0.1 & 0.6 & 0.8 & -1.3 & -0.4 & 0.3 & 0.2 & 1.2 & 1.0 \\
\hline$\tau^{f}$ & -0.4 & 1.0 & -0.8 & -0.8 & -1.4 & -0.5 & 0.5 & 0.4 & -0.3 & -0.7 & -1.4 & -0.6 \\
\hline$g d$ & 4.3 & -0.3 & 0.2 & 0.8 & -1.3 & -2.1 & 1.4 & 0.3 & -0.2 & 0.4 & -0.4 & -0.8 \\
\hline$\Delta k_{-} \Delta k d$ & 0.2 & 1.0 & -0.8 & -1.1 & -1.3 & -0.2 & 1.2 & 0.6 & -0.5 & -0.5 & -1.5 & -1.0 \\
\hline oil & 0.2 & 0.2 & -0.2 & -0.1 & -0.3 & -0.2 & 0.1 & 0.4 & -0.3 & -0.3 & -0.4 & -0.1 \\
\hline ro & -1.3 & -6.1 & -1.3 & -0.4 & 0.1 & 0.5 & -0.4 & -2.0 & -0.8 & -0.4 & -0.3 & 0.1 \\
\hline$t$ & 0.2 & -1.0 & 0.7 & 0.7 & 0.6 & -0.2 & -0.3 & -1.0 & 0.8 & 1.0 & 1.3 & 0.3 \\
\hline$\Delta z$ & -0.3 & -0.1 & 0.0 & 0.1 & 0.0 & -0.1 & 0.0 & 0.1 & -0.1 & -0.1 & -0.2 & -0.1 \\
\hline Total* & 1.8 & -4.3 & -1.4 & -1.5 & -3.5 & -2.1 & 1.2 & -1.6 & -0.9 & -0.3 & -1.5 & -1.3 \\
\hline
\end{tabular}



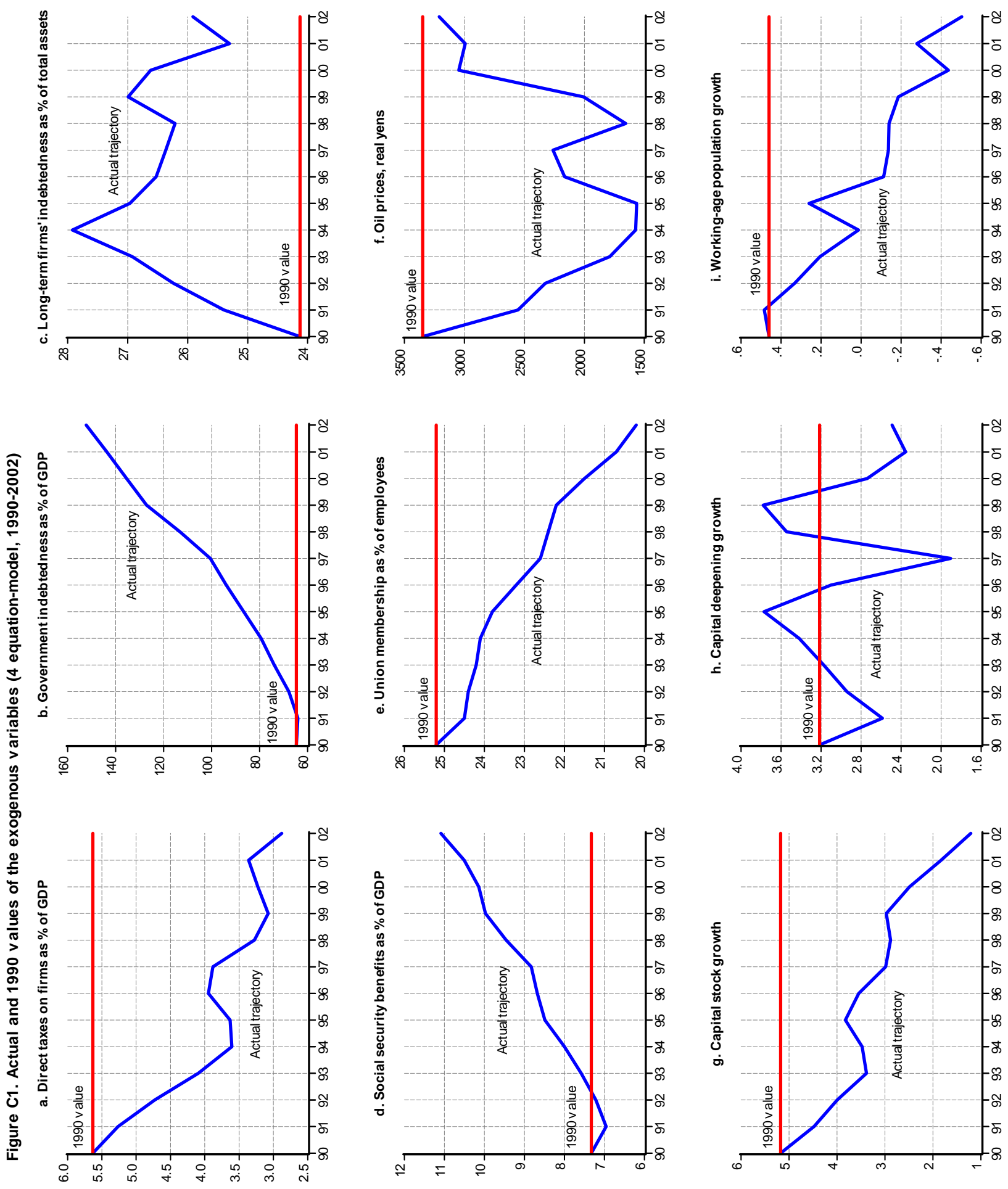

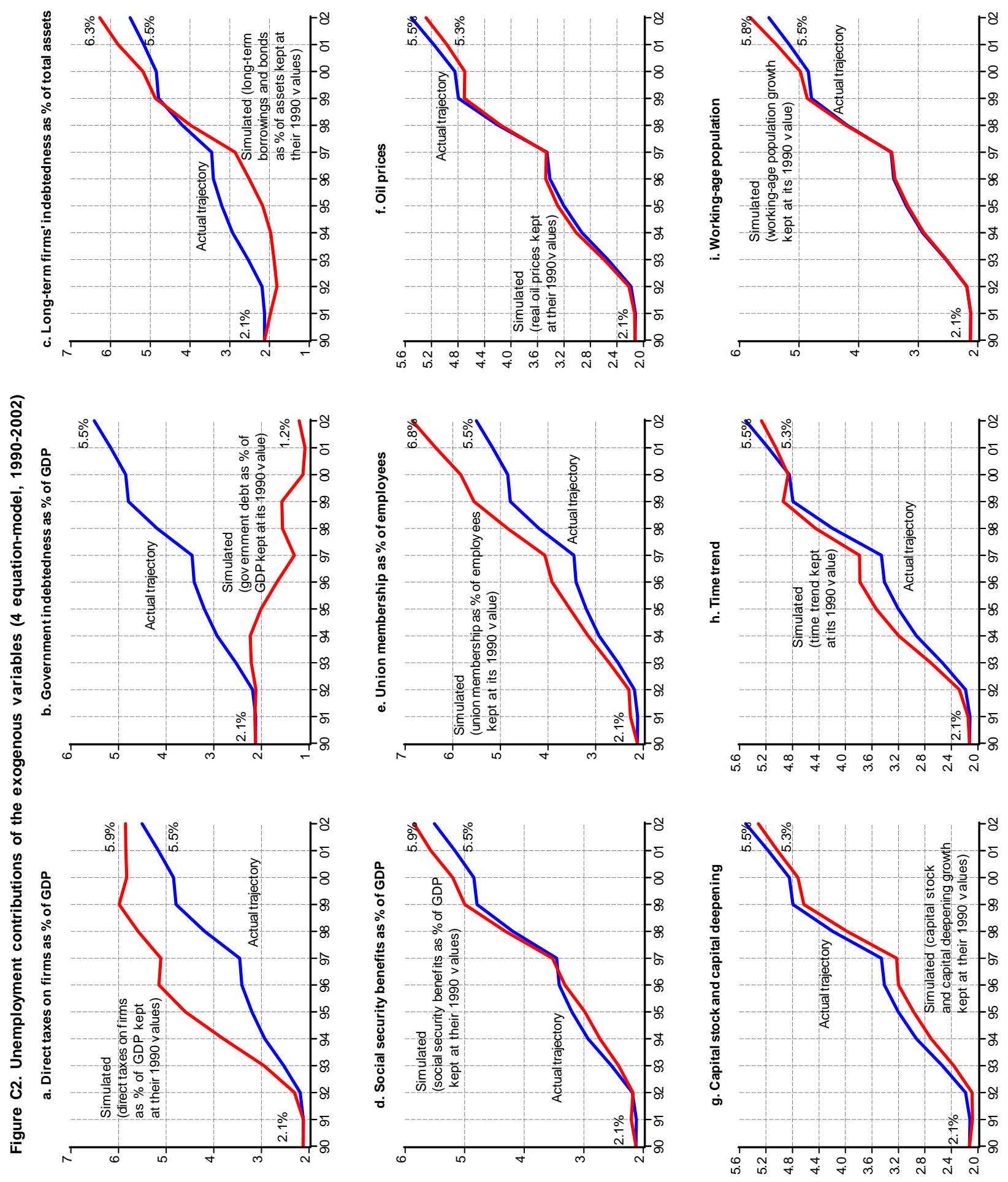

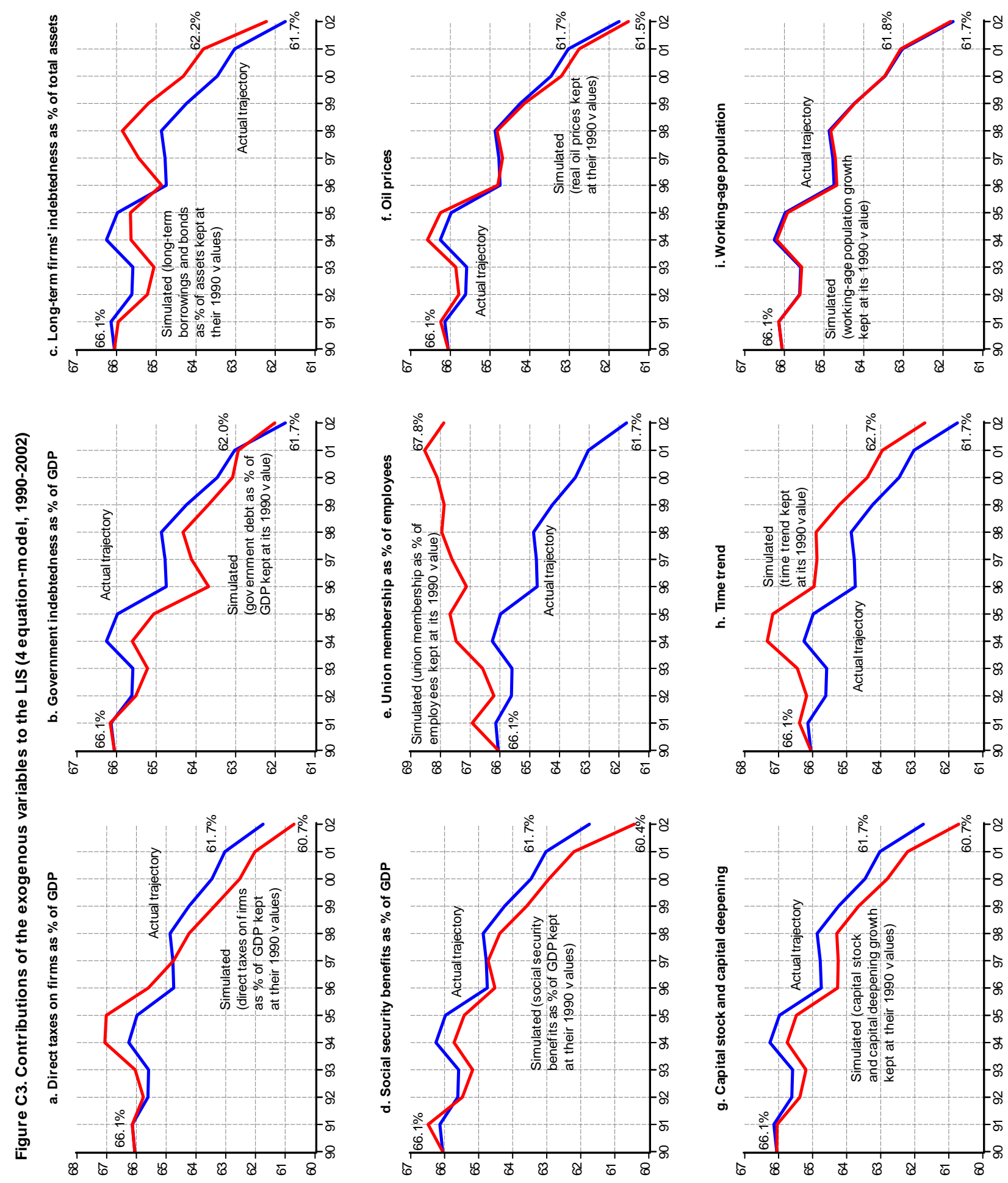

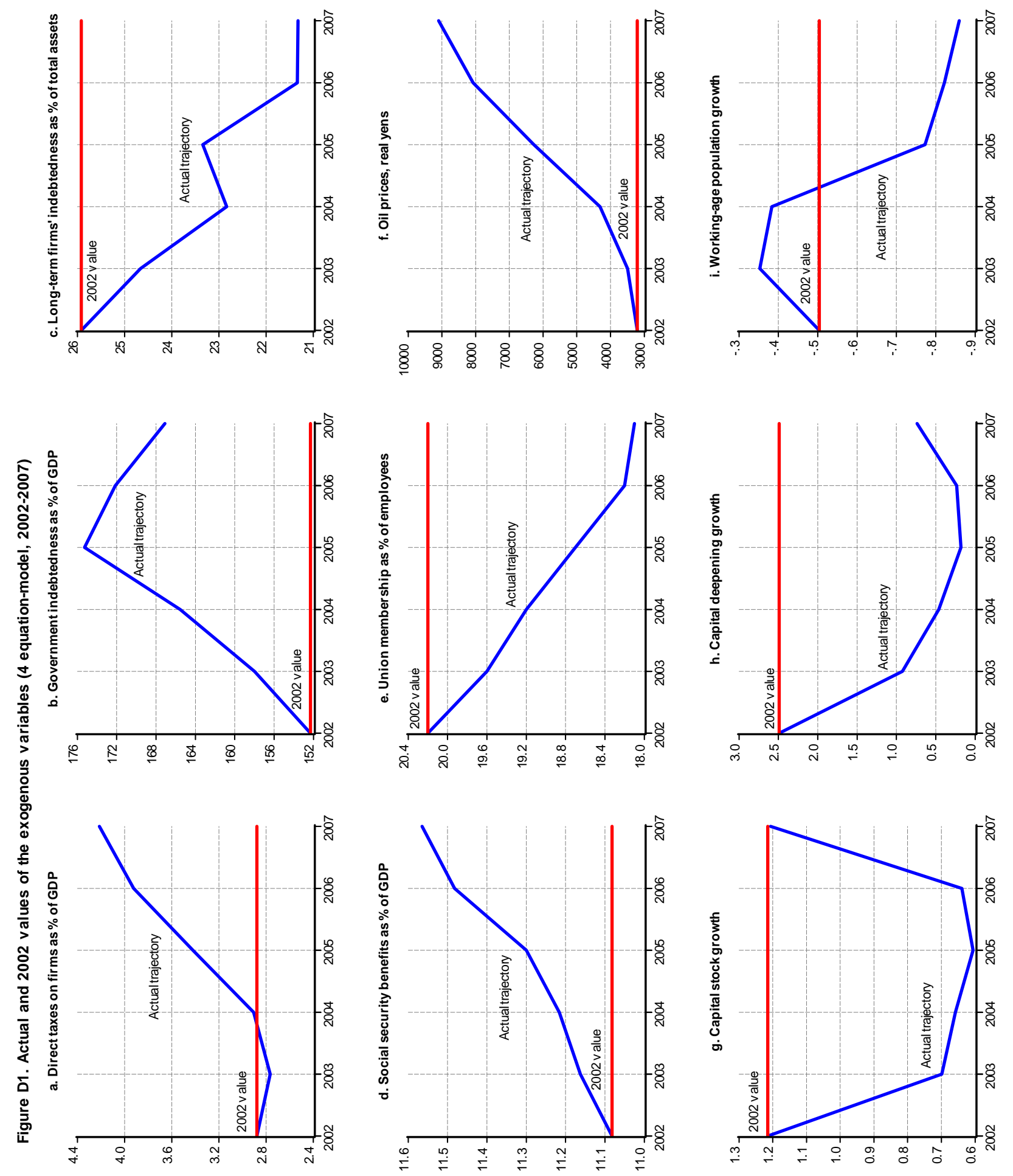

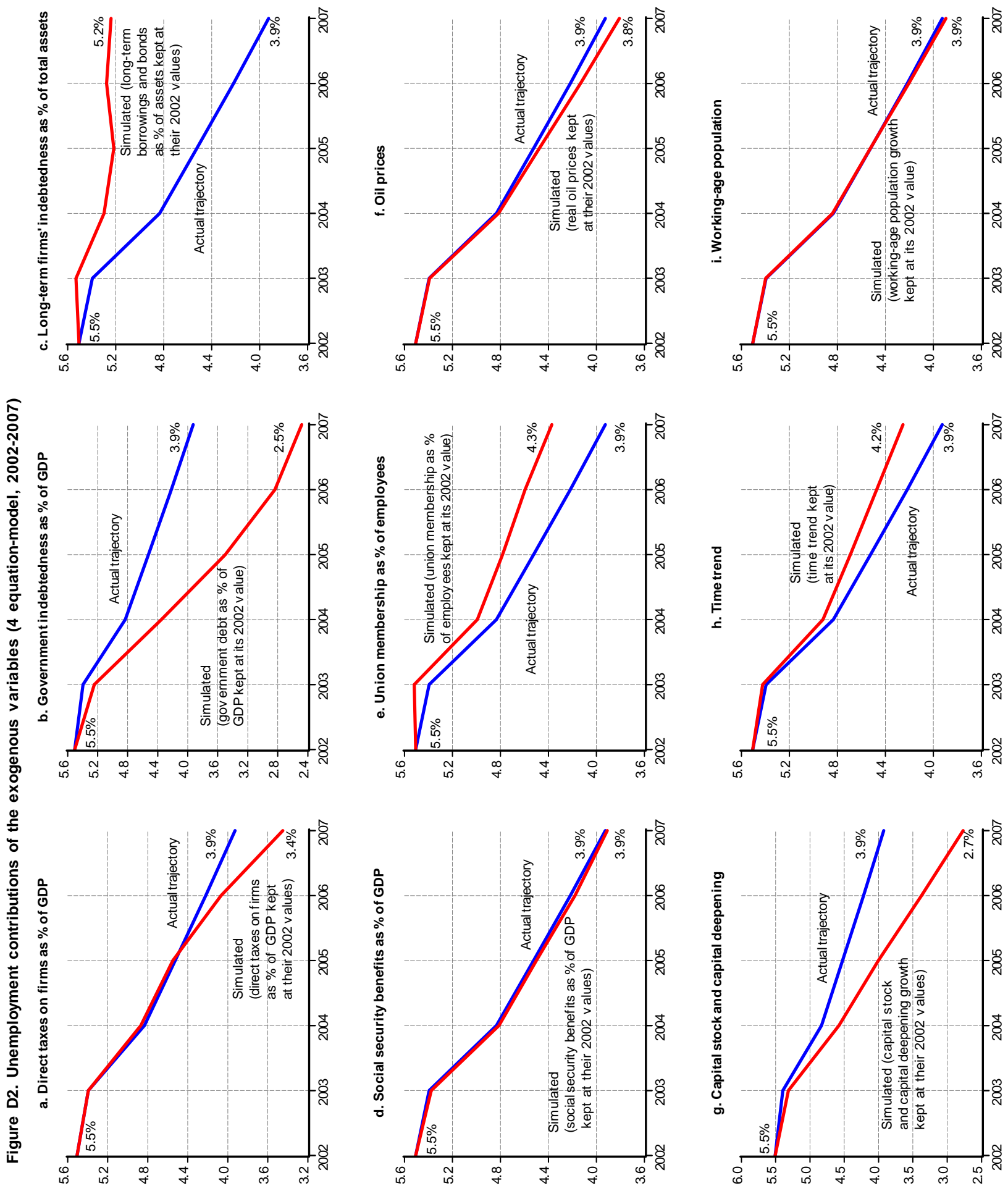

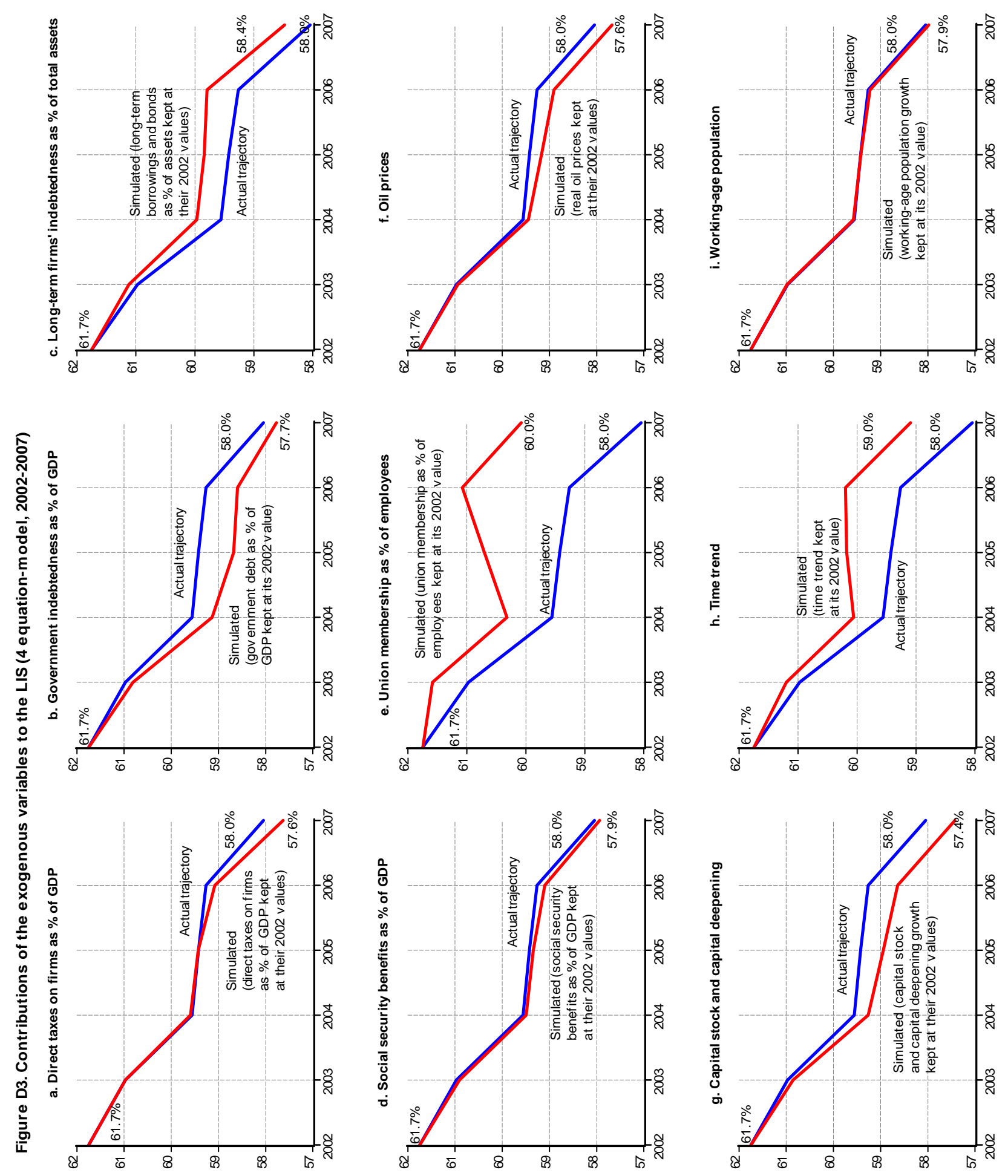